\title{
Application of the Asymmetric Pictet-Spengler Reaction in the Total Synthesis of Natural Products and Relevant Biologically Active Compounds
}

\author{
Majid M. Heravi *, Vahideh Zadsirjan * and Masumeh Malmir \\ Department of Chemistry, Alzahra University, Vanak, Tehran 1993893973, Iran; masi.malmir@yahoo.com \\ * Correspondence: mmh1331@yahoo.com or mmheravi@alzahra.ac.ir (M.M.H.); z_zadsirjan@yahoo.com (V.Z.); \\ Tel.: +98-218-804-4040 (M.M.H. \& V.Z.)
}

Academic Editors: Jiantao Guo and Wei Niu

Received: 22 March 2018; Accepted: 12 April 2018; Published: 18 April 2018

\begin{abstract}
Tetrahydroisoquinolines are the framework of numerous natural products predominantly alkaloids, an important and one of the most wide spread families of naturally occurring compounds in the plant kingdom. Tetrahydroisoquinolines are commonly constructed through an old reaction, the so-called Pictet-Spengler Reaction (PSR). In this reaction, a $\beta$-aryl ethylamine undergoes an acid mediated condensation with a suitable aldehyde or ketone, followed by ring closure. In this review, we aim to highlight the applications of the asymmetric variant of this old name reaction in the total synthesis of natural products, chiefly, alkaloids, which exhibit significant biological properties.
\end{abstract}

Keywords: tetrahydroisoquinolines; asymmetric Pictet-Spengler reaction; total synthesis; natural products; biologically active compounds; $\beta$-aryl ethylamine

\section{Introduction}

Indole and isoquinoline derivatives, historically and currently are synthesized via an old reaction, the so-called Pictet-Spengler reaction (PSR). This old reaction nowadays has found a few new perspectives. It is currently and frequently used as a vital step in the total synthesis of natural products especially in those bearing indole and isoquinoline alkaloids as scaffolds in their complex structures [1-3].

The PSR was discovered more than a century ago, in 1911 by Ame Pictet and Theodor Spengler [4]. As illustrated in Scheme 1, they condensed phenethylamine 1 with methylal that is $\mathrm{CH}_{2}(\mathrm{OMe})_{2}$ to obtain tetrahydroisoquinoline 2 [4]. Commonly, the PSR is a chemical reaction in which a $\beta$-arylethylamine such as tryptamine is cyclocondensed with an aldehyde or ketone under acidic and thermal conditions [5,6]. Some reactive substrates give acceptable yields even at physiological conditions [7]. Remarkably, the PSR can be considered as a special type of Mannich reaction.

The PSR has been initially used for the synthesis of tetrahydroisoquinolines in the total synthesis of indole and isoquinoline alkaloids [3]. Since it was disclosed that isoquinoline alkaloids are generated in plants biosynthetically through the condensation of $\beta$-arylethyl amines with carbonyl compounds, this reaction has found useful practicality in the total synthesis of naturally occurring compounds bearing isoquinolines in their complex structures [8]. Typically, tryptamine and secologan are condensed to generate strictosidine, stereoselectively. As a matter of fact, tryptamine is the common precursor for the syntheses of all indole alkaloids $[9,10]$. 


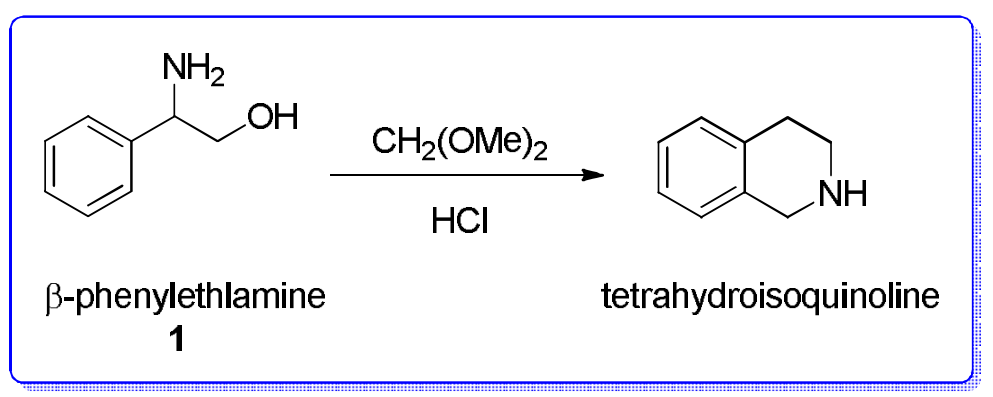

Scheme 1. The first example of the Pictet-Spengler Reaction (PSR), resulted in the synthesis of the tetrahydroisoquinoline (THIQ).

The asymmetric type of this reaction was applied in various instances for stereospecific acceptance of this method and has played a key role in the total synthesis of various indole, oxindole, bisindole and in general, alkaloids [11-18]. In 2016, Dalpozzo reported an overview of the asymmetric PSR, in which the chirality was induced by optically pure amines or carbonyl compounds, obtained from natural sources or from asymmetric synthesis to assemble the reaction partners [19].

Alkaloids, are undoubtedly, the most important and widespread family of natural products in the kingdom of plants. A plethora of alkaloids has been extracted, isolated, screened and their biological properties have been evaluated, to mostly exhibit remarkable and various biological and pharmacological activities, thus, they have exceptionally attracted the attention of organic synthetic and bio-organic chemists. Alkaloids are natural products which include mostly one or more basic nitrogen atoms [20]. Moreover, this family includes some relevant neutral compounds and some of them can be even weakly acidic [21]. Alkaloids, in addition to carbon, hydrogen and nitrogen, may contain other elements such as oxygen, sulfur and even infrequently may have unusual elements such as, chlorine, bromine, and phosphorus.

Alkaloids are provided by a vast range of organisms including bacteria, fungi, plants and animals. They are typically purified from crude extracts of these organisms through acid-base extraction. Alkaloids exhibit a wide variety of biological activities for example quinine, the known anti-malaria agent, anticancer e.g. homoharringtonine [22], cholino mimetic such as galantamine [23], vasodilatory like vincamine, antiarrhythmic such as quinidine, analgesic such as the notorious morphine [24] antibacterial such as. chelerythrine [25], and antihyperglycemic like piperine [26]. Many of them have found found applications in traditional or modern medicinal chemistry or as starting points in novel drug discovery. Many others show also psychotropic (e.g. psilocin) and stimulant activities for example the notorious cocaine and morphine, the familiar caffeine, and the carcinogenic nicotine. Several of them are also used in entheogenic rituals or as medicines. Several of the alkaloids have been screened and evaluated as being toxic for instance atropine and tubocurarine [27]. Importantly, alkaloids are uniquely included in metabolic systems in humans and other animals. Most alkaloids have a bitter and unpleasant taste [28].

Among the accumulation of alkaloids, isoquinoline and $\beta$-carboline alkaloids have attracted much interest because of their extensive existence in plants and even in the animal protectorate. Furthermore, the above-mentioned alkaloids and particularly those including the isoquinoline scaffold commonly exhibit a comparative dominance of physiological properties [29]. Their biological activities, which range distinctly from extremely toxic, for example strychnine [30] to antihypertensive ajmalicine [31] and reserpine [32]. Moreover alkaloids show cytotoxic properties exhibited by vincoleucoblastine and vincristine are components applied in the cancer chemotherapy protocol $[33,34]$. Strikingly and fascinatingly, all these biologically active alkaloids are principally generated indoles from tryptamine attained from tryptophan and a terpenoid part that in turn is biosynthesized via the iridoid glucoside secologanin. Tryptamine and secologanin are condensed stereoselectively to create 
strictosidine, which is used as precursor for the total synthesis of virtually all alkaloids bearing the indole moiety in their structures [10,35].

The total synthesis of natural products including multiple generations of chiral centers remains attractive in both industrial research and development ( $R$ \& D) as well as academic research [36-38]. In this line, predominantly, multi-component cascade, tandam, domino and sequential reactions, in the total synthesis of natural products and synthetic scaffolds within complex molecules, are involved [39-42]. Alkaloids constituting the indole moiety are a significant class of natural products. Particularly, the indolo[2,3-a]quinolizidine scaffold is a common frame work present in numerous biologically active significant products $[43,44]$.

We are particularly interested in heterocyclic chemistry [45-51] and heterocyclic compounds exhibiting comparatively acceptable biological properties [51-53]. Recently, we have underscored the applications of several name reactions and stereoselective synthesis in the total synthesis of biologically active naturally occurring compounds [54-59]. In this report, we try to underline the most recent and current applications of another old but significant name reaction, PSR as a vital step in the total synthesis of biologically active natural products, specially, alkaloids.

\section{Pictet-Spengler Reaction in the Total Synthesis of Natural Products}

\subsection{Indole Scaffold}

Several alkaloids contain indole as a scaffold in their structure. In addition, numerous indole alkaloids involve isoprene groups and are therefore called terpene indole or secologanin tryptamine alkaloids. Notably, more than 4100 various alkaloids have been recognized thus, it is one of the largest groups in the plant kingdom [60]. Several of them contain important physiological properties and some of them have been applied in medicine. Remarkably, the amino acid tryptophan is the biochemical precursor of indole alkaloids [61].

(+)-Ajmaline 7 was extracted in 1931 from the roots of Rauwolfia serpentine [62] and was found to contain six rings and four heteroatoms, along with stereogenic centers. Significantly [62,63], it is a clinically important cardiovascular indole alkaloid [64-66] having historical prominence and is correlated to the sarpagine bases [67]. The most significant action of ajmaline is an anti-arrhythmic influence on the heart which is just less marked than that of the prescribed drug propranolol [66].

Furthermore, alkaloid G $\mathbf{8}$ was extracted from plant cell cultures of Rauwolfia serpentina Benth by Stöckigt and co-workers [68], which upon feeding tests with ajmaline is also structurally analogous to 7 . Cook and co-workers in 1999 reported a common method (oxyanion-Cope strategy) for the formation of ajmaline indole alkaloid [69]. (+)-Ajmaline $\mathbf{7}$ and alkaloid G $\mathbf{8}$ as well as norsuaveoline $\mathbf{9}$ were provided from D-(+)-tryptophan in an enantiospecific approach through the enantioselective PSR and a stereo controlled oxyanion-Cope rearrangement as the main steps. With this route, total synthesis of natural products ajmaline 7, alkaloid G 8 and $\mathbf{9}$ were achieved starting from D-(+)-tryptophan 3 . Then, D-(+)-tryptophan 3 was converted into the tryptophan methylester $4 \mathbf{b}$ that was transformed to the $N_{\mathrm{b}}$-benzyltryptophan derivative on stirring tryptophan methylester $4 \mathbf{b}$ with benzaldehyde in methanol at ambient temperature, followed by reduction of the imine provided by using sodium borohydride as reductive agent. Next, HOAc was added to the reaction mixture to destroy any remaining $\mathrm{NaBH}_{4}$ and the solvent was evaporated under reduced pressure. In the following, methyl 4,4-dimethoxybutyrate, chloroform, and trifluoro acetic acid were added directly to the reaction vessel and the solution was refluxed to produce the trans diester $\mathbf{5 b}$ in excellent yield (overall yield $>85 \%$ ). The trans isomer $\mathbf{5 b}$ via epimerization and a Dieckmann cyclization produced the $\beta$-ketoester after that the solvent was removed under reduced pressure. Noticeably, $\mathrm{HOAc}$ and $\mathrm{HCl}$ were added cautiously to the reaction vessel and, on heating, ketone $6 \mathbf{b}$ was formed in more than $98 \%$ enantioselectivity (overall yield from $4>74 \%$ ). The ketone 6 a was also synthesized by a similar method. Significantly, five chemical conversions from tryptophan methylester 4 to the (-)-tetracyclic ketone 6 were performed in two reaction vessels. The usefulness of this enantiospecific two-pot sequence 
through the trans transfer of chirality in the enantioselective PSR is the key feature because these reactions can be accomplished on a multi-hundred gram-scale to give the (-)-tetracyclic ketone $6 \mathbf{a}$ or $\mathbf{6 b}$, that can be used as an easily accessible initiating precursor for the construction of optically pure sarpagine/macroline/ajmaline alkaloids. Moreover, D-(+)-tryptophan and L-(-)-tryptophan are easily accessible from marketable sources allowing entry into both antipodes of the natural products for biological examination. Lastly, (+)-ajmaline 7 and alkaloid G 8 were synthesized in $93 \%$ and $92 \%$ yield, respectively. In addition, the total synthesis of norsuaeoline 9 was accomplished in 10 reaction vessels with an overall yield of $28 \%$. Remarkably, for the formation of these indole alkaloids a stereospecific PSR/Dieckmann method was used to make the main intermediate, $(-)-\mathrm{N}_{\mathrm{b}}$-benzyl tetracyclic ketone $\mathbf{6 a}$ or $\mathbf{6 b}$, which was transformed to (+)-ajmaline 7, alkaloid G $\mathbf{8}$ and norsuaveoline 9 (Scheme 2) [69].

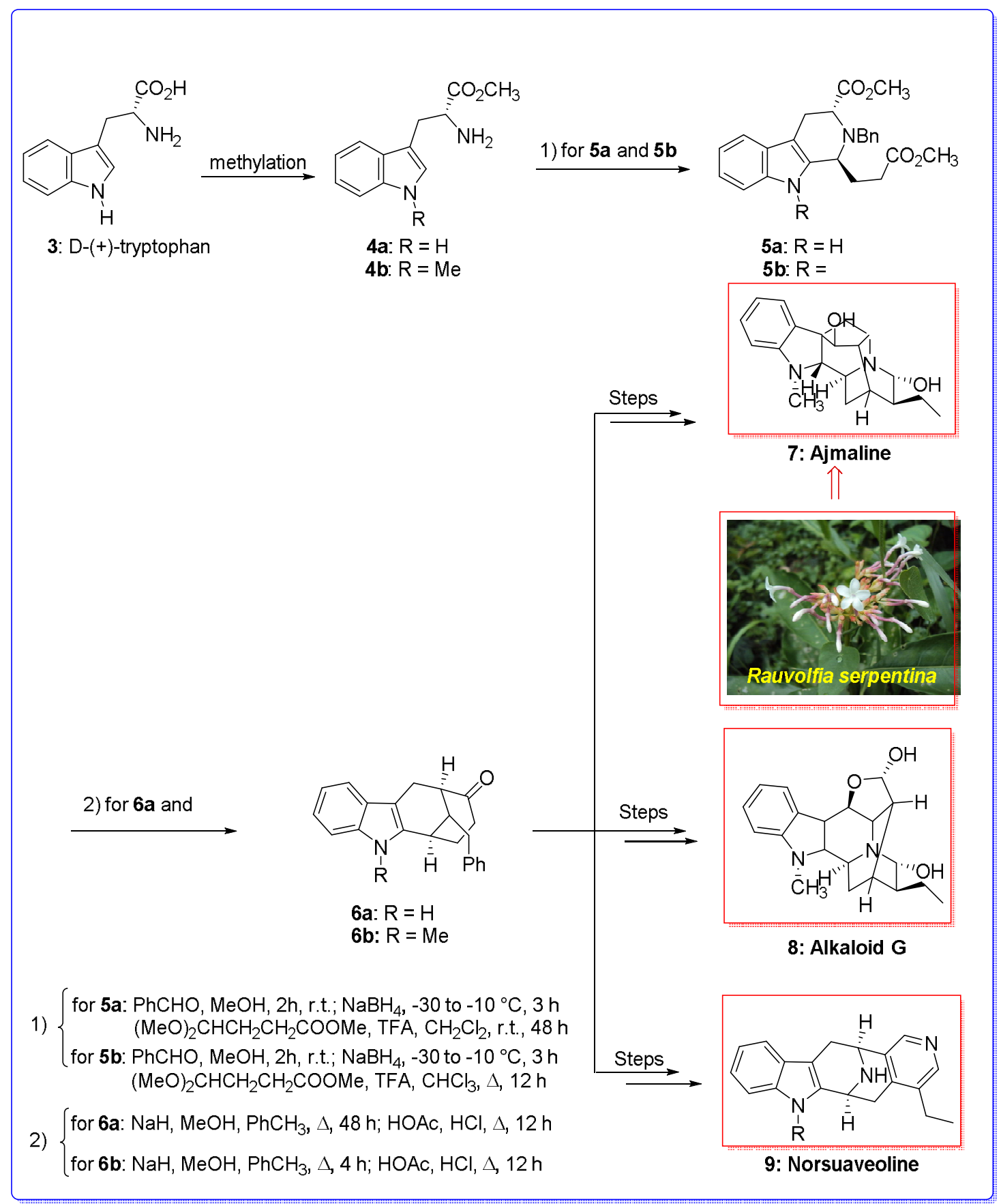

Scheme 2. Total synthesis of ajmaline 7, alkaloid G 8 and norsuaveoline $\mathbf{9 .}$ 
During the last decades, numerous macroline/sarpagine correlated indole alkaloids were isolated from different species of Alstonia [67,70,71]. Interestingly, the macroline/sarpagine alkaloids originated as a result of folktales, demonstrating the medicinal activities of the plants from which these alkaloids were extracted [72,73]. A range of alkaloids from Alstonia angustifolia were demonstrated to contain antiprotozoal property against Plasmodium falciparum or Entamoeba histolytica in vitro [74], whereas other sarpagine alkaloids were known to include sedative, ganglionic blocking, antibacterial or hypoglycemic properties [70]. These alkaloids were examined for activity against HIV [75-77] and cancer [75]. Noticeably, talpinine 15 is a characteristic illustrative of a seven-membered sub group of talpinine-related alkaloids that show pharmacological properties [70]. Inappropriately, to date, none of these bases have been provided or examined in vivo in detail. Talcarpine 16 is also a related macroline/sarpagine indole alkaloid whose total synthesis has not been reported so far [67,71]. Furthermore, two closely related ring-A methoxylated derivatives of alstonerine [71] contain parts of the bisindoles macralstonine and alkaloid $\mathrm{H}$ [67]. Macralstonine and its derivatives, in fact, were known to show significant hypotensive and antiamoebic properties, respectively [78-80]. The correlated monomer anhydro macrosalhine-methine $\mathbf{1 8}$ results in them being part of the bisindole (-)-macrocarpamine.

The asymmetric total synthesis of talpinine $\mathbf{1 5}$ and talcarpine $\mathbf{1 6}$ was performed in 13 steps (11 reaction vessels) in 10\% and 9.5\% overall yields, respectively. Furthermore, this synthetic method was used for the synthesis of alstonerine $\mathbf{1 7}$ and anhydromacrosalhine methane 18 in 14 reaction steps (12\% overall yield) and 12 steps (14\% overall yield), respectively. D-(+)-Tryptophan 3 acted here both as the chiral auxiliary and the initiating precursor that provided a simple pathway [from L-(-)-tryptophan] to the antipodes of these alkaloids, if desired. The stereo specific transformation of 3 into $14 \mathbf{a} / \mathbf{b}$ on a multi-hundred gram-scale occurred in only two reaction vessels.

Total synthesis of talpinine 15 was initiated from D-(+)-tryptophan 3. After several steps, compound $\mathbf{1 0}$ was formed. To introduce the corresponding stereocenter at the C1 position having similar chirality to that of the natural macroline/sarpagine/ajmaline alkaloids, Soerens and co-workers [81] and Sakai and co- workers [82] performed the Pictet-Spengler condensation between $\mathrm{N}_{\mathrm{a}}-\mathrm{H}, \mathrm{N}_{\mathrm{b}}$-benzyl tryptophan methylester $\mathbf{1 0}$ and $\alpha$-ketoglutaric acid $\mathbf{1 1}$. This approach gave a mixture of ester acids (trans-12a/cis-12b) and $\delta$-lactams (trans-13a/cis-13b) with satisfactory trans diastereoselectivity (Scheme 3) [83].

The sarpagine alkaloid (+)-vellosimine 21 was extracted from the tree Geissospermum Vellosii in 1958 by Rapoport and co-workers [84,85]. Amorphous extracts of this bark, found as paopereira, have long enjoyed a reputation as a febrifuge [86]. Also, in Brazilian folk medicine it was described to have curare-like properties [87]. Moreover, (+)-vellosimine was extracted from different species of Rauwolfia that are widely dispersed thought Asia and Africa [88-91]. These plants are broadly used in traditional Chinese medicine for the treatment of hypertension [89,92] neuralgia, and migraine [93].

The first stereospecific total synthesis of the $N_{a}$-H functionalized indole alkaloid (+)-vellosimine 21 was performed by Cook and co-workers in 2000 from market purchasable D-(+)-tryptophan methylester 19 in seven reaction steps in 27\% overall yield through the enantioselective PSR and a stereo controlled intramolecular Pd (enolate-catalyzed) coupling reaction as main steps [94].

Significantly, the chirality at C-3 and C-5 was developed by the enantioselective PSR and Dieckmann reaction in a two-pot approach [95]. Next, benzylation of the $N_{b}$-amino scaffold of D-tryptophan methyl ester 19 afforded $N_{\mathrm{a}}-\mathrm{H}, \mathrm{N}_{\mathrm{b}}$-benzyl D-tryptophanmethyl ester, that was readily transformed to the trans diastereomer 20 with 100\% diastereoselectivity based on the improved conditions of the PSR ( $83 \%$ yield). Upon several steps, the trans diester afforded the natural product vellosimine 21 (Scheme 4) [94]. 
<smiles>NC(Cc1c[nH]c2ccccc12)C(=O)O</smiles>

3<smiles>CC(=O)N1[C@@H](CCC(=O)O)Cc2c([nH]c3ccccc23)[C@H]1CNc1ccccc1</smiles>

12a trans
1. $\mathrm{HCl}, \mathrm{MeOH}$, reflux, $2 \mathrm{~h}, 95 \%$

2. $\mathrm{PhCHO}, \mathrm{MeOH}$, r.t. $3 \mathrm{~h}$, $\mathrm{NaBH}_{4},-5^{\circ} \mathrm{C}, 4 \mathrm{~h}, 95 \%$<smiles>O=CC(CNc1ccccc1)Cc1c[nH]c2ccccc12</smiles>

$(+)-10$

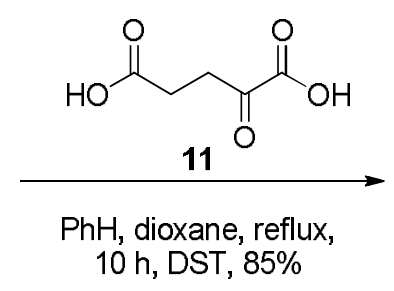

$10 \mathrm{~h}, \mathrm{DST}, 85 \%$ $\underset{\text { reflux, } 48 \mathrm{~h}, 86}{\stackrel{\text { PhH, dioxane, } p \text {-TSA, DST }}{\longrightarrow}}$

$12 \mathrm{~b}$ cis

(4:1)<smiles>CC(=O)N1C(Cc2ccccc2)Cc2c3c(n4ccccc24)CCCC31C(C)=O</smiles>

13b Cis<smiles>CC(=O)N1Cc2c3c(n4ccccc24)C(=O)CCC3N1Cc1ccccc1</smiles>

13a Trans
Steps<smiles>[R]n1c2c(c3ccccc31)C[C@H]1C(=O)C[C@H]2[C@@H]2c3ccccc3[C@H]12</smiles>

14a: $\mathrm{R}=\mathrm{H}$

14b: $\mathrm{R}=\mathrm{Me}$

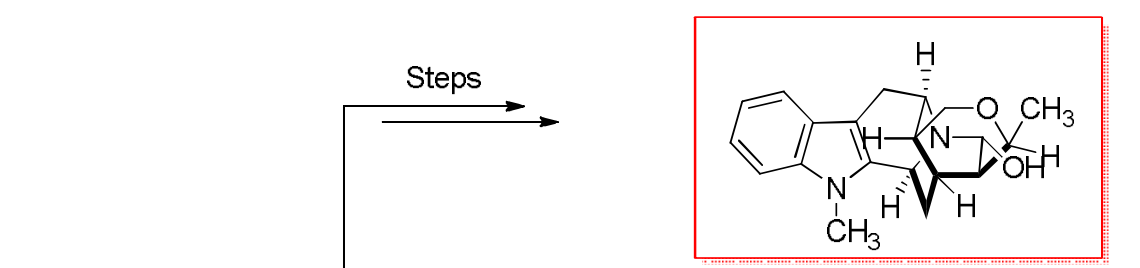

15 : Talpinine

$14 a$ or $b$

\section{Steps}

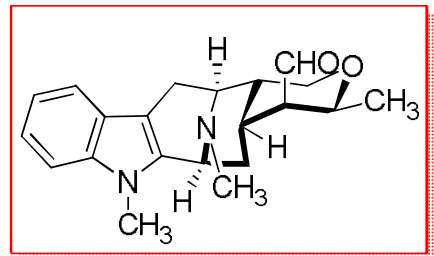

16 : Talcarpine

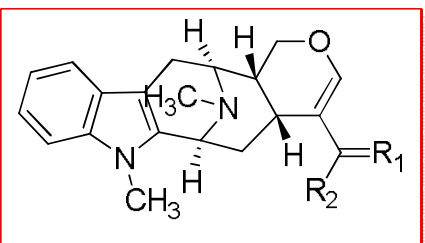

17: $\mathrm{R}^{1}=\mathrm{O}, \mathrm{R}^{2}=\mathrm{Me}$, Alstonerine

18: $R^{1}=\mathrm{CH}_{2}, \mathrm{R}^{2}=\mathrm{H}$, Anhydromacrosalhine-methine

Scheme 3. Total synthesis of natural products talpinine 15 , talcarpine 16 , alstonerine 17 , and anhydro macrosalhine methine 18. 


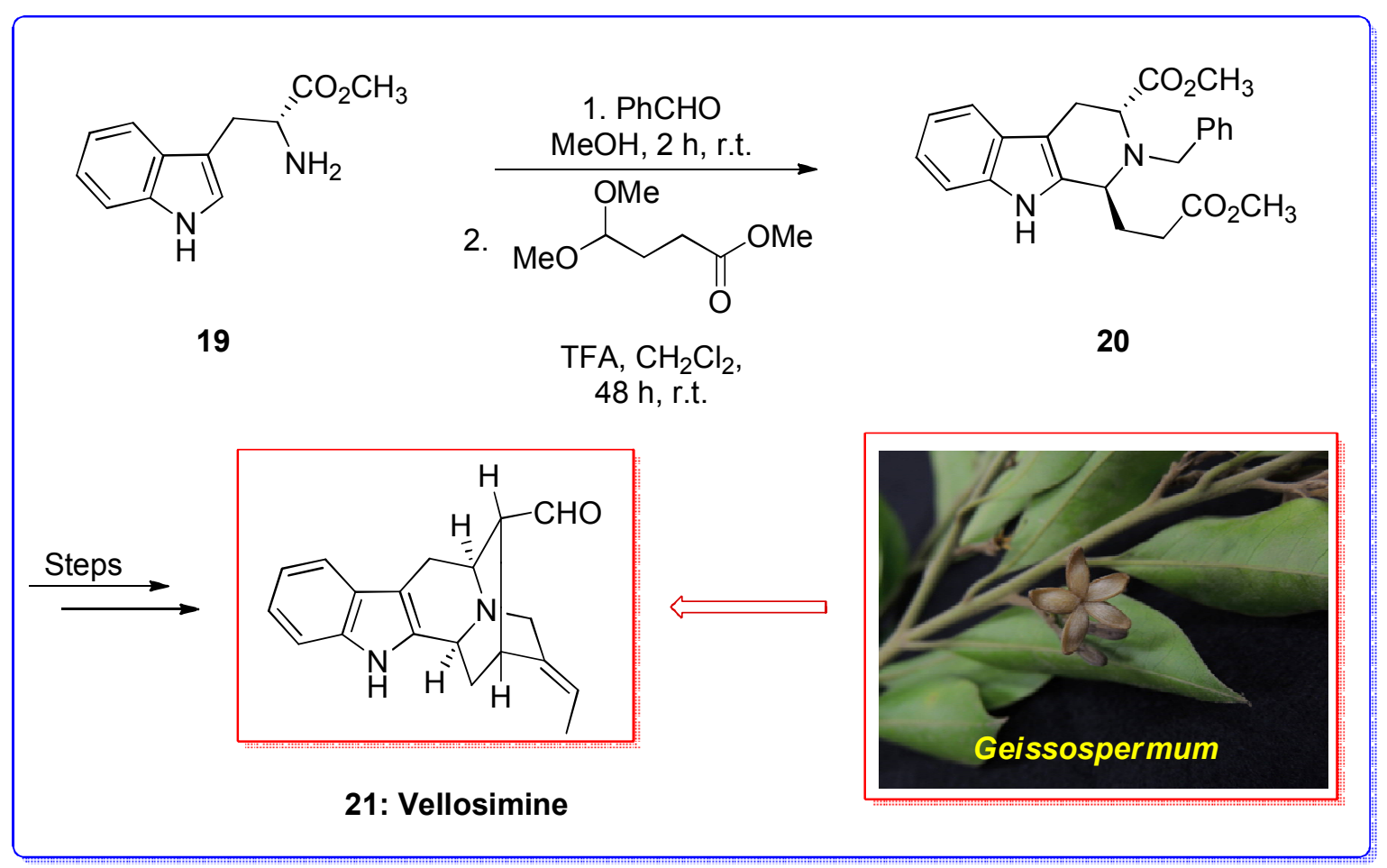

Scheme 4. Total synthesis of vellosimine 21.

The asymmetric synthesis of 7-methoxy-D-tryptophan was performed using a combination of the Larock hetero annulations method with a Schöllkopf-relied chiral auxiliary in satisfactory yield. Remarkably, this ester was used in the first total synthesis of (+)-12-methoxyaffinisine, (+)-12-methoxy- $\mathrm{N}_{\mathrm{a}}$-methyl vellosimine, and (-)-fuchsiaefoline in a regiospecific, stereospecific approach in high overall yield. The enantioselective PSR and enolate-driven Pd-mediated cross coupling methods acted as the main steps. In this route, initially, 2-iodo-6-methoxyaniline 22 [96] and the propargyl-functionalized Schöllkopf chiral auxiliary 23 [97] reacted to provide $N_{\mathrm{b}}$-benzylester 24, after several steps [98]. In the following, the Pictet-Spengler condensation of aldehyde and the $\mathrm{N}_{\mathrm{b}}$-benzylamine 24 occurred using HOAc in dichloromethane to provide a mixture (at C-1) of cis-26a and trans-26b diesters in approximately quantitative yield in a ratio of 1:2. Once trifluoro acetic acid/dichloromethane was used in this stage instead of acetic acid/dichloromethane, decomposition of a considerable amount of the 7-methoxytryptophan $\mathbf{2 4}$ was detected. Mechanistic studies on the carbocation-catalyzed cis/trans isomerization $[99,100]$, showed that once the PSR was completed, five equivalents of trifluoroacetic acid had to be added to the reaction mixture to epimerize the cis diastereomer 26a into the corresponding trans diastereomer 26b. Finally, the formation of (+)-12-methoxy- $N_{\mathrm{a}}$-methyl-vellosimine 27, (+)-12-methoxy-affinisine 28, and (-)-fuchsiaefoline 29 was performed (from D-tryptophan) in 7,8, and 9 reaction steps, respectively. The enantioselective PSR and an enolate-driven Pd-catalyzed cross-coupling reaction are the two essential stages used to develop the correct stereochemistry in the senatorially occurring compounds (Scheme 5) [98].

A range of bisindole alkaloids extracted from Alstonia [70,101] species were exhibited to show anti-malarial properties [74] against a drug resistant (K-1) strain of Plasmodia falciparum comprising macrocarpamine, villalstonine, and macralstonine $O$-methylether $[102,103]$. Bisindoles have noteworthy importance since they show more significant biological properties than the monomeric parts that contain them $[74,102,103]$, which is reminiscent of the significant anti-tumor properties of the Vinca alkaloids, vinblastine, and vincristine. The bio mimetic coupling reaction of macroline with the obligatory monomeric alkaloid to give the Alstonia bisindoles villalstonine $[104,105]$ macralstonine [106] and alstonisidine [104,107] was initiated by LeQuesne. These alkaloids were 
synthesized from the distinctive attack of a monomeric part at $C(9)$ of the sarpagine 33a-c ring system. The latter ring-A oxygenated indole derivatives are not that stable, therefore only trace amounts of the bisindoles (for example 35) $[107,108]$ have been provided from plants.

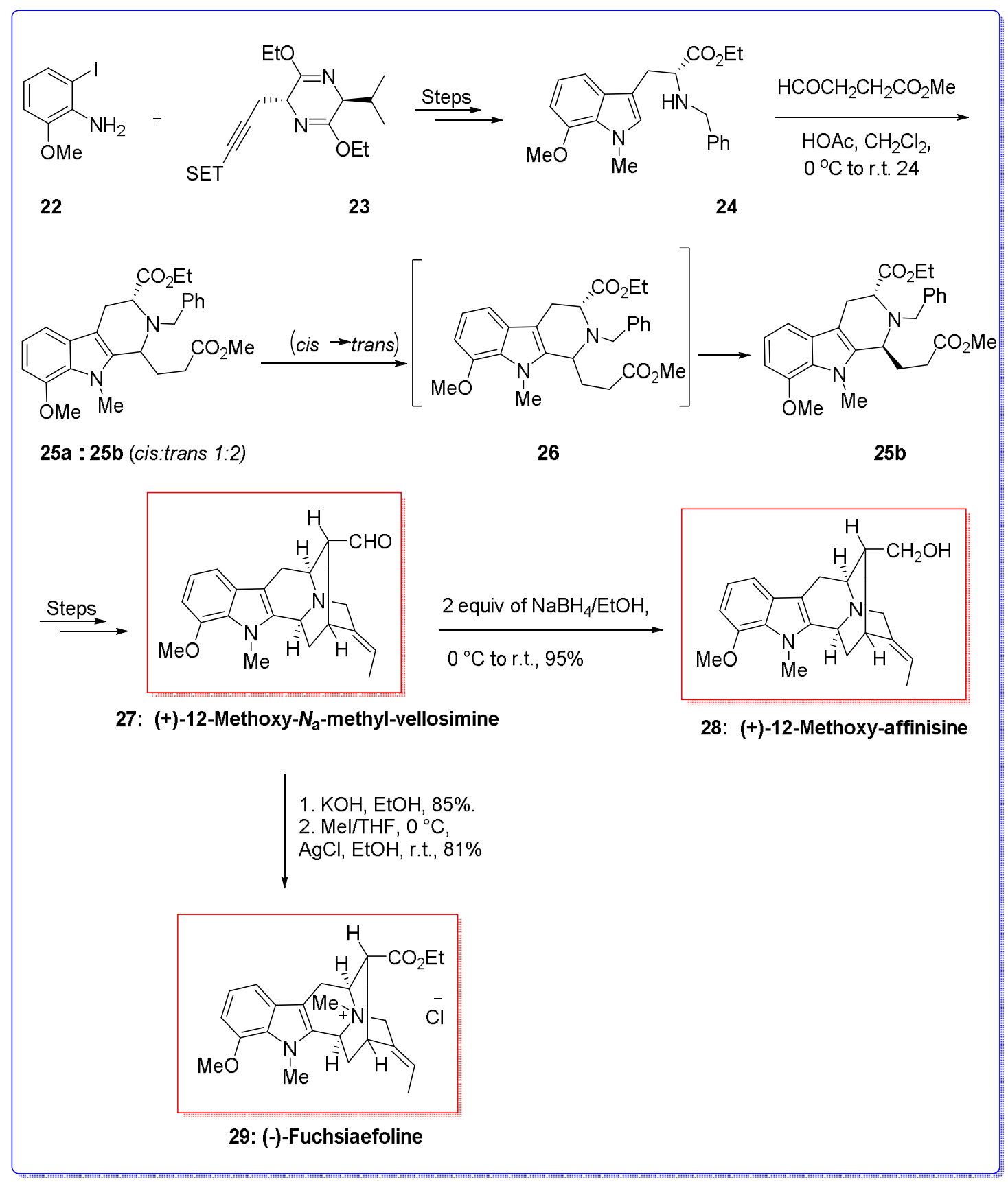

Scheme 5. Total synthesis of natural products (+)-12-methoxy- $N_{\mathrm{a}}$-methyl-vellosimine 27, (+)-12-methoxy-affinisine 28 and (-)-fuchsiaefoline 29.

The asymmetric stereospecific total synthesis of majvinine 33a, 10-methoxyaffinisine $33 \mathbf{b}$, and $\mathrm{N}_{a}$-methylsarpagine 33c were developed by Cook and co-workers in 2002 [109]. In addition, this strategy led to the total synthesis of the Alstonia bisindole macralstonidine 35.

This approach is the initial stereospecific synthesis of ring-A alkoxylated indole alkaloids in the sarpagine series. This methodology is distinctive because the natural series $(33 \mathbf{a}, 33 \mathbf{b}, 33 \mathbf{c})$ can be synthesized from the inexpensive L-valine and the stereochemistry of the E-ethylidene function can be 
literally controlled by the enolate catalyzed $\mathrm{Pd}^{0}$ cross coupling route. The method to synthesize the bisindole 35 is doubly convergent because the similar key tereochemical methods (enantioselective PSR and enolate catalyzed $\mathrm{Pd}^{0}$ method) were used [110] to provide both monomeric parts that could be coupled through the pioneering work of LeQuesne and Garnick [107].

The synthesis started with the easily accessible 3-methyl-5-methoxy indole, which is synthesized [111] through the Japp Kingemann/Fischer indole method [112]. After several steps, $N_{\mathrm{a}}$-methyl-5-methoxy-D-tryptophanethylester $\mathbf{3 1}$ was formed. Favorably, the conversion of $\mathbf{3 1}$ into the corresponding trans diester 32 should have followed the well-documented trans transfer of chirality in the enantioselective PSR [99] in a direct technique; though, this was not the case. The presence of the 5-methoxy group in $\mathbf{3 1}$ assisted the PSR (with benzaldehyde); furthermore, this 5-methoxy indole system was not stable in trifluoro acetic acid/dichloromethane for prolonged periods of time. Noticeably, if amine $\mathbf{3 1}$ was transformed to the desired $N_{\mathrm{b}}$-benzylimine with benzaldehyde/ethanol at ambient temperature [99], important quantities of the 1-phenyltetrahydro $\beta$-carbolines were provided [110]. Although, if the imine was provided at $0{ }^{\circ} \mathrm{C}$, followed by reduction at $-5^{\circ} \mathrm{C}$, merely the desired $N_{\mathrm{b}}$-benzyl analogue was detected. Next, compound 31 was not stable in dichloromethane/trifluoro acetic acid for prolonged periods, and the PSR occurred with the aldehyde (instead of the acetal [99]) in acetic acid/dichloromethane. When the cyclization was accomplished to give a mixture of trans and cis diastereomers, a few drops of trifluoro acetic acid were added $[99,110]$ to assist epimerization (at C-1) of the cis isomer into the corresponding trans diastereomer $(>98 \% \mathrm{de})$.

After several reaction sequence involving the Wittig/hydrolysis/epimerization reaction, (+)-majvinine 33a was obtained. (+)-Majvinine 33a (obtained from tryptophanethyl ester 31) was synthesized in gram quantities ( 8 steps) in $28 \%$ overall yield and acted as the key, stable intermediate for the formation of other naturally occurring compounds in this sequence (Scheme 6) [109].

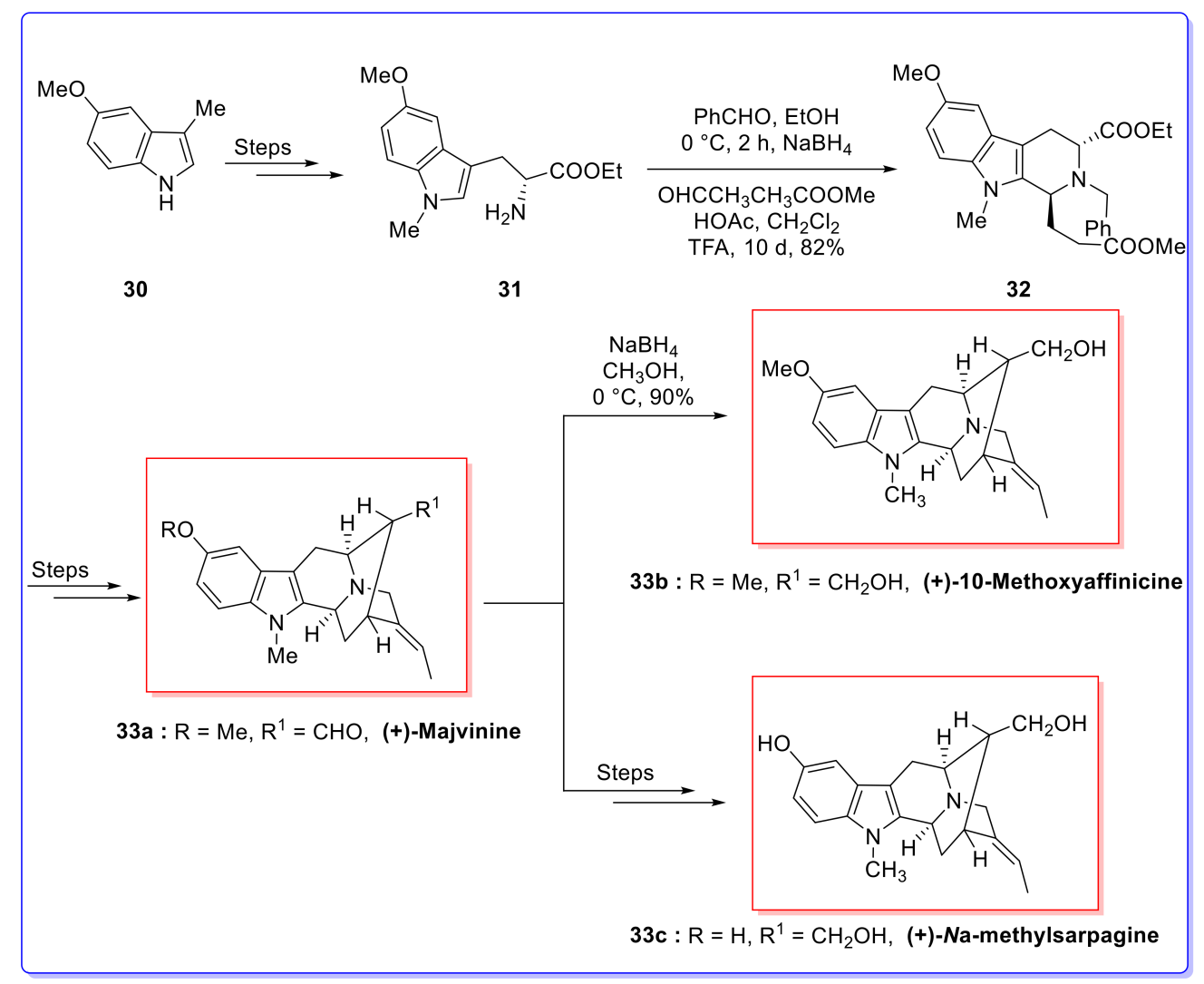

Scheme 6. Total synthesis of natural products (+)-majvinine 33a, (+)-10-methoxyaffinicine, and (+)-Na-methylsarpagine 33c. 
Besides, the alkaloid (+)-majvinine 33a has been used for the total synthesis of $(+)-N_{\mathrm{a}}$-methyl sarpagine 33c. Remarkably, (+)-macroline can be reacted with $N_{\mathrm{a}}$-methylsarpagine 33c based on the bio mimetic conditions of Garnick [107] to give 35; therefore, this provides the initial total synthesis of a bisindole alkaloid in the Alstonia groups. More significantly, the trans transfer of chirality using the Schöllkopf chiral auxiliary once coupled with the trans transfer that occurs in the enantioselective PSR necessarily defines that natural ring-A alkoxylated indoles can be synthesized from inexpensive L-valine whereas D-valine is vital for the antipodal series (Scheme 7) [109].

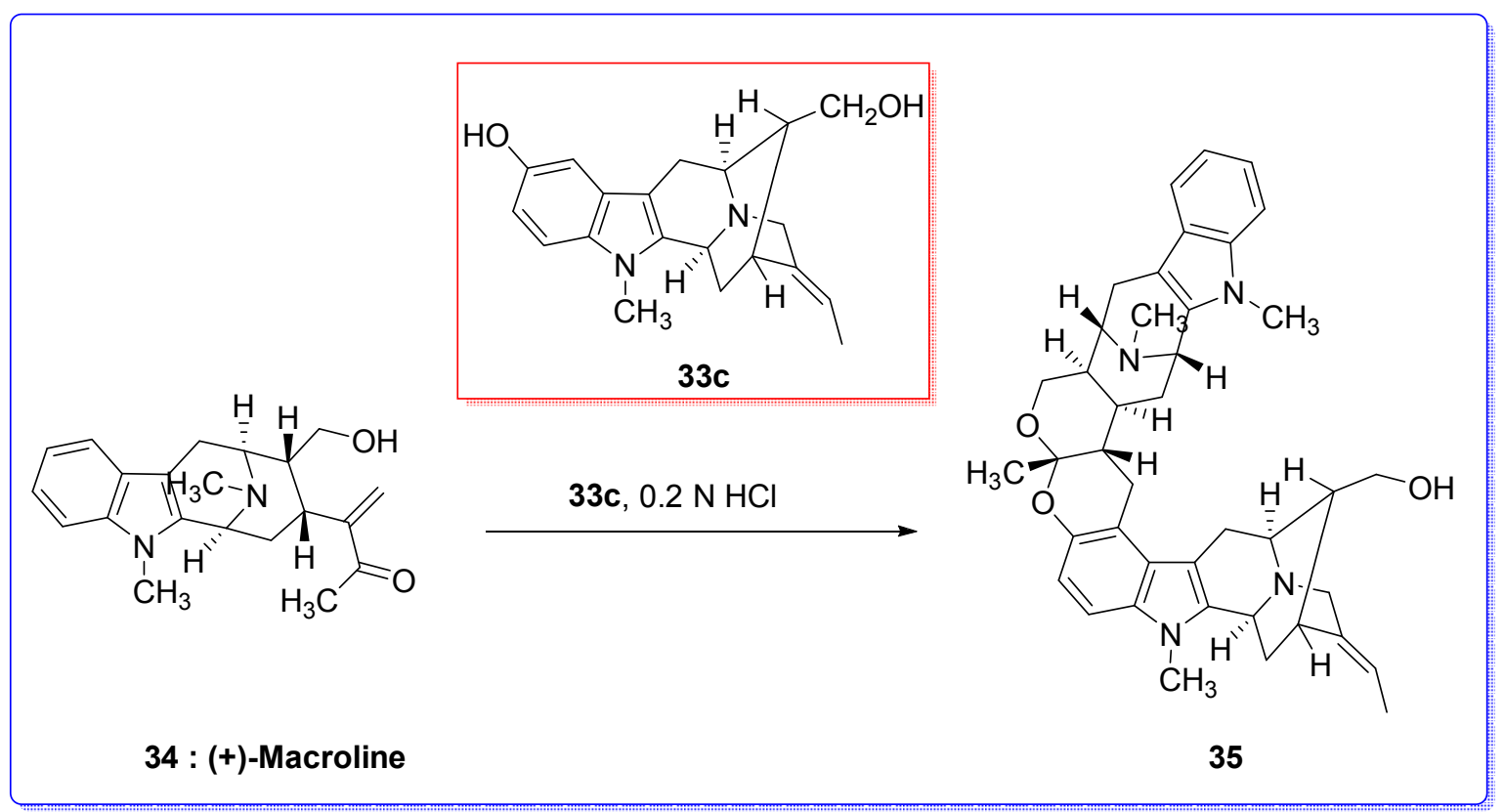

Scheme 7. Total synthesis of bisindole macralstonidine 35 using PSR as the key step.

Strychnofoline belongs to a family of naturally occurring compounds, extracted from the leaves of Strychnos usambarensis [113], that shows antimitotic property against cultures of mouse melanoma and Ehrlich tumor cells with strychnofoline exhibiting the uppermost properties [114]. An important structural aspect of these and correlated spirotryprostatin alkaloids [115] is the existence of the aspiro[pyrrolidin-3, $3^{\prime}$-oxindole] core.

Carreira and co-workers in 2002 demonstrated a significant synthesis of the antitumor alkaloid $( \pm)$-strychnofoline. A key feature of the development of the extremely convergent method described, is the coupling reaction of acyclicimine with spiro[cyclopropan-1,3'-oxindole], which occurs in a highly diastereoselective manner [116].

In this route, for the synthesis of $( \pm)$-strychnofoline, the reaction of $\mathbf{3 6}$ and imine $\mathbf{3 7}$ occurred and after several steps afforded aldehyde 38. With this pathway, PSR [117] between aldehyde 38 and $\mathrm{N}$-methyl-tryptamine $39 \mathrm{using}$ acetic acid in toluene at $80^{\circ} \mathrm{C}$ gave a diastereomeric mixture of products 40a and corresponding 40b nonselectively (1.5:1) in a combined yield of $64 \%$ [118,119]. Remarkably, deprotection of $\mathbf{4 0 b}$ gave $( \pm$ )-strychnofoline 41 in $82 \%$ yield (Scheme 8 ) [116].

Eudistomins, extracted by Rinehart and co-workers in 1984 [120-122] from a Caribbean tunicate (Eudistoma oliVaceum), are members of the tetrahydro- $\beta$-carboline group of marine alkaloids. Among eudistomins, eudistomin C, E, K, L, and F, containing the hither to unknown oxathiazepine ring, demonstrated highly significant antiviral properties against both RNA and DNA viruses as well as antimicrobial and antitumor properties [122,123]. 


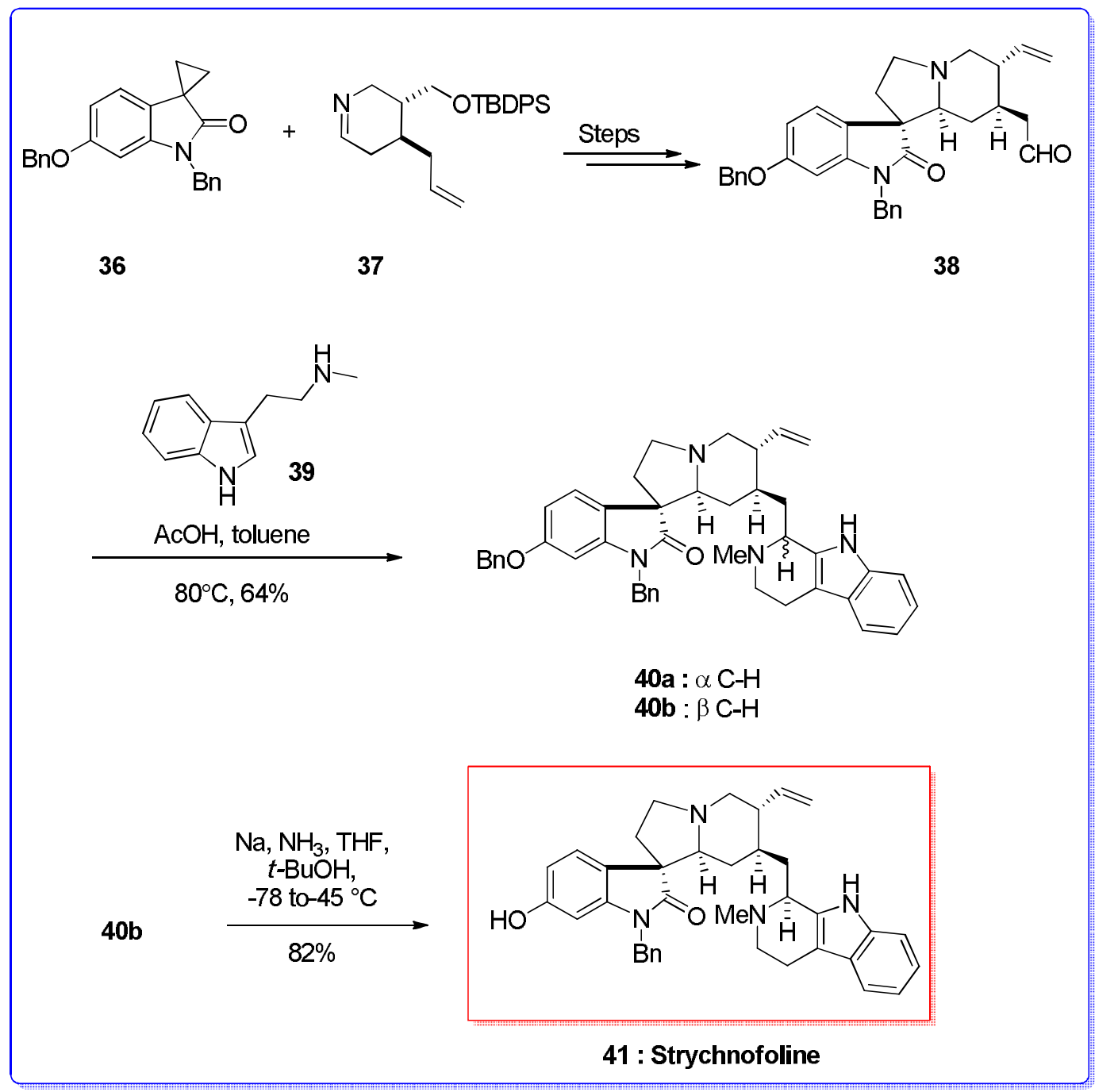

Scheme 8. Total synthesis of strychnofoline 41.

Fukuyama and co-workers in 2005 demonstrated the stereo controlled total synthesis of (-)-eudistomin C 46 which relied on the development of the Brønsted acid-mediated diastereoselective PSR and the unprecedented production of an unusual oxathiazepine ring. The 18-step reaction with an overall yield of $7.7 \%$ permitted the gram-scale formation of eudistomin $C$ to be performed as well as diverse derivatives.

In this method, for the synthesis of (-)-eudistomin C 46, at first, the synthesis of the indole part [124] initiated from nitroaniline 42 , was easily synthesized from $m$-anisidine in four stags [124]. The diastereoselective production of tetrahydro- $\beta$-carboline could be achieved by the PSR [125] of the tryptamine derivative and Garner aldehyde $\mathbf{4 3}$ [126,127]. The researchers focused their attention on the critical PSR of Garner aldehyde 43. Meanwhile, a first effort using a model substrate of 44 lacking the bromo and methoxy substituents afforded the unexpected diastereomer as the major product (3:1) under conventional reaction conditions (trifluoro acetic acid in dichloromethane, $-78^{\circ} \mathrm{C}$ ), They examined a wide range of acid catalysts and solvents. Astonishingly, they realized by using a catalytic quantity of dichloro-acetic acid or chloro-acetic acid in toluene the reaction proceeded smoothly at $0{ }^{\circ} \mathrm{C}$ to give the corresponding diastereomer 45 with excellent selectivity (11:1). After several steps, compound 45 was converted into the natural product (-)-eudistomin C 46 (Scheme 9) [128]. 


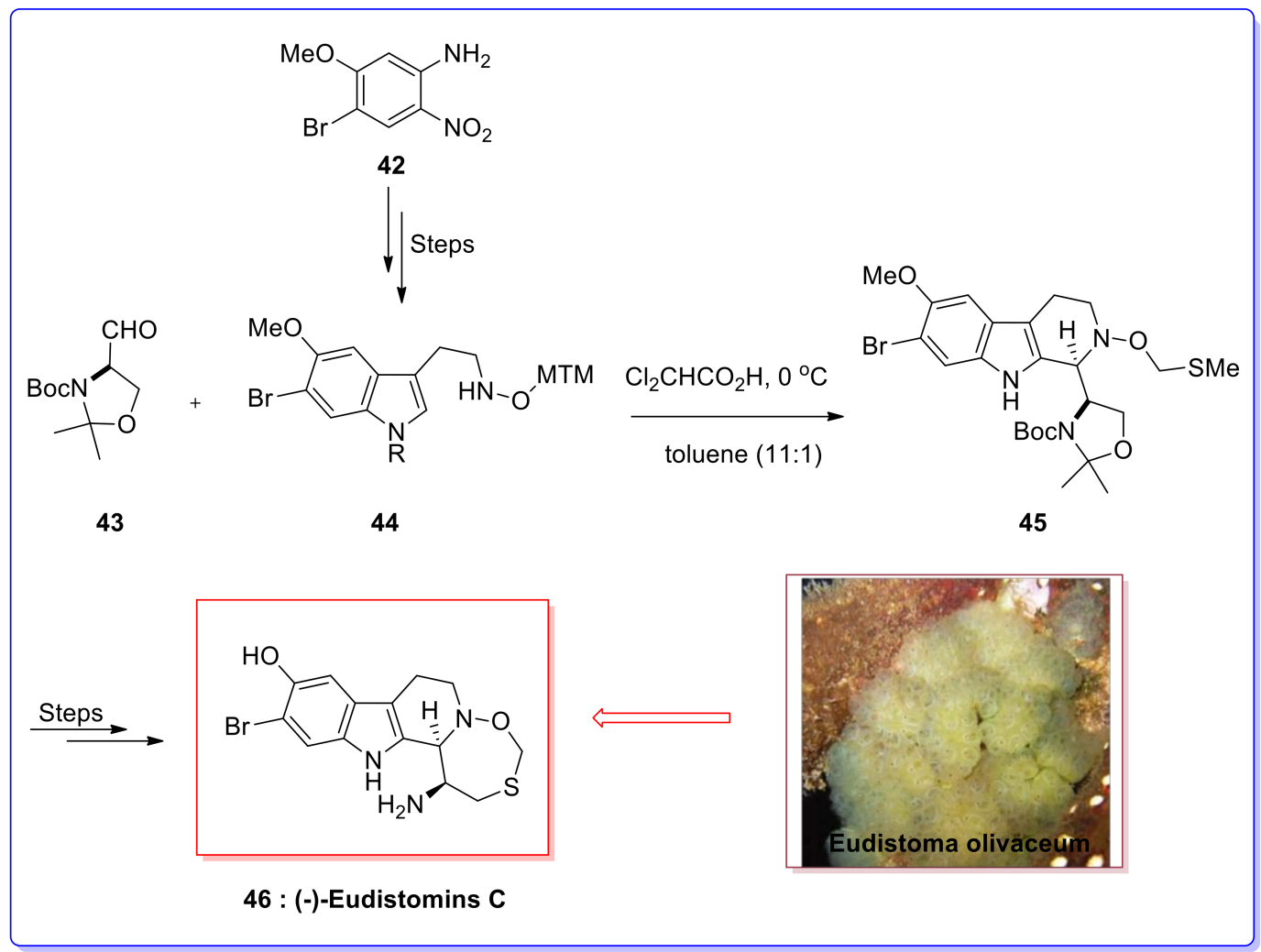

Scheme 9. Total synthesis of eudistomins C 46.

Mitragynine 52 was extracted from Mitragyne speciosa Korth $[129,130]$ and used as a substitute for opioids of painin in Thailand. In 1965, the X-ray crystal structure of the hydroiodide salt of mitragynine was obtained for its certain structural elucidation [131]. However, mitragynine was the main alkaloid from the extract of Mitragyne speciosa, a more careful examination demonstrated that a more significant alkaloid, was existent in the mature leaves of M. speciosa (Thailand). In addition, this hydroxyl derivative could be provided from the oxidation reaction of mitragynine with iodobenzene di-acetate [132]. Fascinatingly, the methoxyl functional substituent was known, being required for its analgesic property [133].

The alkaloid 9-methoxy-geissoschizol [132] was extracted from the bark of Strychnos guianensis [134], that is known in the basin of the upper and middle Orinoco rivers and throughout the Amazon basin. The crude extracts from the root and stem bark demonstrated a muscle relaxant property [135]. The related 9 -methoxy- $N_{\mathrm{b}}$-methylgeissoschizol $\mathbf{5 4}$ that is a quaternary indole alkaloid was recognized later [136].

An asymmetric strategy for the formation of 4-methoxy tryptophan was accomplished through a regiospecific Larock hetero annulation and used for the initial total synthesis of 9-methoxy geissoschizol 53, 9-methoxy- $N_{\mathrm{b}}$-methylgeissoschizol 54 , and the total synthesis of mitragynine 52 , starting from 4-methoxy-D-tryptophan 47 . The enantioselective PSR and $\mathrm{Ni}(\mathrm{COD})_{2}$-catalyzed cyclization reaction acted as main stages to setup the stereochemistry at $C(3)$ and $C(15)$ in these indole alkaloids.

Total synthesis of natural products 52, 53, and 54 were initiated from 4-methoxytryptophan which after several steps afforded the secondary amine 48. The corresponding stereocenter at C-3 was accomplished through the enantioselective PSR [4] of the secondary amine 48 and the aldehyde [137] 49 to supply the tetrahydro- $\beta$-carboline $\mathbf{5 0}$. Next, this diester 50 was transformed into the corresponding $\alpha, \beta$-unsaturated ester 51 in $64 \%$ overall yield through a number of normal conversions comprising elimination of one equiv of thiophenol from tetrahydro- $\beta$-carboline $\mathbf{5 0}$, followed by an oxidation reaction with meta-chloroperoxy benzoic acid and a sulfoxide removal 
sequence [137,138]. Next, after several steps, 9-methoxygeissoschizol 53 was synthesized in $90 \%$ yield. In addition, 9-methoxy- $N_{\mathrm{b}}$-methylgeissoschizol 54 was formed through the $N_{\mathrm{b}}$-methylation of 53 with methyl iodide followed by exchange of the iodide to the chloride by silver chloride. The ${ }^{13} \mathrm{C}-\mathrm{NMR}$ data of synthetic (+)-54 was in agreement with those determined for the naturally occurring compound $[134,136]$. Besides this, through another approach from $\alpha, \beta$-unsaturated ester 51, after several steps, mitragynine 52 was synthesized (Scheme 10) [139].

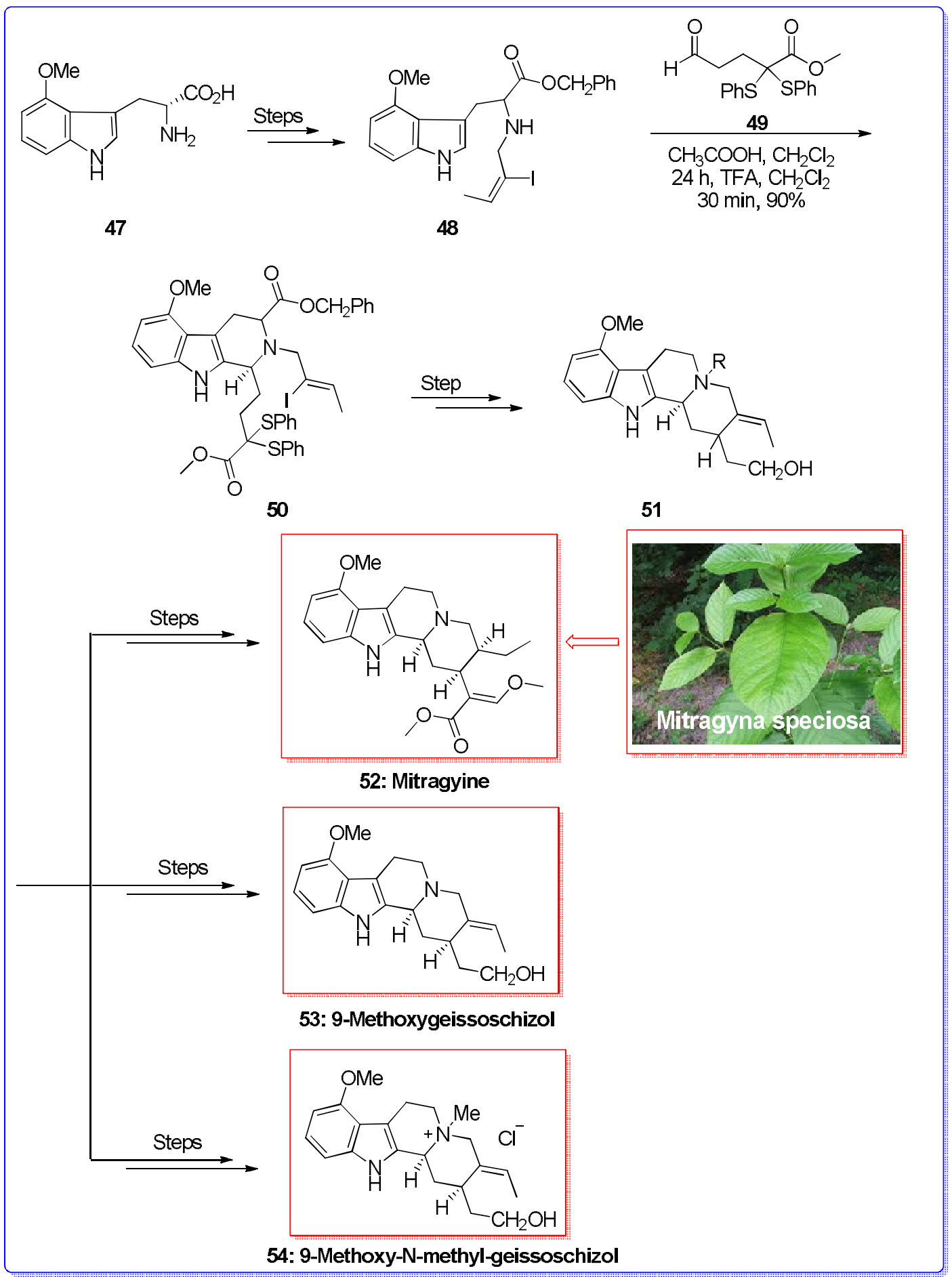

Scheme 10. Total synthesis of mitragyine 52, 9-methoxygeissoschizol 53, and 9-Methoxy- $\mathrm{N}_{\mathrm{b}}$ methylgeissoschizol 54 . 
Yohimbine 59, a significant member of the monoterpenoid indole alkaloids, belongs to a large group of naturally occurring compounds which shows synthetically challenging structures showing different biological properties $[140,141]$. The total synthesis of $(+)$-yohimbine was accomplished in 11 steps and 14\% overall yield in 2008 by Jacobsen and co-workers [142]. The absolute configuration was developed by an extremely asymmetric thiourea-mediated acyl-PSR, and the remaining four stereocenters were set concurrently in a substrate-controlled intramolecular Diels-Alder reaction.

In this pathway, total synthesis of (+)-yohimbine was begun with the formation of $N$-acetyltetrahydro- $\beta$-carboline 58 through the acyl-PSR [143]. Condensation of tryptamine 55 with aldehyde 56 [144], and the resultant imine with acetylchloride and 2,6-lutidine using thiourea catalyst $57(10 \mathrm{~mol} \%)$ gave 58 in $81 \%$ yield and $94 \%$ ee on a gram scale. After several steps, (+)-yohimbine 59 was provided in 14\% overall yield (Scheme 11) [142].

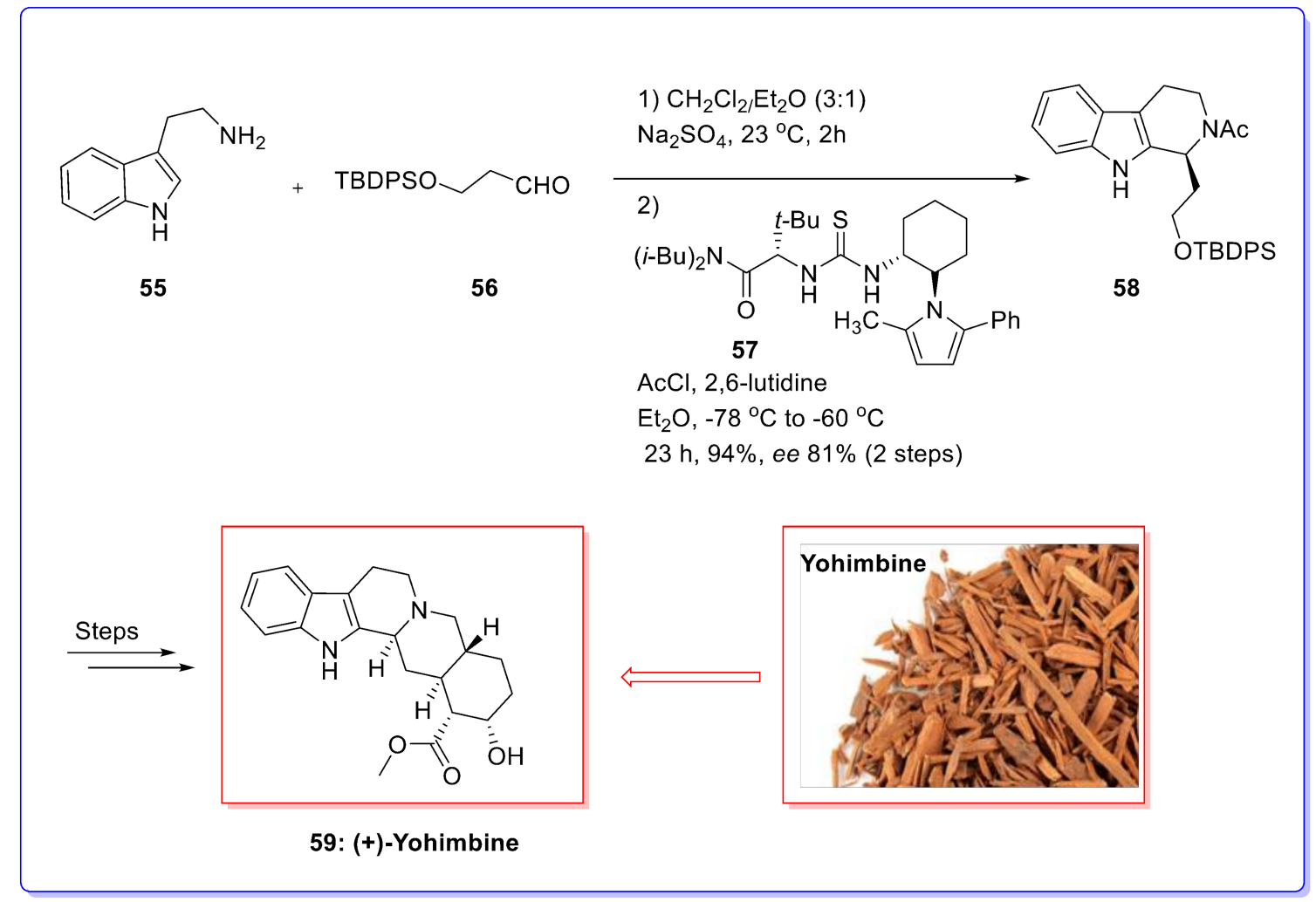

Scheme 11. Total synthesis of yohimbine 59.

The deplancheine-typetetracyclic indole alkaloid arboricine 65, extracted from the leaves of Kopsiaarborea by Kam and co-workers in 2009, exhibited an adequate ability to reverse multi-drug resistance in vincristine-resistant $\mathrm{KB}(\mathrm{VJ} 300)$ cells [145].

Hiemstra and co-workers in 2009 reported, a significant six-step synthesis initiated from tryptamine affording the tetracyclic-carboline arboricine in 33\% overall yield through an asymmetric organocatalytic PSR and intramolecular palladium(0)-mediated vinyliodide-enolate coupling as the main stages. Another three-step pathway initiated from tryptamine afforded arboricine in an overall yield of $35 \%$ but lower ee.

The synthesis initiated with the tryptamine [146], generated in one-step through alkylation reaction of tryptamine and Z-2-iodo-2-butene-1-olmesylate in 84\% yield (not shown in the Scheme) [146] PS condensation reaction of 60 with aldehyde 61 a catalyzed by (R)-3,3'-triphenylsilyl-binolphosphoricacid 63a ((R)-binol-PA, 5 mol\%) afforded $\beta$-carboline (S)-62a together with aminal 64 in 55\% yield and a 75/25 ratio, respectively, and an unacceptable $38 \%$ ee for both (S)-62a and 64, as identified by chiral HPLC. Happily, masking of ketone 61a as the dioxolane 
$\mathbf{6 1 b}$ not only evaded aminal construction therefore solely affording (S)-62b in 81\% yield but also increased the $e e$ to $78 \%$. It is significant that installing the acetal masking substituent, that is quite remote from the iminium intermediate, increases both the enantioselectivity and the rate of the PSR using lower catalyst loadings down to $1 \%$. The mildness of the method is underscored by the fact that the dioxolane-protected ketone stayed unaffected. Clearly, $(R)-\mathbf{6 2} \mathbf{b}$ has been produced initiated from (S)-binol-PA. Remarkably, the best ee was obtained using the sterically somewhat more demanding catalyst $(R)-\mathrm{H}_{8}$-binol-PA $63 \mathrm{~b}$, which afforded (S)-62b in $86 \%$ yield and $89 \%$ ee. Scaling up the reaction to $5 \mathrm{mmol}$ only required $1 \mathrm{~mol} \%$ of catalyst $63 \mathbf{a}$ giving $(S)-62 \mathbf{b}$ in an extracted yield of $92 \%$ and $78 \% e e$.

To circumvent the probable racemization through acid-mediated scission of the bond between the enantioselective carbon atom and $N_{\mathrm{b}}$ [147] during the hydrolysis of the acetal scaffold, a Boc-masking substituent was achieved on the indole. Reaction of $\mathbf{6 2} \mathbf{b}$ with $\mathrm{Boc}_{2} \mathrm{O}$ and DMAP followed using diluted hydrochloric acid in acetone afforded the corresponding ketone which in two steps gave (-)-arboricine 65 in $81 \%$. Synthetic arboricine was enantio pure by HPLC (method A).

In another pathway, dissolving $\mathbf{6 2 b}$ in dilute hydrochloric acid in acetone afforded quantitatively a mixture of 62a together with aminal 64 in a 2/3 ratio, respectively. Gratifyingly, based on the slightly basic conditions of the final palladium(0)-mediated cyclization, an equilibrium between $62 \mathbf{a}$ and 64 existed permitted a significant and diastereoselective transformation to arboricine 65 in a yield of $78 \%$, although ee dropped from 86\% to 65\% (method B) (Schemes 12 and 13) [148].

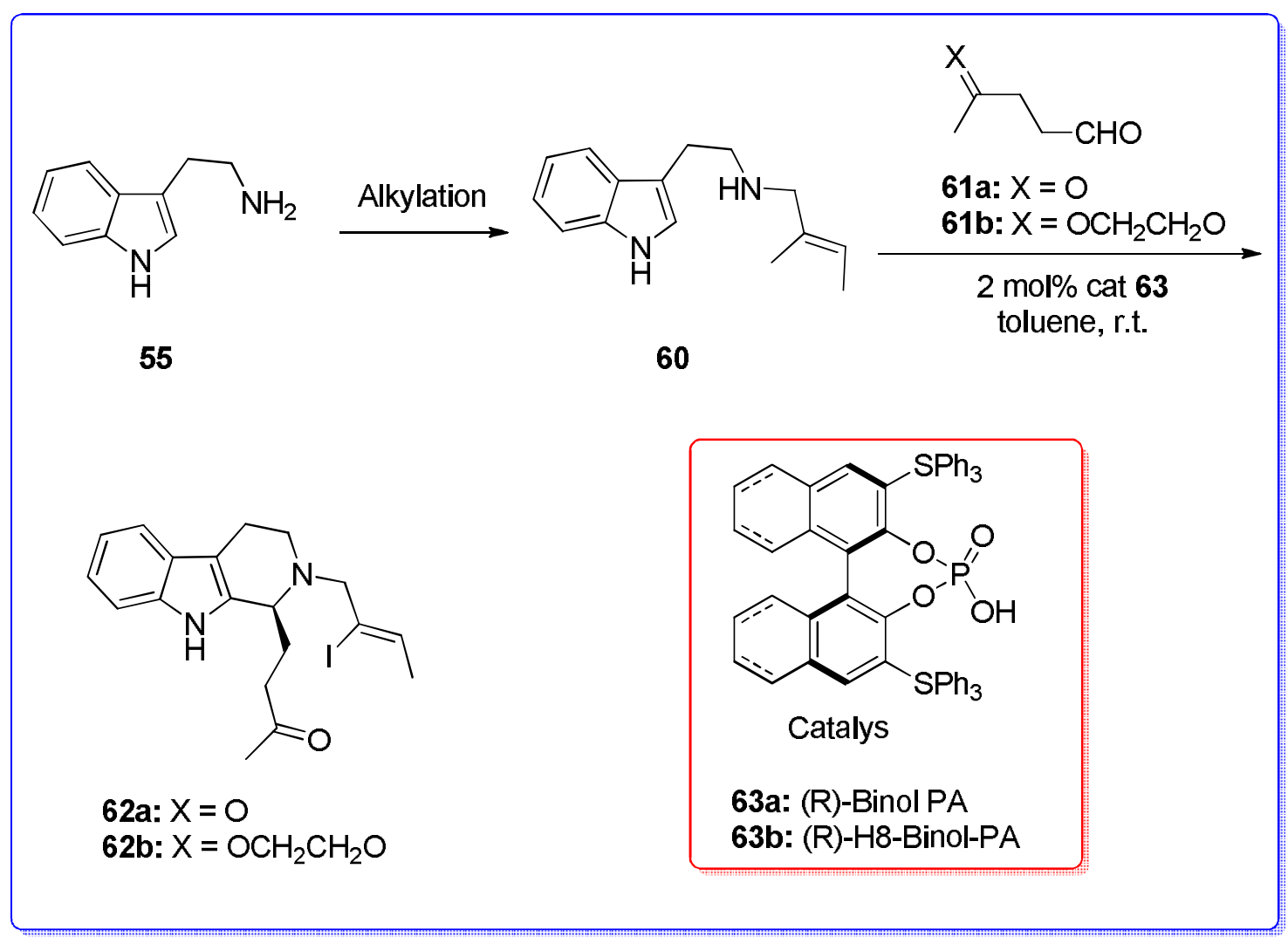

Scheme 12. PSR in the presence of 63 as a catalyst. 


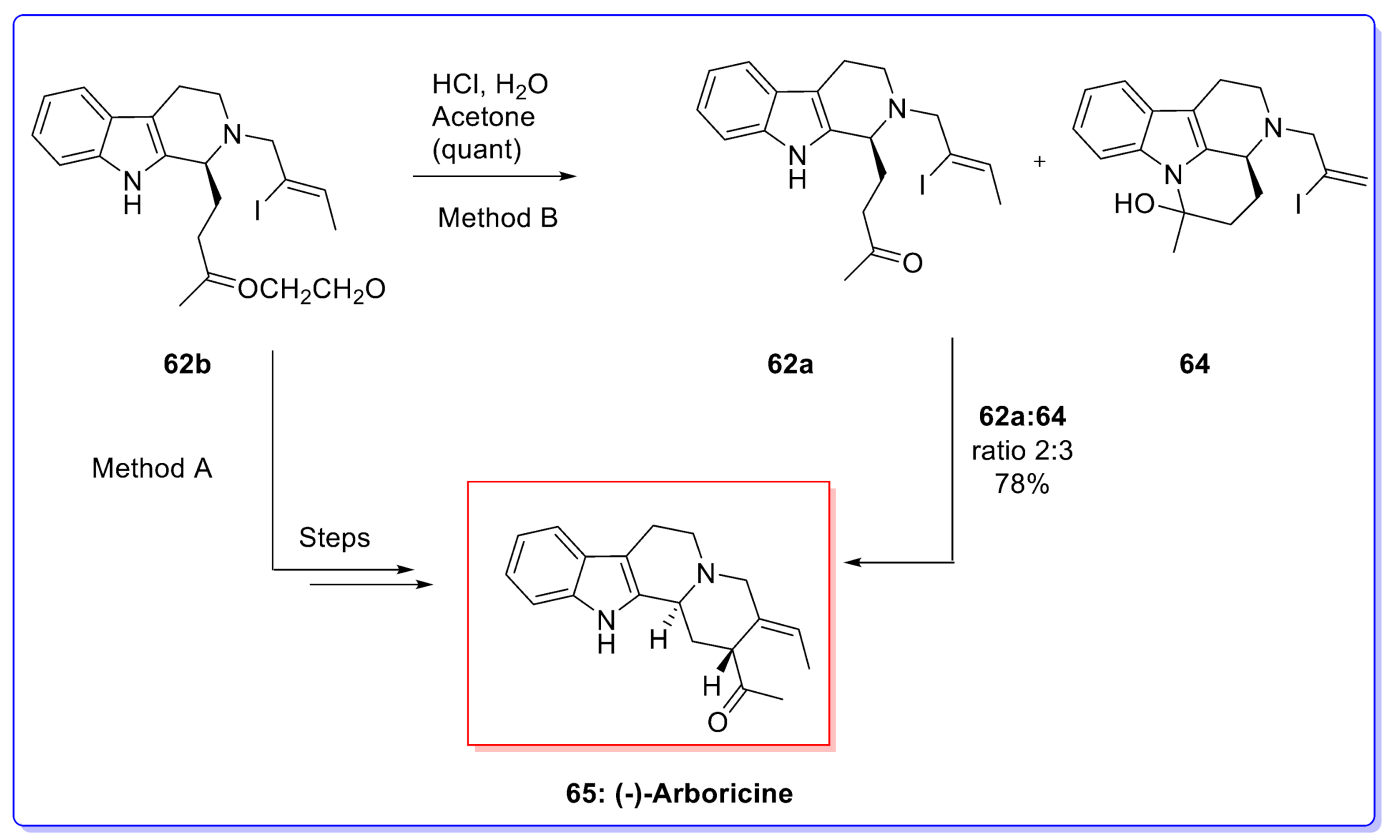

Scheme 13. Total synthesis of tetracyclicindole alkaloid (-)-arboricine 65.

Henrycinols A and B, two indole alkaloids, extracted from Melodinus henryi CRAIB of Apocynaceae genus by Zhang and co-workers [149]. These alkaloids belong to the class of $1,2,3,4$-tetrahydro- $\beta$-carbolines, a structural scaffold, that is, abundant in a range of indole alkaloids [150]. Structurally henrycinols A and B differ from simple 1,2,3,4-tetrahydro- $\beta$-carbolines with the presence of two hydroxyl substituent on the $D$ ring of the alkaloid. The total synthesis of indole alkaloids henrycinol A and B were performed initiating from L-tryptophan methyl ester. The main step is a stereochemically flexible PSR provided by the presence or absence of an $N$-allyl substituent in the tryptophan precursor. The natural products henrycinol A and B were obtained in satisfactory overall yield in eight and nine steps, respectively. Therefore, the synthetic sequence starting with the PSR of the desired aldehyde [151,152] obtained from (-)-2,3-O-isopropylidene-D-threitol 66 with L-tryptophan methylester 67 gave a separable mixture of 1,3 -cistetrahydro- $\beta$-carboline $69 \alpha$ as the main product in $50 \%$ yield and 1,3-trans tetrahydro- $\beta$-carboline $69 \beta$ in $18 \%$ yield [149].

Since the naturally occurring compound included the trans tetrahydro- $\beta$-carboline isomer, it was posed with the challenge of procuring the needed 1,3-trans-1,2,3,4-tetrahydro- $\beta$-carboline in excellent yield in the PSR. Pioneering work by Cook's group [153-155] established the transformation of 1,3-cis to 1,3-trans products in the PSR of tryptophan methylester with benzaldehyde. They detected that the reaction of $N$-functionalized tryptophan esters rendered the 1,3-trans-1,2,3,4-tetrahydro- $\beta$-carbolines using non-acidic conditions, whereas simple tryptophan esters without substitution gave the 1,3-cis carbolines under acidic conditions. Considering these results, it was reasoned that the PSR of $N$-allyl-L-tryptophan methylester 68 with the corresponding aldehyde should provide the 1,3-trans-1,2,3,4-tetrahydro- $\beta$-carboline 70b. Actually, this was known to be the case, and the reaction between $N$-allyl-L-tryptophan methylester 68 and the corresponding aldehyde obtained from (-)-2,3-O-isopropylidene-D-threitol 66), gave the 1,3-trans-1,2,3,4-tetrahydro- $\beta$-carboline $70 \beta$ as the main product in $79 \%$ yield. After several steps, the 1,3-trans-1,2,3,4-tetrahydro- $\beta$-carboline $70 \beta$ gave henrycinol A $\mathbf{7 1}$ in $78 \%$ yield.

The stereochemistry of the freshly provided stereogenic center in the PSR and the structure of the natural product was definitely confirmed by $\mathrm{X}$-ray crystal structure analysis of henrycinol A 71. Furthermore, reaction between henrycinol A 71 and isobutyrylchloride using $\mathrm{Bu}_{2} \mathrm{SnO}$ and CsF [156,157] gave henrycinol B 72 in $24 \%$ yield, the regioisomer 73 in 10\% yield and the recovered initiating compound henrycinol A 71 in $47 \%$ yield. Significantly, stereoselective first total synthesis 
of the indole alkaloids henrycinol A 71 and B 72 were performed from $N$-allyl-L-tryptophan methylester 68 and (-),2,3-O-isopropylidene-D-threitolin $34 \%$ and $8 \%$ overall yields, respectively in eight and nine linear stages. The key conversion was the trans-selective construction of 1,3-dialkyl-1,2,3,4-tetrahydro- $\beta$-carboline in the Pictet-Spengler cyclisation (Scheme 14) [158].

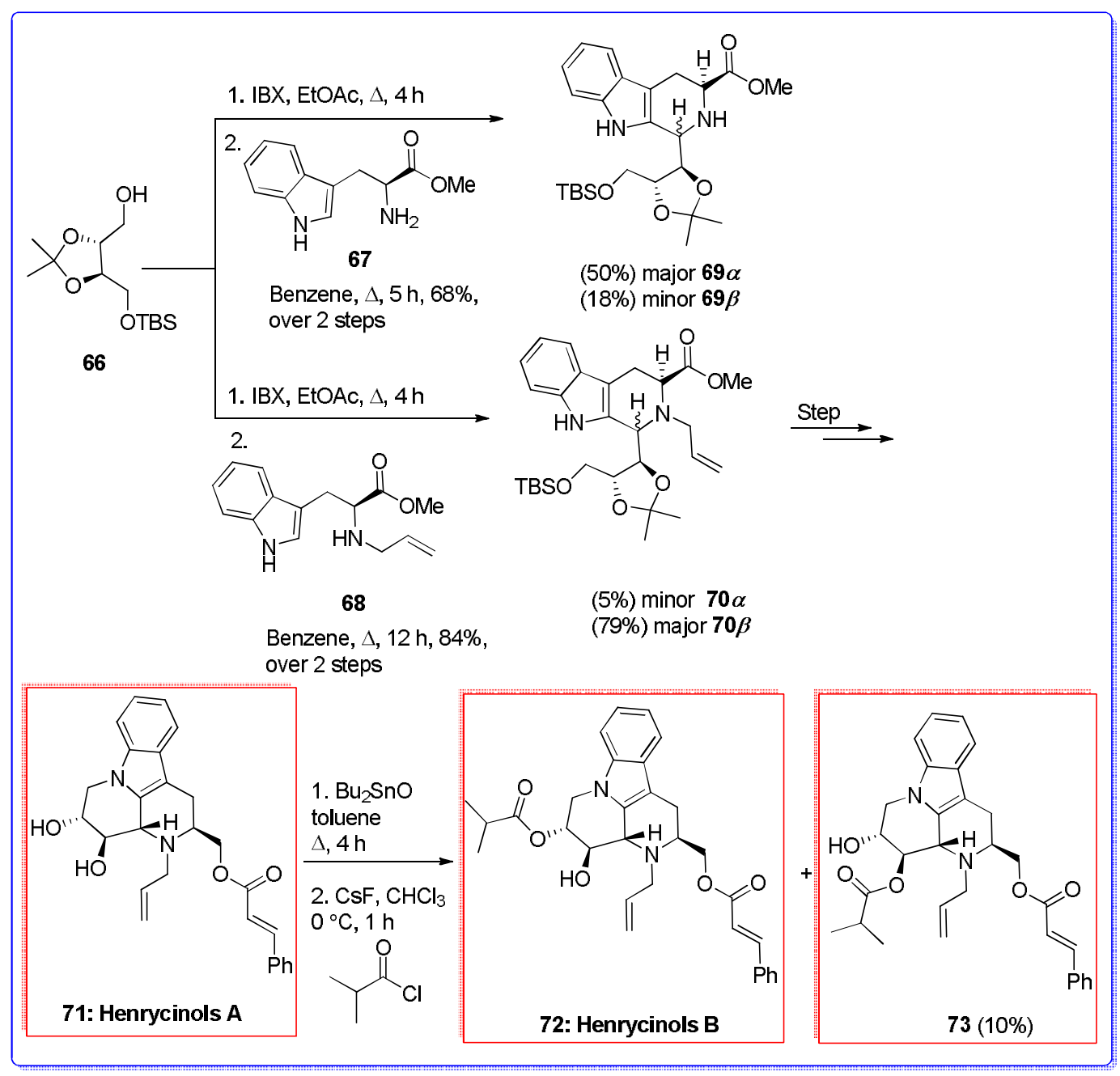

Scheme 14. Total synthesis of natural products henrycinols A 71 and B 72.

The remarkable pharmacological activities in cerebral circulation and neuronal homeostasis of eburnamine-vincamine indole-type alkaloids, including vincamine 79a, eburnamine $\mathbf{7 9 b}$, and vinpocetine 79c [159,160], make them striking products for total synthesis [161]. Until 2014, the most usual method to develop the [ABCD]-ring system of these compounds was to begin from an indole subunit to make the final E-ring [162-164]. Significant production of a cis-[ABCD]-ring intermediate, the katsubenitrile 78 , is the main stage for synthesis of 79. The katsubenitrile $\mathbf{7 8}$ is a building block in the three usual synthetic pathways, that all apply various methods, for the production of the cis-stereocenters of 79 . An efficient synthesis of the katsubenitrile is accomplished through a significant diastereoselective PSR of 3-ethyl-2-hydroxy-1-[2-(1H-indol-3-yl)ethyl]-6-oxopiperidine-3-carbonitrile to form the cis-[CD] rings in 1-ethyl-4-oxo-1,2,3,4,6,7,12,12 $\beta$ - octahydroindolo[2,3- $\alpha$ ]quinolizine-1-carbonitrile as the main stages.

In this approach, total synthesis of katsubenitrile $\mathbf{7 8}$ was initiated from the readily available ethyl-2-cyanobutanoate [165] and tert-butylacrylate which after several steps gave the $\mathrm{N}, \mathrm{O}$-hemiacetal 76 as an inseparable 3:2 mixture of epimers. Next, the PSR of 76 was explored to construct the tetracyclic compound 77. Reaction of $\mathbf{7 6}$ with trifluoro acetic acid (TFA) in $\mathrm{CH}_{2} \mathrm{Cl}_{2}$ at $-55^{\circ} \mathrm{C}$ afforded 
no reaction, while, elevating the reaction temperature to $20^{\circ} \mathrm{C}$ afforded the corresponding compound 77 as a 2:1 mixture of epimers. A short investigating action of different acids occurred, and it was recommended that chlorotrimethylsilane was the most effective for control over the diastereoselectivity at ambient temperature, giving 77 in a 96\% yield with a diastereomeric ratio of 3.5:1. These epimers of 77 could be easily separated by chromatography. In addition, the extremely crystalline nature of the epimers permitted X-ray crystallographic analysis, thus confirming the stereochemical assignment. Upon two steps, katsubenitrile 78, a main synthetic intermediate for eburnamine-vincamine alkaloids, was provided in satisfactory yields (2:68\%, 12-epi-2:65\%) (Scheme 15) [166].

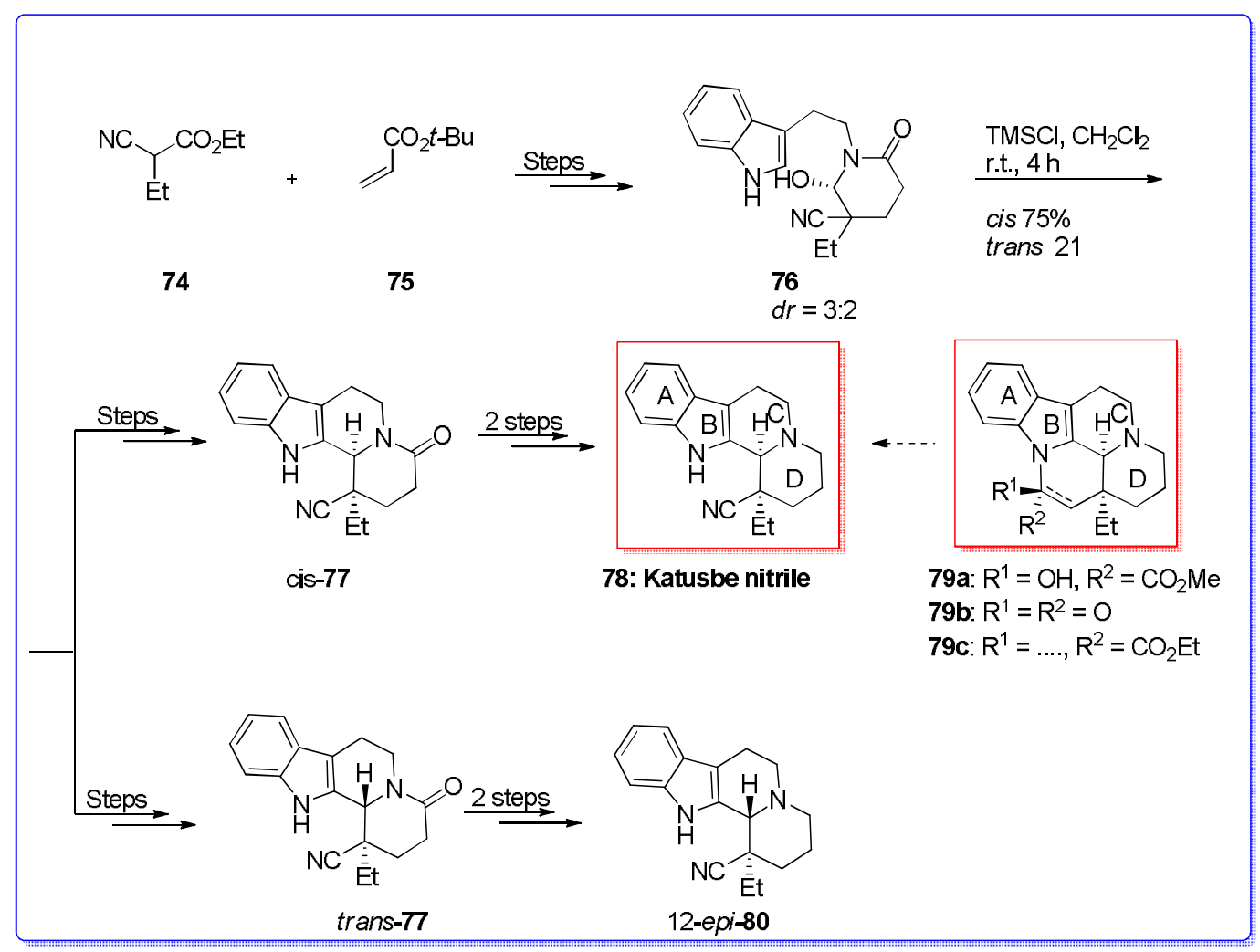

Scheme 15. Total synthesis of katusbenitrile 78 using PSR as key step.

Lindera aggregate is extensively dispersed in China and widely employed in traditional Chinese medicine for the treatment of a number of physiological symptoms [167]. Pharmacological investigating actions on L. aggregata (Lauraceae) demonstrated diverse important bioactivities, comprising super oxide anion radicals avenging, and protection against post-ischemic myocardial dysfunction, as well as slowing down the progression of diabetic nephropathy in $\mathrm{db} / \mathrm{db}$ mice [168-170]. Linderaggrine A 85 is a $\beta$-carboline alkaloid, from the roots of L. aggregata. $\beta$-Carboline alkaloids are a predominant class of biologically active naturally occurring compounds having an extensive range of pharmacological and structural diversity [171-173]. The successful construction of linderaggrine A 85 and 89 gave unambiguous evidence for the determination of the naturally extracted product. Wu and co-workers in 2014 designed synthesis of 1 -functionalized $\beta$-carbolines, using a single-step PSR [174]. The synthetic approaches employed to provide linderaggrine A 85 and its isomer by single-step PSR of 5-methoxytryptamine or 6-methoxy tryptamine with $p$-methoxy phenyl glyoxal were demonstrated. The precursors 5-methoxy tryptamine or 6-methoxy tryptamine and $p$-methoxy phenyl glyoxal were reacted by PSR to result in a mixture of dihydro- $\beta$-carbolines 83 or 87 and $\beta$-carbolines $\mathbf{8 4}$ or $\mathbf{8 8}$. To increase the yield of this conversion, $\mathrm{MnO}$ assisted dehydrogenation provided the aromatic $\beta$-carbolines $\mathbf{8 4}$ or $\mathbf{8 8}$ in satisfactory yields ( $38 \%$ and $40 \%$, respectively). The deprotection of the methyl substituent in both phenyl rings was examined by either $\mathrm{HCl}$ or $\mathrm{AlCl}_{3}$; though, only one 
of the methyl substituents could be disintegrated. Thus, the hydrobromic acid-acetic acid pair was applied to deprotect the two methyl substituents in one step with satisfactory yields ( $30 \%$ for 85 and $40 \%$ for 89 , respectively). But, there is a slight difference between the synthetic products of 85 and 89 . In the deprotection reaction of $\mathbf{8 8}$ to $\mathbf{8 9}, 8$-brominated product $\mathbf{9 0}$ was afforded because of the bromine provided from the decomposition of $\mathrm{HBr}$. In contrast, demethylation of $\beta$-carboline $\mathbf{8 4}$ merely afforded the mono-demethylation product 85 and the desired di-demethylation product 86 . The bio-activity consequences demonstrated the application of the roots of L. aggregata as herbal medicines in the reaction of inflammatory diseases, and linderaggrine A 85 may be potential in examining novel anti-inflammatory lead drugs (Schemes 16 and 17) [175].

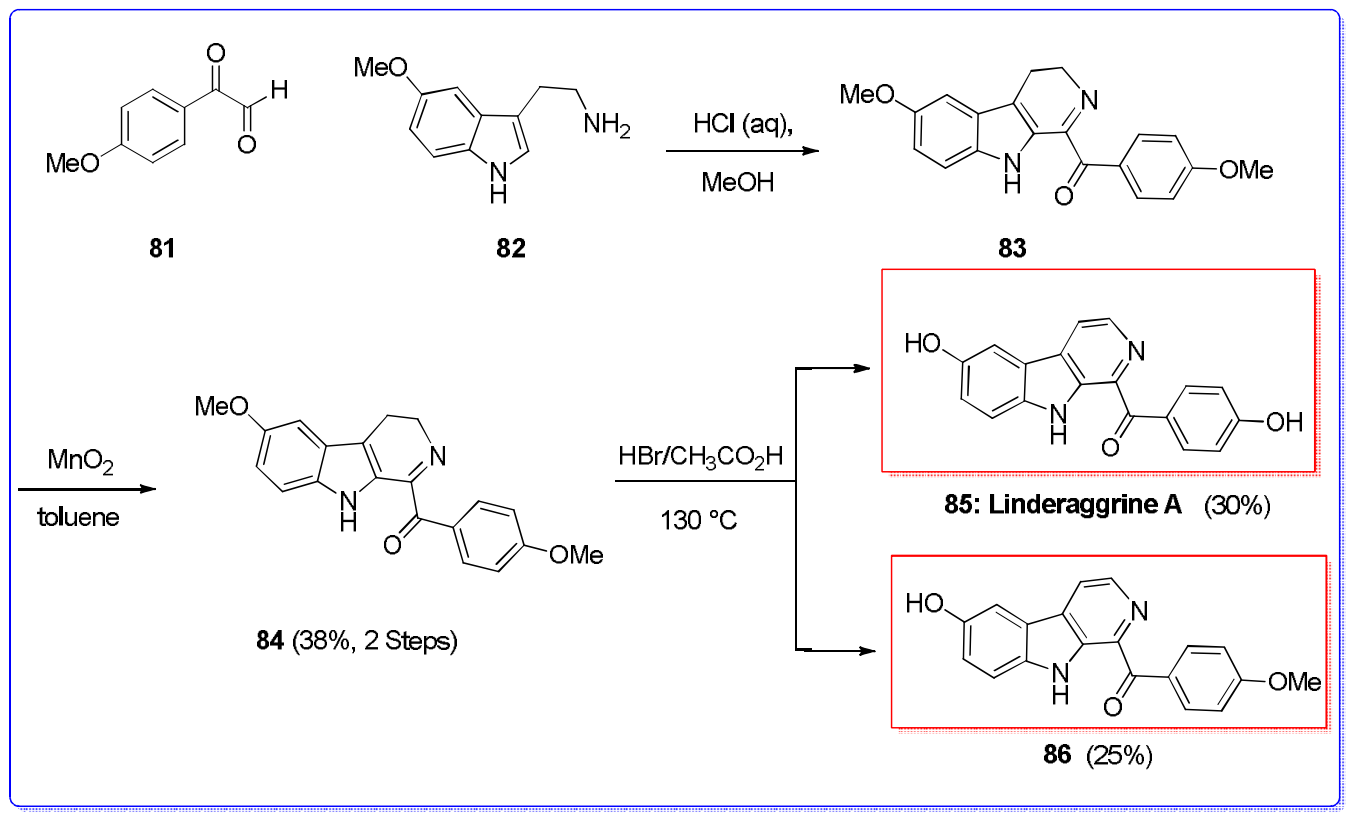

Scheme 16. Synthesis of linderaggrine A 85 and mono-demethylation product 86 .

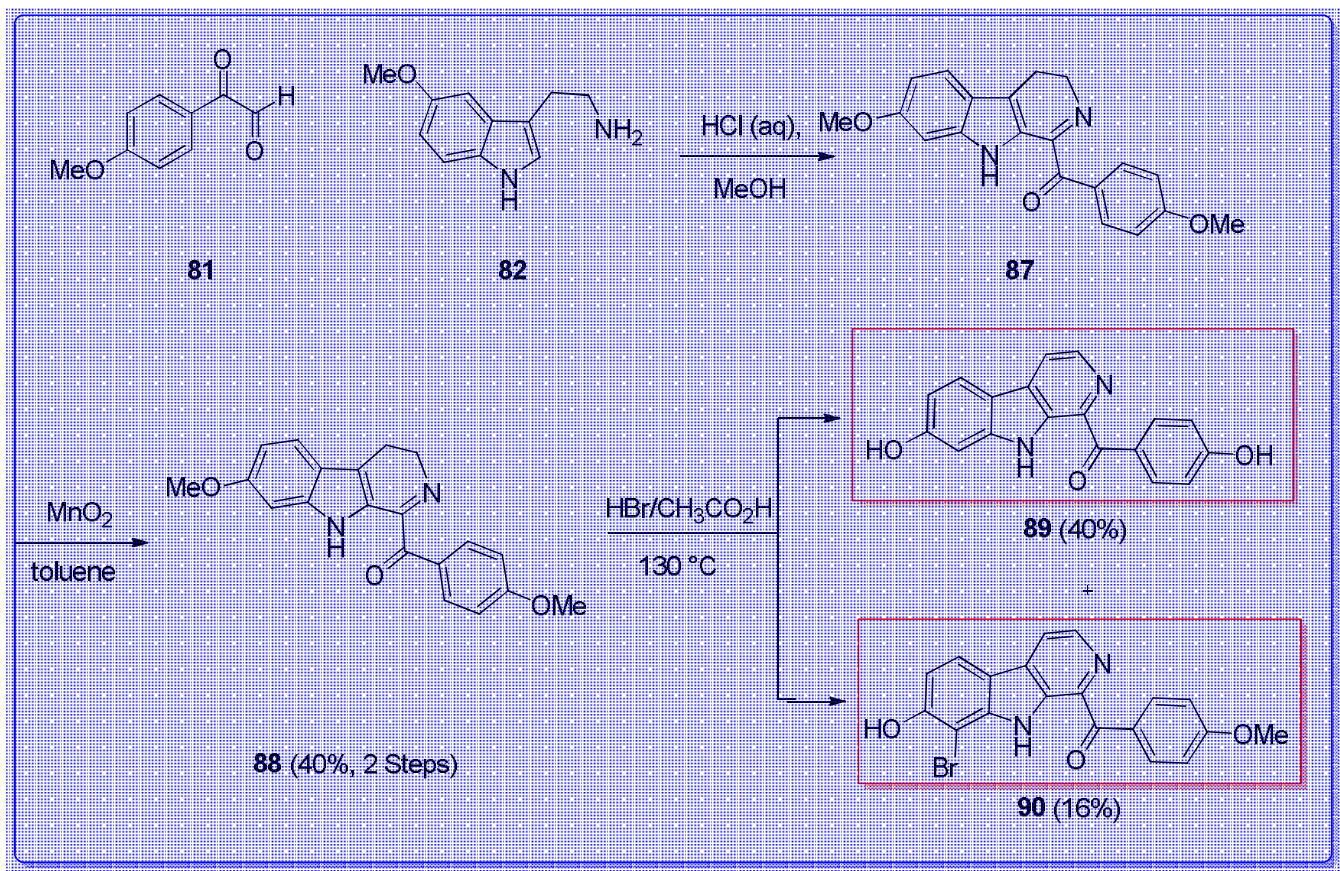

Scheme 17. Synthesis of product 89, the isomer of linderaggrine A, and 8-brominated product 90. 
Peganumine A 94, a dimerictetrahydro- $\beta$-carboline alkaloid, was extracted by $\mathrm{Li}$, Hua and co-workers in 2014 from the seeds of Peganum harmala L [176]. Its octacyclic structure having a distinctive 3,9-diazatetracyclo-[6.5.2.00] [176-179] pentadec-2-one moiety has been unprecedented. It demonstrated importantly the toxic property against MCF-7, PC-3, Hep G2 cells and selective influence on HL-60 cells. A gram-scale asymmetric total synthesis of (+)-peganumine A was achieved in seven steps from market purchasable 6-methoxytryptamine. Key stages comprised a Liebes kind-Srogl cross coupling; a one-pot production of the tetracyclic scaffold from an $\omega$-isocyano- $\gamma$-oxo-aldehyde through a sequence of an unprecedented carbon-carbon bond providing lactamization and trans annular condensation reaction; as well as a one-pot organo-catalytic method merging two a chiral building blocks into an octacyclic structure through a sequence of asymmetric PSR and by a trans annular cyclization reaction. This last reaction generated two spiro cycle derivatives and $\alpha$-2,7-diazabicyclo[2.2.1] heptan-3-one part along with excellent control of both the absolute and relative stereochemistry of the two freshly generated quaternary stereocenters. Generally, (+)-peganumine A 95 was formed in seven steps with 33\% overall yield (er 96/4) from the market purchasable 6-methoxytryptamine; the application of this synthetic method being accepted. In the following, the conditions to achieve a catalytic enantioselective synthesis of (+)-peganumine A were examined. The reaction of 91 and 92a using chiral phosphoric acid (TRIP) indeed gave $9^{\prime}$-demethoxy-peganumine A 94, although with poor yield (7\%) and ee (er 64.5/35.5) [180]. Employing Jacobsen's chiral thio urea catalyst (S)-93 was known to be more satisfactory [181]. Then, trifluoro acetic acid was added and the reaction mixture was refluxed for an additional two days to give (+)-9'-demethoxy-peganumine A 94 in $67 \%$ yield with er of $96 / 4$. Applying $\mathrm{PhCOOH}$ as co-catalyst was of greatest significance for the enantioselectivity of the reaction since employing acetic acid in place of $\mathrm{PhCOOH}$ under otherwise similar conditions afforded compound 94 (75\% yield) with significantly decreased ee (er 72/28). Condensation reaction of 91 with $\mathbf{9 2 b}$ gave (+)-peganumine A $95(69 \%$, er $96 / 4)$ in which the spectroscopic data were identical in all respects to those reported for the naturally occurring compound. As a result, the natural enantiomer was generated using (S)-93 as catalyst (Scheme 18) [182].

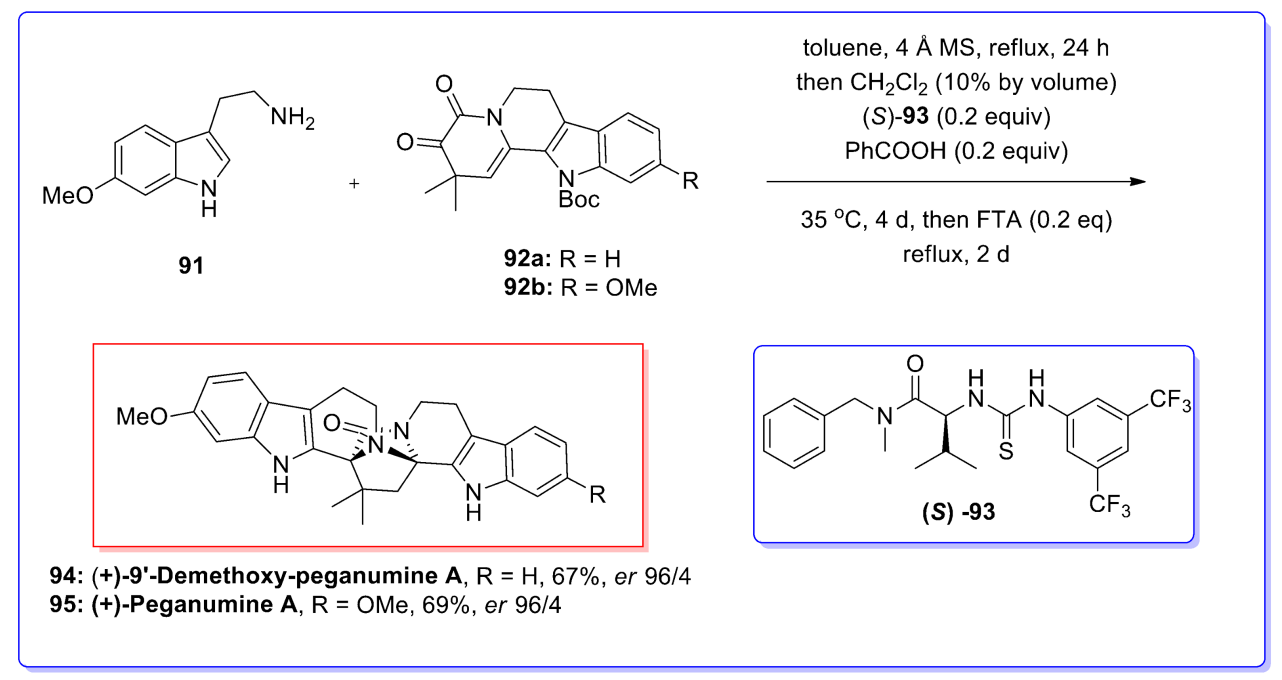

Scheme 18. Thiourea-catalyzed enantioselective synthesis of (+)-peganumine A 95 by PSR as the key step.

In this route, total synthesis of (+)-peganumine A 95 began with 6-methoxytryptamine. The condensation reaction of amine 91 with $\alpha$-ketoamide $92 \mathrm{~b}$ gave imine 96 , that underwent the asymmetric aza-Friedel-Crafts addition under the effect of the thiourea $(S)-93$ and $\mathrm{PhCOOH}$ to give the enantio enriched 97. After addition of a catalytic quantity of strong acid (trifluoro acetic acid), enamine-imine tautomerization occurred to form $\mathbf{9 8}$, that, after stereo specific trans annular addition of 
the secondary amine to iminium, provided octacycle 99. Elimination of $N$-Boc provided the natural product 95. Two quaternary stereocenters were made from two a chiral building blocks with excellent control of both de and ees (Scheme 19) [182].

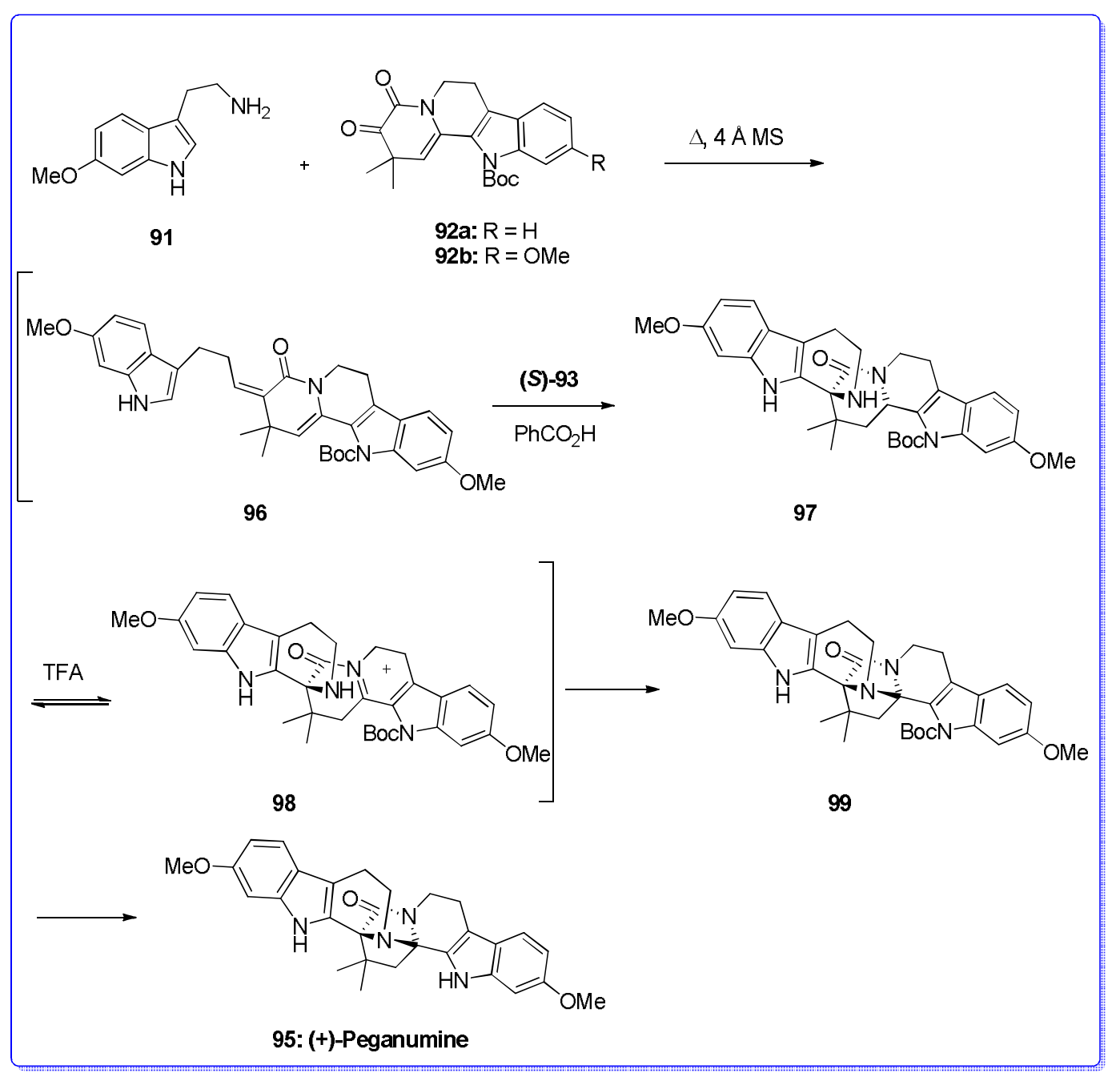

Scheme 19. Total synthesis of (+)-peganumine A 95.

The genus Kopsia, that belongs to the family Apocynaceae, is a rich source of mono terpenoid indole alkaloids containing extensive series of biological properties and structural diversity [183]. Takayama completed the structure clarification of different unique monoterpenoid indole alkaloids from Kopsia arborea, native to the Yunnan Province in China, [184,185] including an intriguing significant alkaloid named kopsiyunnanine $\mathrm{K}$ 104, that has an unprecedented azepine-fused tetrahydro- $\beta$-carboline ring moiety. A monoterpenoid indole alkaloid, kopsiyunnanine K 104, was extracted from Kopsia arborea. Its fascinating rearranged structure and absolute configuration, inferred from spectral data, and the probable biosynthetic route were identified on the basis of a 13-step enantioselective total synthesis.

Takayama and co-workers in 2016 reported the enantioselective total synthesis of kopsiyunnanine $\mathrm{K} 104$ through an enantioselective Ireland-Claisen rearrangement and an intramolecular diastereoselective PSR, and exhibited its significant rearranged framework and absolute configuration. Total synthesis of kopsiyunnanine K 104, was initiated from market purchasable valerolactone 100, and after several steps comprising oxidation, Mitsonubu reaction, ozonolysis, and alkylation afforded aldehyde 103. Next, deprotection of the $\mathrm{N}_{\mathrm{s}}$ group on the $\mathrm{N}_{\mathrm{b}}$ position in $\mathbf{1 0 3}$ followed through 
intramolecular diastereoselective PSR of the obtained amine using trifluoroacetic acid (TFA) afforded kopsiyunnanine K $\mathbf{1 0 4}$ as a single diastereomer in a measurable yield. Recrystallization of the product gave optically pure 104. Noticeably, the structure and the $16 R, 20 R$ configuration of synthetic 104 were confirmed by X-ray crystallographic analysis (Scheme 20) [186].

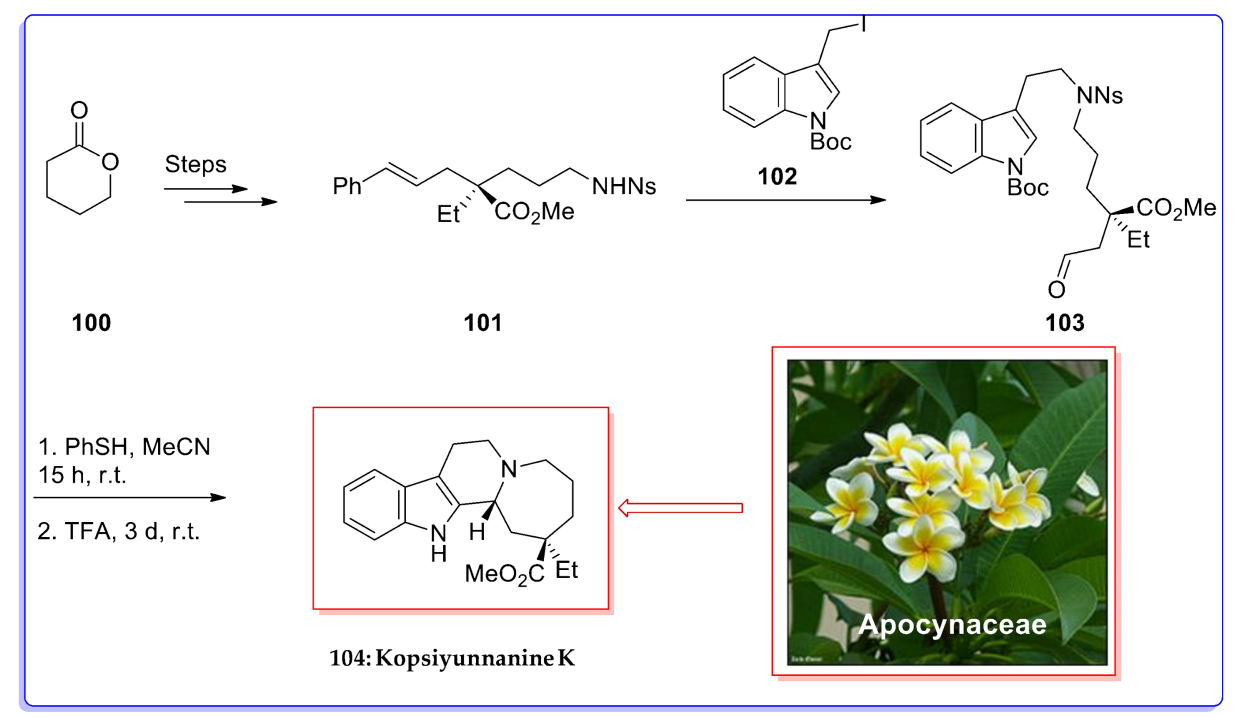

Scheme 20. Total synthesis of kopsiyunnanine K 104.

Spirooxindole alkaloids are interesting and challenging synthetic products, that have extremely complicated building blocks combined with favorable properties in numerous therapeutic areas [187,188]. Illustrative spirooxindole alkaloids contain trychnofoline 109, spirotry prostatins [115], palmirine [189], citrinadins [190], gelsemine [191], and cyclopiamines [192]. Amongst these attractive molecules, 109 seems to be a significant target for chemical synthesis and biological examination. It was extracted from the leaves of Strychnos usambarensis by Angenot and co-workers in 1978, and exhibited extremely promising antimitotic property against cultures of Ehrlich tumor cells and mouse melanoma. A striking synthesis of $( \pm)$-109 was shown by the Carreira group, in 2002, utilizing an elegant, extremely diastereoselective cyclopropane ring expansion method [116]. The five stereocentres and the unique spiro[pyrrolidin-3,3'-oxindole]scaffold show a substantial challenge for its synthesis.

Strychnofoline is a Strychnos alkaloid that has a significant spirooxindole framework and has a significant anticancer property. $\mathrm{Xu}$ and co-workers in 2018, for the first time, demonstrated the asymmetric synthesis of strychnofoline proceeding in only nine steps from market purchasable 6-methoxytryptamine.This method is highlighted by a one-pot, catalytic enantioselective production of the quinolizidine intermediate 108. The efficacy of the synthesis derives from the use of two sequential conversion stages in the catalytic enantioselective production of the spiro[pyrrolidine- $3,3^{\prime}$-oxindole] scaffold in a simple method. Remarkably, the $\beta$-carboline framework could be generated through a late stage PSR. This pathway was performed through sequential acylation/enantioselective Michael addition/PSR/oxidative rearrangement.

Total synthesis of strychnofoline was initiated from market purchasable 6-methoxytryptamine 91. By sequentially adding 91; diketene 105, acrolein derivative 106; organocatalyst 107 (Hayashi-Jorgensen catalyst); and acyl chloride to the reaction mixture, they were able to obtain the quinolizidine derivative 108 in satisfactory yield with high ee (67\% yield, ee >99\%). After several steps, total synthesis of the anti-tumor alkaloids trychnofoline 109 was completed and the synthesized material, showed equal spectroscopic and analytical properties to that demonstrated for the naturally occurring compound [113,116]. A useful construction of $\mathbf{1 0 9}$ will be of great assistance in addressing its therapeutic promise (Scheme 21) [193]. 


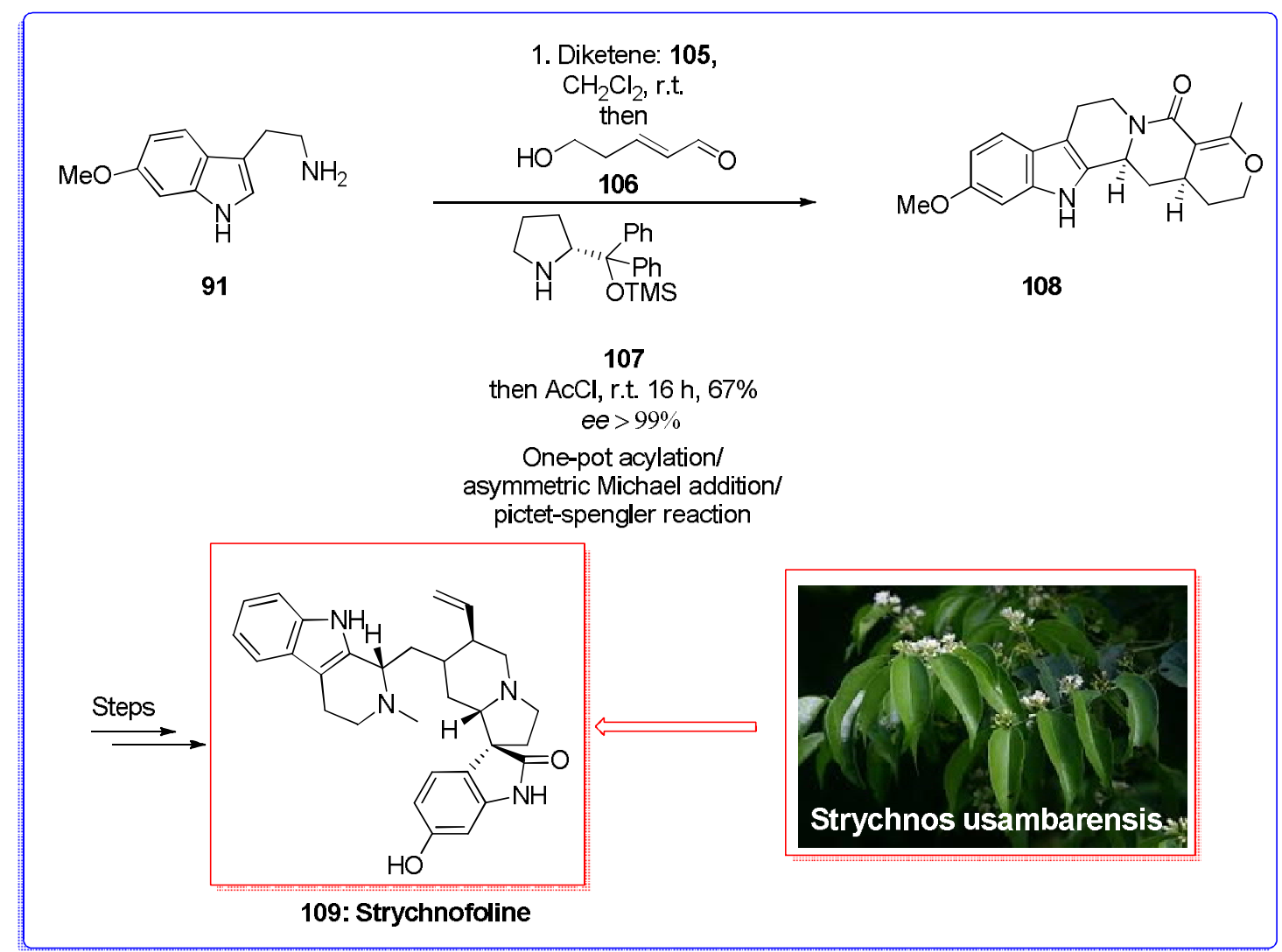

Scheme 21. Total synthesis of strychnofoline 109.

The C-19 methyl functionalized macroline/sarpagine and ajmaline alkaloids are an emerging group of biosynthetically related indole alkaloids, some of which have historical importance [194], and were principally extracted from different medicinal plants of the Apocynaceae group. Most of these alkaloids were not examined for their biological property, probably, because of the paucity of extracted material. Macrocarpines B were extracted from the stem bark of Alstonia macrophylla by Kam [195]. Talcarpine 117, extracted from Alstonia macrophylla and Pleiocarpa talbotii, showed antimalarial properties [71]. N(4)-Methyl-N(4), 21-secotalpi-nine 118, extracted from Pleiocarpa talbotii, and Alstonia angustifolia, exhibited remarkable anti-leishmanial properties [195-197].

The majority of these alkaloids have the $\beta$-methyl configuration at C-19, a few contain the $\alpha$ C-19 methyl function (for example dihydroperaksine 119, also found as dihydrovomifoline and deoxyperaksine) [198]. All of these alkaloids contain either a $N_{\mathrm{a}}$-methyl or $N_{\mathrm{a}}$-hydrogen functionalized indole nitrogen atom. Also, the $N_{\mathrm{b}}$-nitrogen atom differs in the pattern of substitution. Furthermore, all of these alkaloids include a 6 or 7 quaternary center showing different substitution patterns and configurations that render the synthesis of these alkaloids of interest.

Extension of the enantioselective PSR to bulkier $N_{\mathrm{b}}$-alkylated tryptophan led to an increased stereospecific admittance to the key bi-cycle [3.3.1] nonane unit of bioactive C-19 methyl functionalized sarpagine/macroline/ajmaline indole alkaloids having high diastereoselectivity through internal enantioselective induction. Full stereo control of the C-19 methyl function in either the $\alpha$-or $\beta$-configuration has been accomplished that allows the total synthesis of any member from this class of thirty alkaloids. In 2017, the total synthesis of macrocarpines (A-C) 114, 115, 116, talcarpine 117, $N(4)$-methyl-N(4), 21-secotalpinine 118, dihydro-peraksine 119, and deoxyperaksine 120 was reported. In this route, the total synthesis was initiated from market accessible D-(+)-tryptophan $\mathbf{1 1 0}$ and the optically pure ethinyl tosylates which was transformed to compound 111. After several steps, the $N_{\mathrm{b}}$-alkylated intermediate $\mathbf{1 1 1}$ reacted with the actetal $\mathbf{1 1 2}$ based on the thermodynamically controlled 
conditions of the enantioselective Pictet-Spengler condensation to supply the corresponding trans diester 113a in high yield and $>95: 5 \mathrm{de}$. After several steps and by different routes natural products (-)-macrocarpine A 114, (-)-macrocarpine B 115, (-)-macrocarpine C 116, (-)-talcarpine 117 and $(+)-N(4)$-methyl-N(4), 21-secotalpinine 118 were synthesized (Scheme 22).

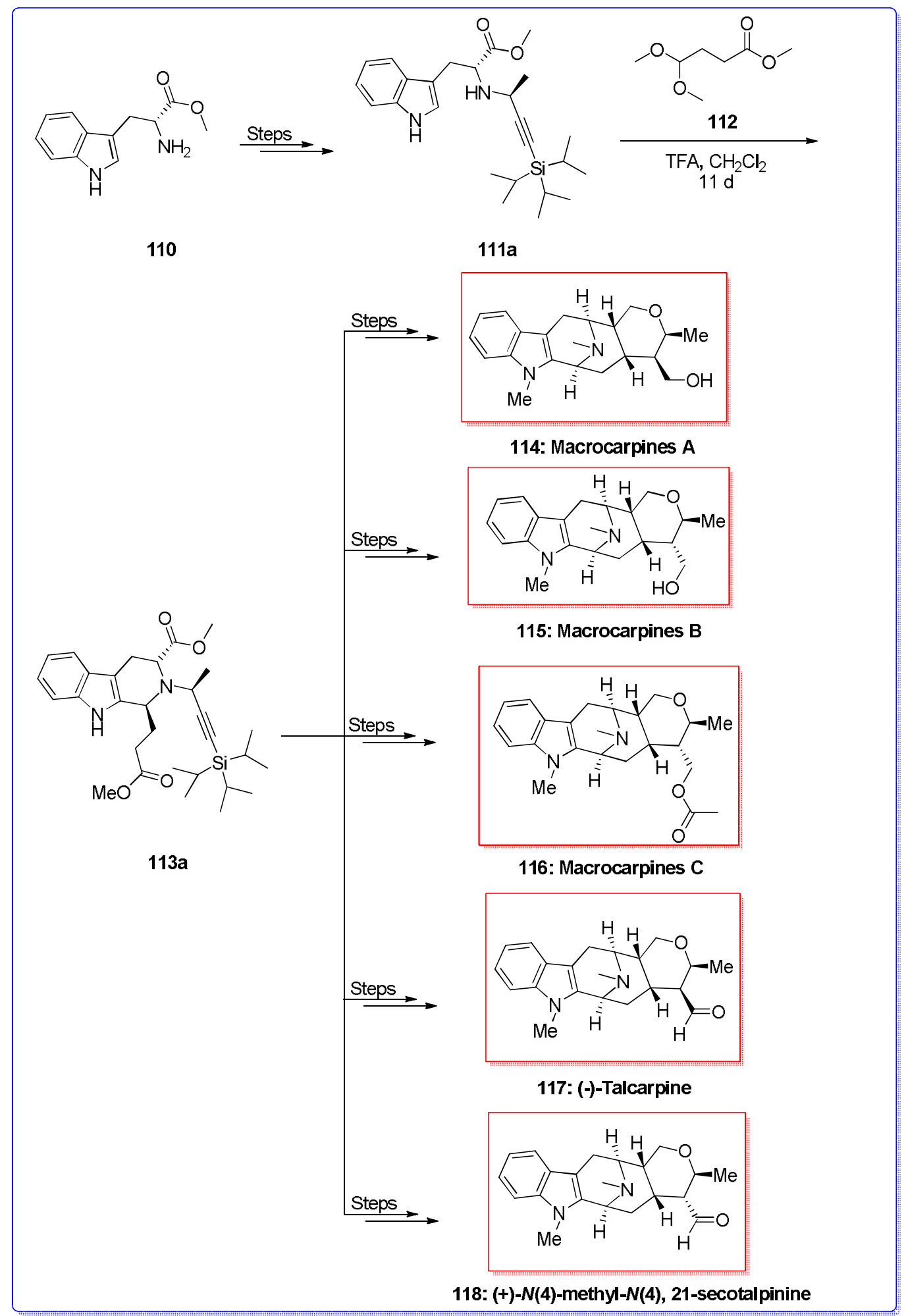

Scheme 22. Total synthesis of (-)-macrocarpine A 114, (-)-macrocarpine B 115, (-)-macrocarpine C 116, (-)-talcarpine 117, and (+)-N(4)-methyl-N(4),21-secotalpinine 118. 
Upon completion of the total synthesis of the C-19 $\beta$-methyl functionalized macroline related alkaloids; 114-118, the focus changed to the synthesis of C-19 $\alpha$-methyl functionalized sarpagine alkaloids (+)-dihydroperaksine 119, and (-)-deoxyperaksine $\mathbf{1 2 0}$. The trans-diester $\mathbf{1 1 3 b}$ was accessed through the approach demonstrated. After several steps, (+)-dihydroperaksine 119 was obtained. The optical rotation and spectral data for this synthetic (+)-dihydroperaksine $\mathbf{1 1 9}$ were in full agreement with the values in the literature [198]. Also, on the other hand, after several steps, (-)-deoxyperaksine 120 was formed.

As a result, the initial total synthesis of sarpagine/macroline related alkaloids was accomplished through the expanded and shorter PSR. Furthermore, this route corrects the optical rotation values of (-)-macrocarpine A 114 and (+)-N(4)-methyl, N(4), 21-secotalpinine 118 demonstrated by others [195]. This route obviously demonstrates that a large group other than the benzyl on the $N_{\mathrm{b}}$-nitrogen atom of the D-(+)-tryptophan initiating precursor can still give $100 \%$ de through internal enantioselective induction (Scheme 23) [199].

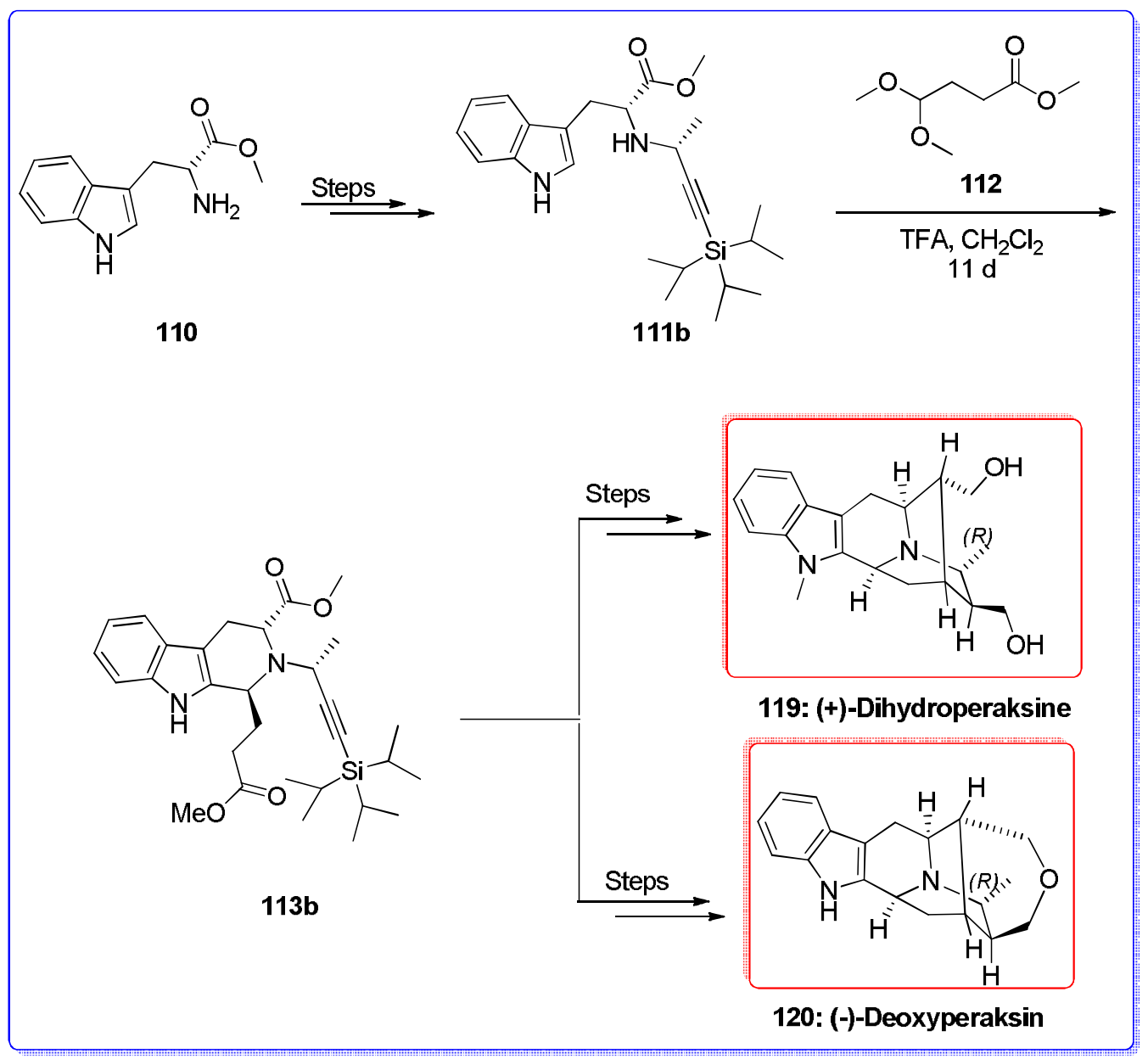

Scheme 23. Total synthesis of alkaloids (+)-dihydroperaksine 119 and (-)-deoxyperaksine 120.

\subsection{Phenyl (Tetrahydroisoquinoline) Scaffold}

Jamtine, one of the significant alkaloids produced by the climbing shrub Cocculus hirsutus [200], is known throughout Pakistan and its parts are reputed for their therapeutic properties in folk medicine [201]. Its isolation and structural elucidation, primarily by 2D-NMR spectra, was reported in 1987 [202]. The first total synthesis of $( \pm$ )-jamtine 124, a tetrahydroisoquinoline alkaloid reputed for its therapeutic activities, was demonstrated by Padwa and co-workers 2002 [203]. The key stage includes a tandem thionium/N-acyliminiumion cyclization using enamidosulfoxide $\mathbf{1 2 2}$. The cascade method 
occurs with excellent diastereoselectivity and in high yield. Total synthesis of ( \pm )-jamtine 124 was initiated from commercially available caprolactone 121, and after several steps gave bromo-enamide 122 as a 4:1(Z/E) mixture of isomers in excellent yield. Heating the compound 122 with camphor sulfonic acid gave the corresponding tricyclic unit of jamtine in high yield (88\%) but as a 5:2:1:1 mixture of diastereomers. The main product obtained corresponded to the corresponding diastereomer 123. The preferential construction of $\mathbf{1 2 3}$ is consistent with earlier stereo chemical clarifications, [200] demonstrating that a $4 \pi$-Nazarov type electro cyclization [204] controls the direction of closure from the $\alpha$-acylthionium ion intermediate. The sub-sequent PSR includes attack of the proximal aromatic ring from the less hindered side of the iminium ion. After several steps, the first total synthesis of this interesting alkaloid, jamtine 124, was completed (Scheme 24) [203].

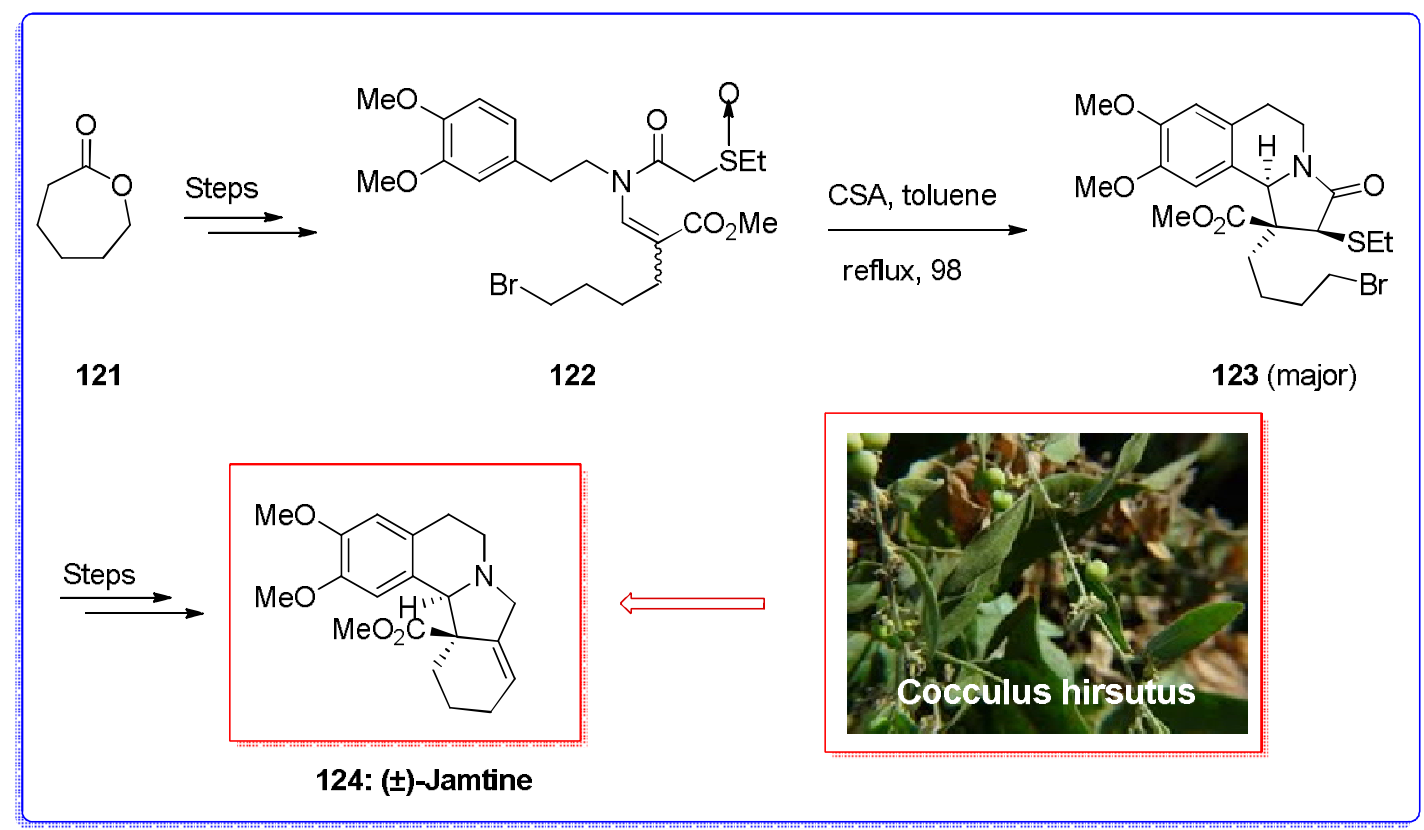

Scheme 24. Total synthesis of Jamtine 124.

Ecteinascidin 743 [205,206] (Et743) $\mathbf{1 3 1}$ is one of the significant marine alkaloids, extracted from the Caribbean tunicate Ecteinascidia turbinata. However, although extracts from this organism have been investigated since the 1960s, the isolation of pure substances did not occur until 1986 [205,206]. Ecteinascidin 743 [205,206] (Et743) 131, as a significant antitumor agent is currently undergoing phase II clinical trials and moreover attracting significant attention [207-209]. The originality of its architecture, the remarkable biological properties, and its natural scarcity make it attractive for total synthesis [210,211]. In terms of its presentation of the unit pentacyclic A-E ring system, Et743 131 contains important structural homology to the saframycin group of antibiotics as well as to similar compounds [207-209]. The largest variance is that in Et 743, position 4 is a higher oxidation level than in the case of the saframycins. The extra functionality in $\mathbf{1 3 1}$ takes the form of a novel 10-membered ring. This sulfur-comprising macrolactone is itself spiro linked to a tetrahydroisoquinoline. The drug accessibility issue in terms of isolation from natural sources is relatively difficult. Corey and Gin developed first total synthesis of Et 743 [212]. Danishefsky and co-workers in 2002 reported the total synthesis of Et 743 [213]. They reported that Pictet-Spengler cyclization affording spiro product 129 shows excellent stereoselectivity. In this route, the final goal was to attain compounds including 129 and 130 in which the C, D, and E rings of Et 743 were deleted. This group tried to examine the issue of stereoselectivity in the PSR providing 129 (vide infra). After several steps, ketone 126 was formed. Next, the reaction of ketone 126, accomplished with amine $\mathbf{1 2 7}$ as demonstrated by Corey and Ginina in a more complex setting [212], produced the spiro tetrahydroisoquinoline $\mathbf{1 2 9}$ in an apparently stereo 
specific method. Because of the rotameric states of $\mathbf{1 2 9}$, it was difficult to determine the orientation of the spiro attachment. The $N$-Boc linkage was removed using a trifluoro acetic acid reaction, providing the amine 130. NOE measurements on 130 demonstrated that the orientation at $\mathrm{C}-1^{\prime}$ corresponded to that required for Et 743. Whether this result is the result of thermodynamic control or reflects some long-range stereochemical preference in mutual presentation of the aromatic sectors of the iminium intermediate (cf. 31) at the kinetic level is not known. In this regard, it is tempting to propose that as the $\mathrm{H}$ ring attacks the iminium ion in 128, the resultant transient electron-deficient cyclohexadienone scaffold is stabilized by stacking to the electron-rich A ring. In this way, the detected sense of face selectivity would be rationalized (Scheme 25) [213].

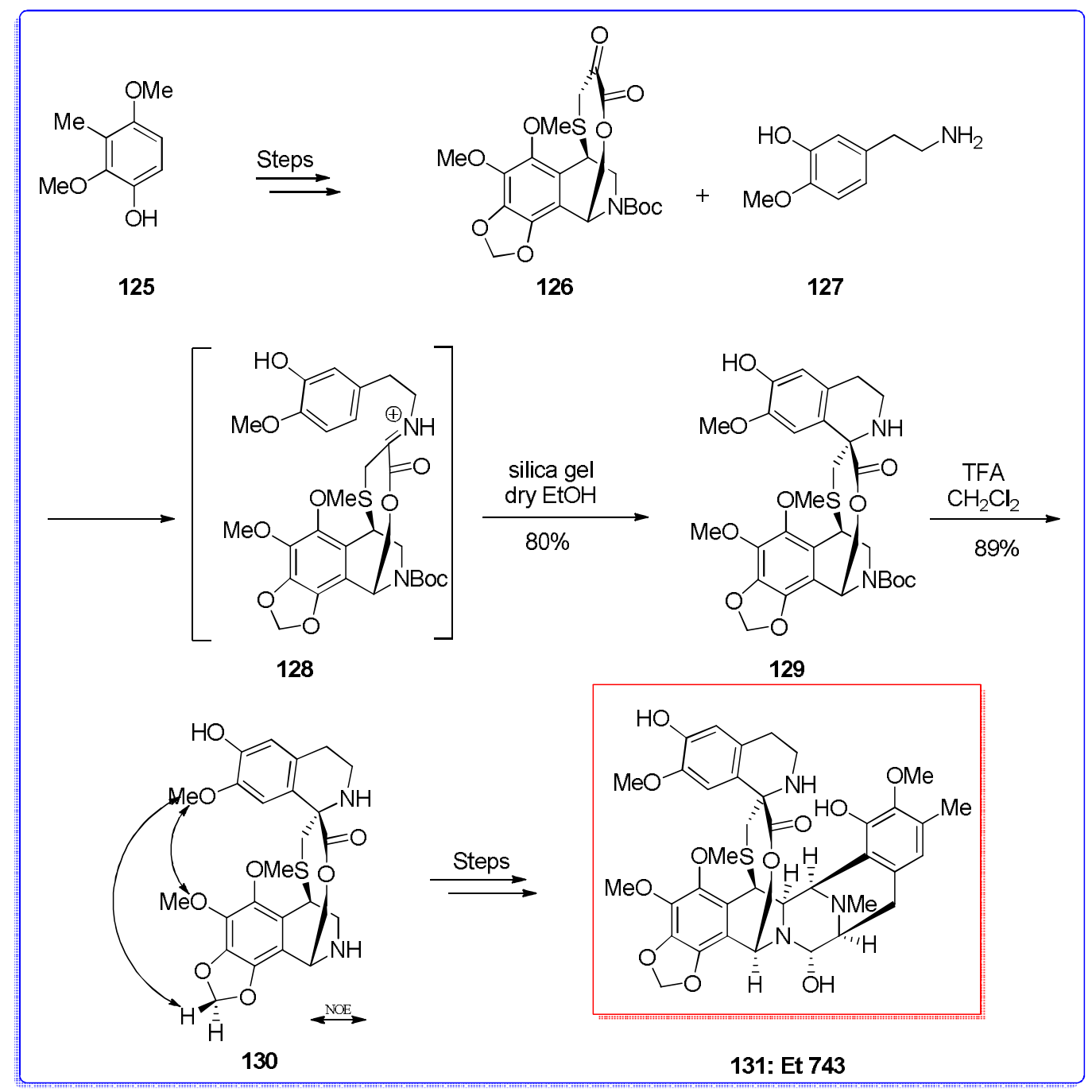

Scheme 25. Total synthesis of Et743 131.

Also, an asymmetric total synthesis of ecteinascidin 743131 was performed in 2002 by Fukuyama and co-workers [214]. In this approach, an Ugi four-component reaction, the intramolecular Heck reaction and PSR can be considered as main steps. By this pathway, total synthesis of Ecteinascidin 743131 was initiated from the reaction between two segments, amine 135 and carboxylic acid 136. Significantly, an extremely functionalized $(R)$-phenyl glycinol derivative $\mathbf{1 3 5}$ was synthesized from the treatment of phenol 132 with iminolactone 133 (in several steps). Instead, (S)-iodophenyl alanine derivative 136 was provided from market purchasable 3-methylcatechol [215]. The treatment of amine 135 and carboxylic acid 136, after several steps gave the corresponding ten-membered sulfide 137. With the corresponding ten-membered sulfide $\mathbf{1 3 7}$ in hand, all that is necessary to complete the 
total synthesis of ecteinascidin 743131 is the production of the last tetrahydroisoquinoline scaffold. Removal of the Troc group followed via reductive alkylation reaction gave $N$-methylamine, whose Alloc group and allylether were instantaneously removed with Pd catalyst to afford the aminophenol. Based on the method reported by Corey [212], biomimetic trans amination reaction [216] gave the known $\alpha$-ketolactone [217], and subsequent PSR with amine 138 provided ecteinascidin 770139 [218]. Lastly, construction of the labile hemiaminal from the aminonitrile affected by reaction with silver nitrate in acetonitrile-water to afford ecteinascidin 743 131, and afforded spectral data in complete agreement with those of the natural product (Scheme 26) [214].

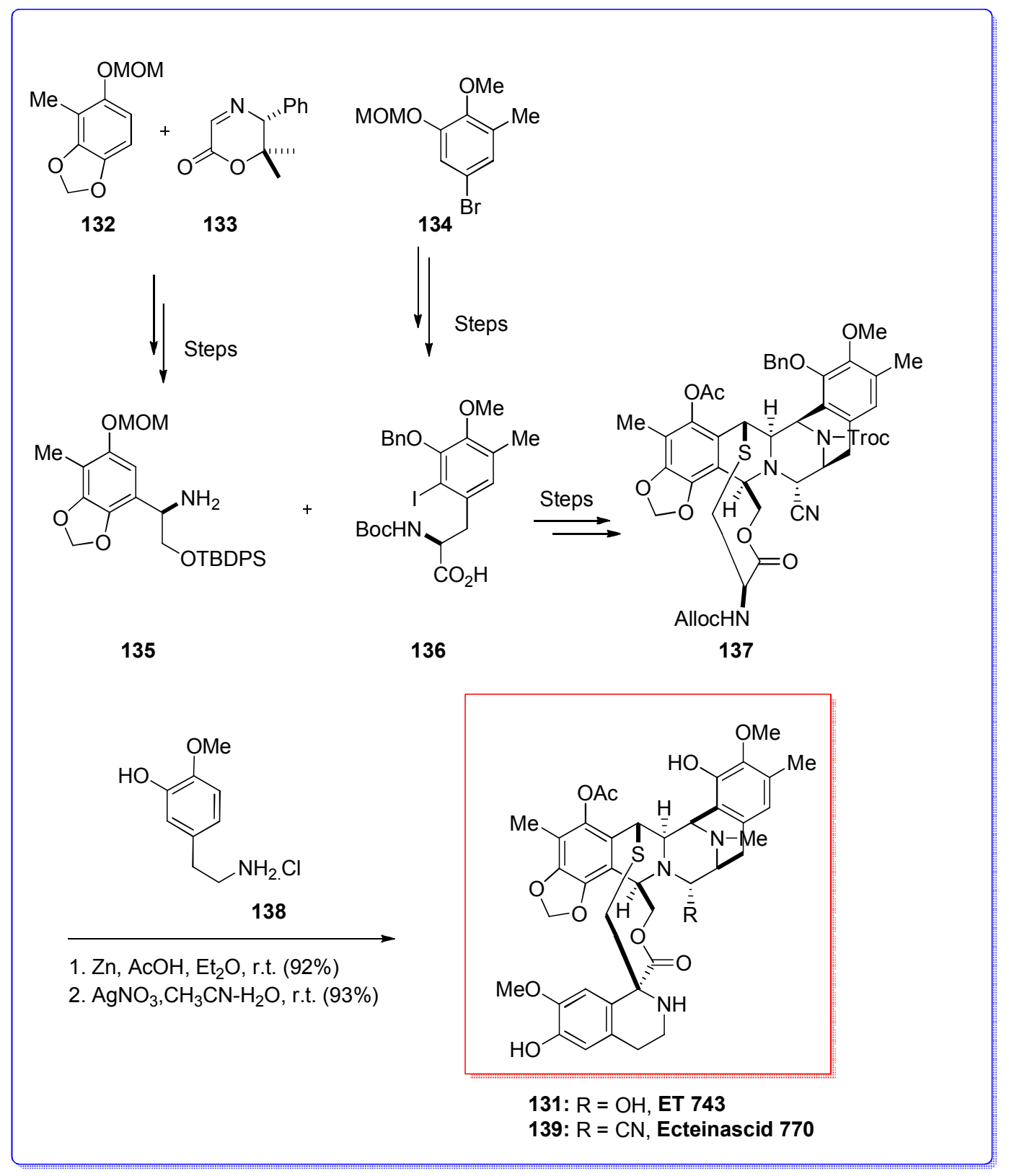

Scheme 26. Total synthesis of Et 743131 and ecteinascidin 770139.

Lemonomycin 145, as a member of the tetrahydroisoquinoline group of antitumor antibiotics, which involves the quinocarcins, ecteinascidins and saframycins was initially extracted in 1964 from a fermentation broth of Streptomyces candidus and was known to have powerful antibiotic properties against Staphylococcus aureus and Bacillus subtilis [219]. The architecture of lemonomycin, though, was 
not clarified until 2000 [220], Besides the connectivity and relative stereochemistry of lemonomycin, the antibiotic property against methicillin-resistant $S$. aureus and vancomycin-resistant Entero-coccus faecium, as well as the cytotoxicity against a human colon tumor cell line were demonstrated. Lemonomycin is significant among the approximately 60 natural products and hundreds of synthetic equivalents in this group in which it contains a glycoside at C (18) [221].

Stoltz and co-workers in 2003 described the first total synthesis of the glycosylated tetrahydroisoquinoline antitumor antibiotic (-)-lemonomycin (15 steps from 140). The merits of this convergent synthesis are the enantioselective dipolar cycloaddition which sets the stereochemistry of the glycone unit, a Suzuki coupling to link the diazabicycle to the aryl subunit, and a stereoselective PSR, which incorporates the aminoglycoside directly without the need for late-step glycosylation or masking group manipulations. This group demonstrated the first total synthesis of (-)-lemonomycin by usage of a stereoselective dipolar cycloaddition and a novel, diastereoselective PSR. For the total synthesis of (-)-lemonomycin, the reaction of bromide salt 140 and the Oppolzer sultam-derived acrylamide 141 [222] after several steps gave aminotriol 141. Instead, an $\alpha$-glycosyloxy acetaldehyde derivative 143 was synthesized from D-threonine [223,224]. In the following, the completion of the total synthesis now based on the success of the unprecedented PSR of the aminoglycosyloxy aldehyde 143 and the trifluoro acetic acid salt of amino triol 142 is given. Simple mixing of the two compounds in ethanol at ambient temperature provided the corresponding adduct $\mathbf{1 4 4}$ as a single diastereomer at $\mathrm{C} 1$ in $95 \%$ yield. Elaboration of tetrahydroisoquinoline $\mathbf{1 4 4}$ to the natural product was straight forward and included hydrogenolytic removal of the CBZ group, bis Swern oxidation, and reaction with CAN to give (-)-lemonomycin 145 . The completely synthetic precursor provided by this reaction was shown to be identical in all respects to a sample provided from natural sources (Scheme 27) [225].

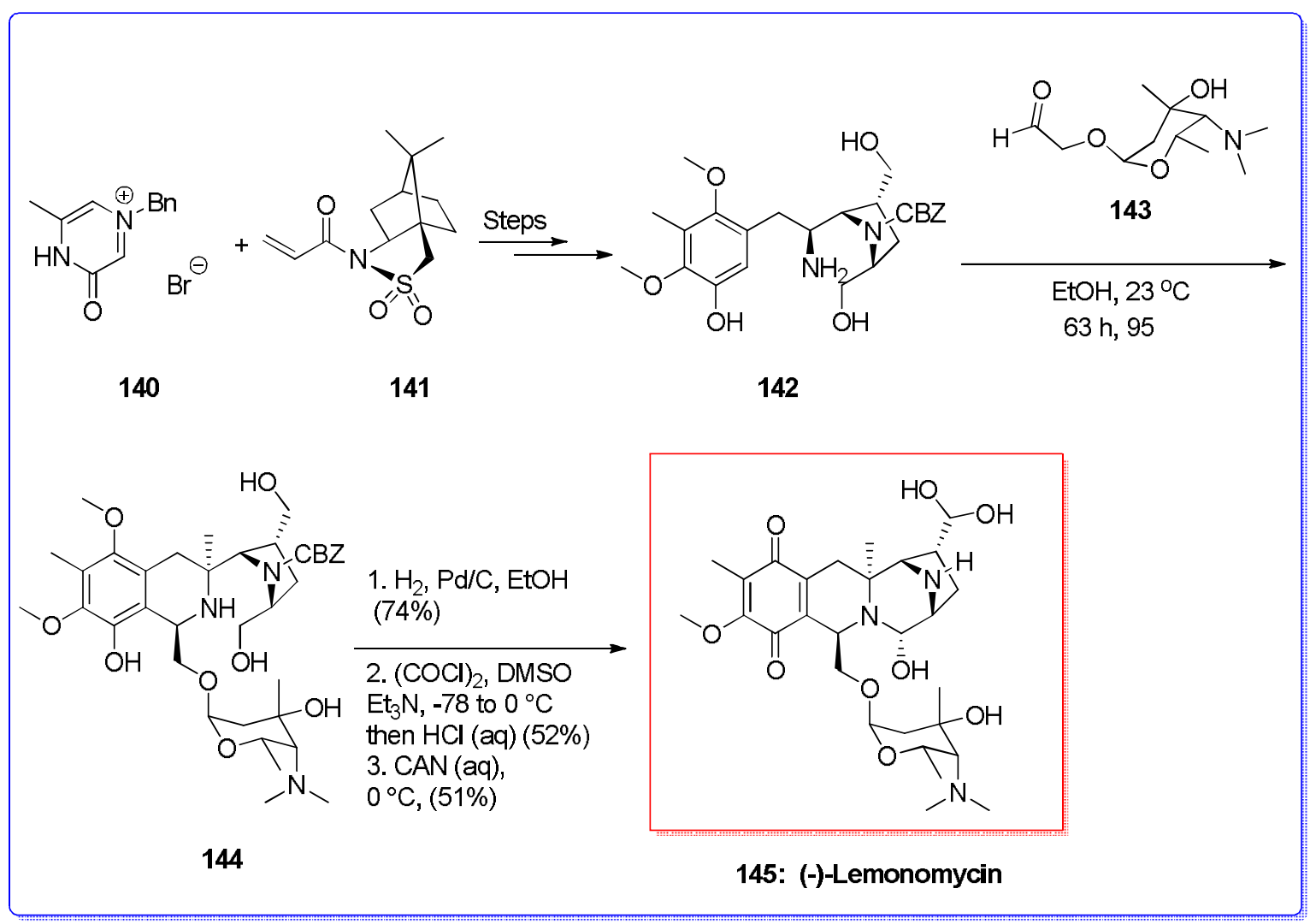

Scheme 27. Total synthesis of Lemonomycine $\mathbf{1 4 5}$.

Cribrostatin 4151 was extracted by Pettit and co-workers in 2000 in the Republic of Maldives from the blue sponge Cribrochalina collected [226]. Shortly afterwards, Kubo and co-workers [227] 
reassigned the architecture of reneiramycin $\mathrm{H}$, extracted by Parameswaran and co-workers from Haliclona cribicutis [228], to be equal to that of cribrostatin 4151 . Cribrostatin 4151 belongs to a large group of complex tetrahydroisoquinoline natural products, that involves ecteinascidin 743 (Et 743), Et 597, and cyanosafracin [221].

A convergent total synthesis of cribrostatin 4151 was completed by Chen and co-workers in 2007 in a long linear sequence of 21 steps from the known phenol 146 in $4.3 \%$ overall yield (or in 26 steps from vanillin in $2.8 \%$ overall yield). Total synthesis of cribrostatin $4 \mathbf{1 5 1}$ was initiated from the aldol condensation reaction of phenol 146 [229] and the garneraldehyde 147 [230]. After several steps, the free aminophenol 148 was formed. The PSR of 148 and benzyloxyacetaldehyde 149 gave the 1,3-cistetrahydroisoquinoline 150 in 91\% yield as a single diastereomer (d.r. >30:1) [137]. After several steps, total synthesis of cribrostatin 4151 was completed (Scheme 28) [231].

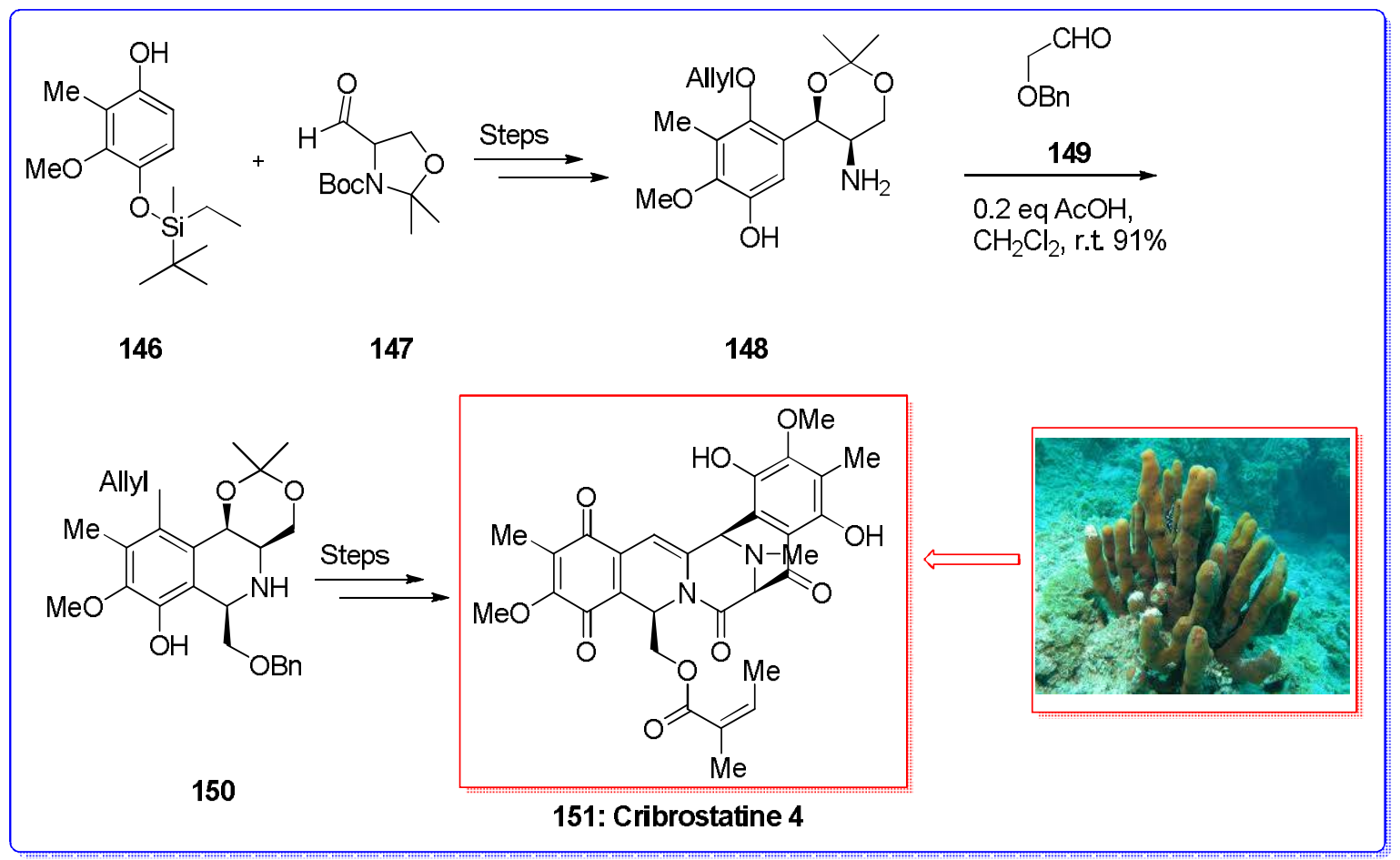

Scheme 28. Total synthesis of Cribrostatine 4151.

(-)-Quinocarcin 155, a pentacyclic tetrahydroisoquinoline alkaloid [221], was extracted from the culture broth of Streptomycesmeluno Vinuceus in 1983 by Takahashi and Tomita [232,233]. It showed significant antitumor properties against a number of tumor cell lines and its citrate salt (KW2152) has been used in clinic trials in Japan [234-237]. The anti-proliferative influence of (-)-quinocarcin was relatively explained by its ability to prevent RNA and/or DNA synthesis although, it was found that (-)-quinocarcin and (-)-tetrazomine showed cytotoxic properties [238]. The total synthesis of (-)-quinocarcin was obtained in a long linear sequence of 22 stages from 3-hydroxybenzaldehyde 152 in $16 \%$ overall yield. Remarkably, total synthesis of (-)-quinocarcin was initiated from 3-hydroxy benzaldehyde that after several steps gave the functionalized phenylalanine derivative 153. The PSR of amino phenol 153 with benzoxy acetaldehyde 149 based on mild acidic tetrahydroisoquinoline conditions afforded $\mathbf{1 5 4}$ as a single diastereomer as a merely isolable stereomer in $91 \%$ yield. After several steps,(-)-quinocarcin 155 was synthesized in 16\% overall yield (Scheme 29) [239]. 


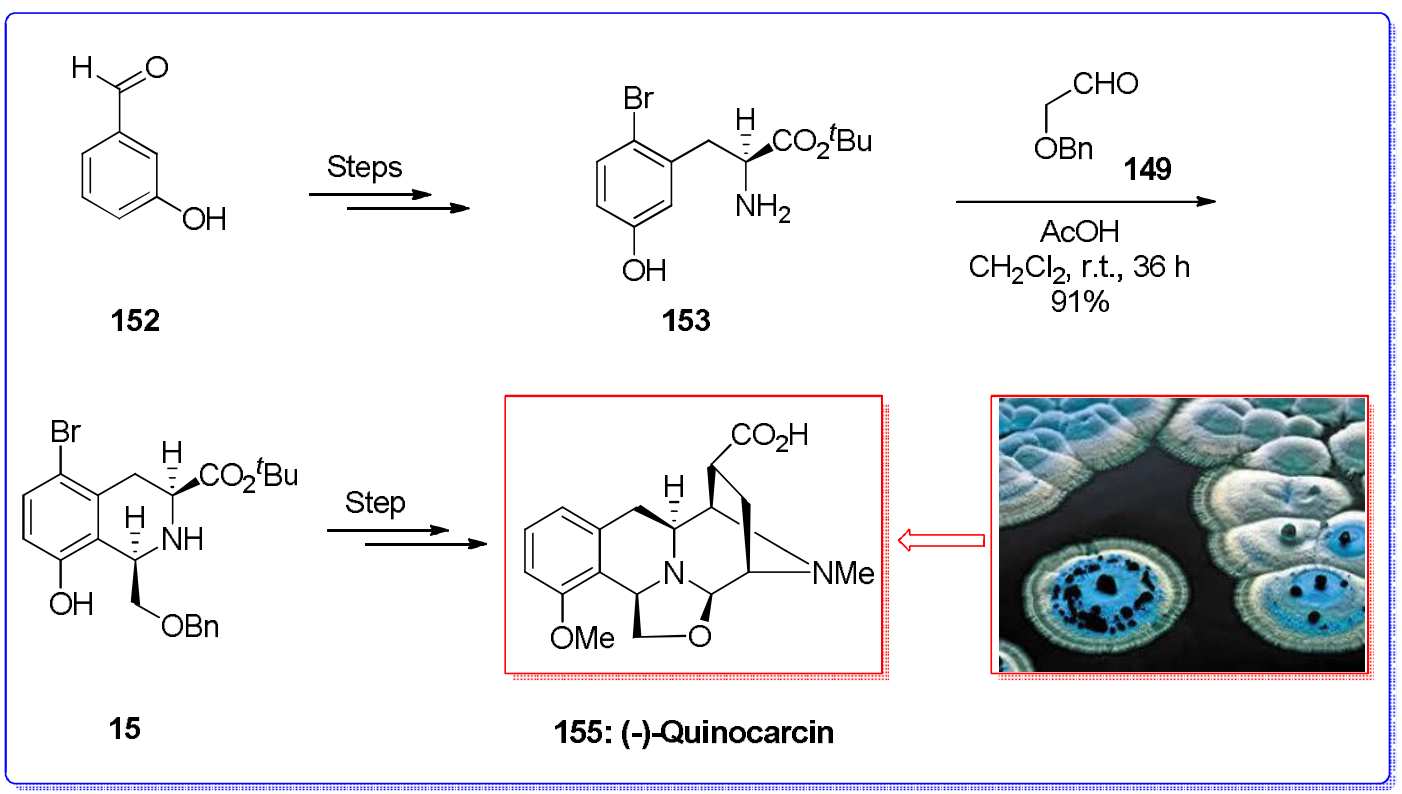

Scheme 29. Total synthesis of Quinocarcin 155.

Renieramycins, ecteinascidins and saframycins belong to marine bis tetrahydroisoquinoline alkaloids that are identified by their usual structural unit of five condensed six-membered rings including two tetrahydroisoquinoline scaffolds. These naturally occurring compounds show a series of significant biological activities for example antimicrobial and anti-tumor properties [240].

Renieramycins, involving jorunnamycins [241] and jorumycin [242], have become a large class in the marine bistetrahydroisoquinoline alkaloid group to date since they were first identified from the Mexican bluesponge Renierasp. by Frincke and Faulkner in 1982 [243]. Renieramycin-type alkaloids can be categorized into two sub-groups based on the C-21 functionalities. Some of these compounds contain carbinolamine or aminonitrile scaffolds at C-21 that are the required functional groups for linking to DNA and possibly other bio macromolecules in tumor cells [244]. Thus, a series of this subgroup of alkaloids for example $\mathbf{1 6 1}$ exhibited nanomolar inhibitory influences in a panel of human tumor celllines $[241,242,245,246]$. Although, these subgroup renieramycins, have an amide carbonyl residue at C-21 in place of carbinolamine and aminonitrile groups, they astonishingly retain their antitumor property $[227,243,247]$. For instance,(-)-renieramycin G 162, a member in the second subgroup extracted from the Fijian sponge Xestospongia caycedoi, demonstrated cytotoxicity against human cancer cells [247].

A flexible and useful method for the enantioselective synthesis of renieramycin-type antitumor alkaloids was demonstrated in 2014 by Chen and co-workers in that the stereoselective PSR of aldehyde 157 and aminoester 158 through regulating temperature and the automatic lactamization upon $\mathrm{N}$-deprotection of the cyclization product were exploited to quickly construct the usual pentacyclic moiety. (-)-Renieramycin $\mathrm{G}$ and (-)-jorunnamycin A were obtaine in 19 steps from L-tyrosine with $15.8 \%$ and $14.3 \%$ overall yield respectively. The asymmetric total synthesis of $(-)$-renieramycin $\mathrm{G}$ and (-)-Jorunnamycin A was initiated from L-tyrosine 156. After several steps, L-tyrosine 156 provided aldehyde 157 (the left partner) containing the A and B rings of the target. Instead, the trifunctionalized phenylalanine ester 158 (the right partner) was obtained from L-tyrosine with excellent overall yield [248]. With the two partners in hand, the step was set for creating the D ring through a PSR. Firstly, 157 and 158 were coupled. The reaction advanced rapidly based on this condition, and two cyclization isomers were obtained. The ratio of the less polar isomer 159 and the more polar isomer $\mathbf{1 6 0}$ was ca. 1:5. After several steps the natural products (-)-renieramycin G $\mathbf{1 6 2}$ and (-)-jorunnamycin A 161 were produced through various pathways. (-)-Jorunnamycin A 161 can be converted into other renieramycin alkaloids and their analogues [249-254] (Scheme 30) [255]. 


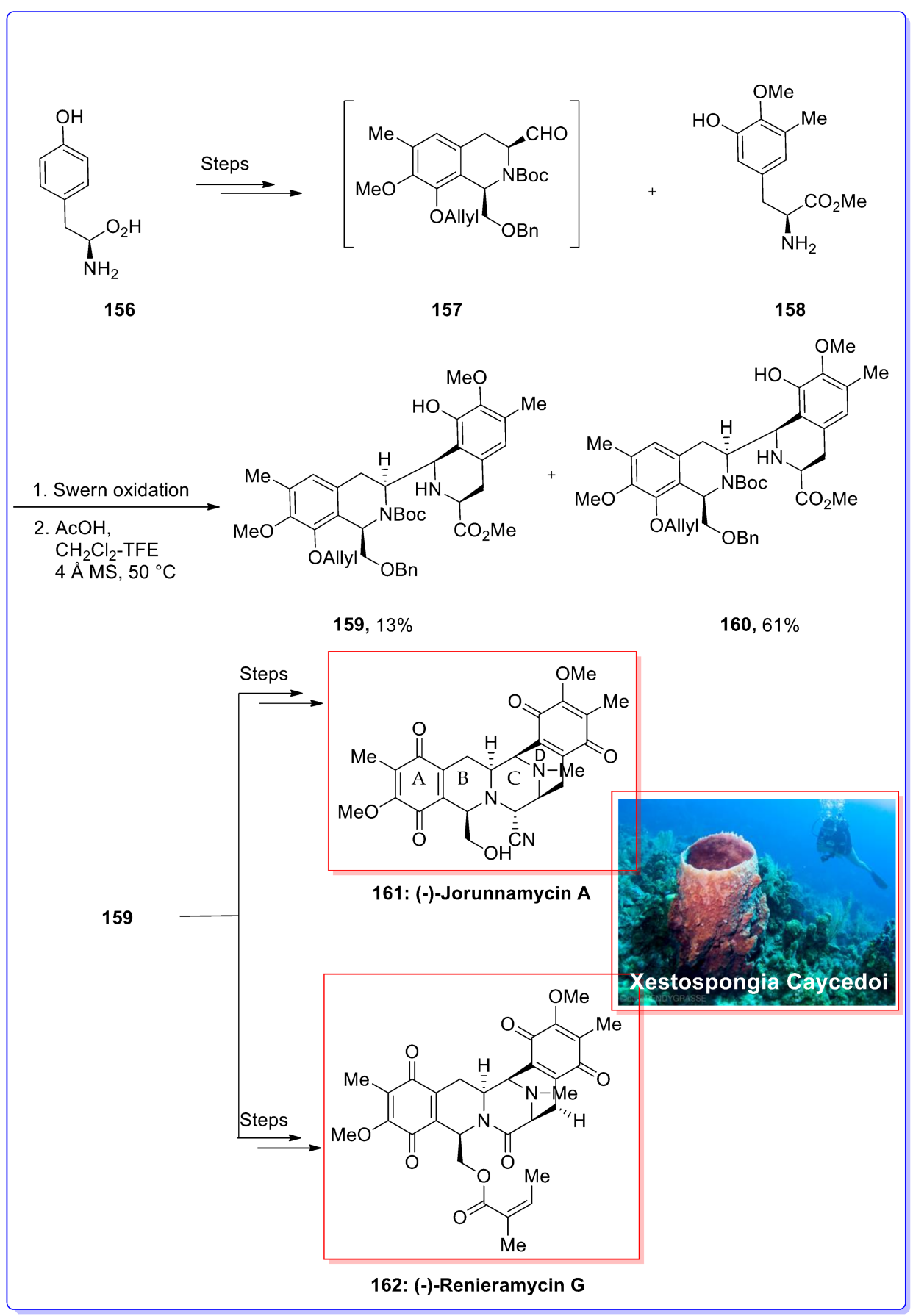

Scheme 30. Total synthesis of renieramycin G 162 and jorunnamycin A 160 through PSR as the key step.

The 1-benzyltetrahydroisoquinoline architecture provides the basis for an enormous number of pharmaceuticals showing various mode of actions [256]. Tetrahydroprotoberberines (THPBs) include an additional methylene group to make a dibenzoquinolizidine ring system. A wide range of biological properties has been described for these alkaloids. To mention a few instances, C-8-unfunctionalized $(-)-(S)$-stepholidine exhibits a stimulating profile on the dopamine D1 and D2 receptors and has potential anti-nociceptive and antipsychotic properties [257]. Isocorypalmine has been established as an anti-cocaine therapeutic [258]. Tetrahydroprotoberberines having a group at the 8-position are less abundant in nature but were also demonstrated to show fascinating biological properties [259]. The regioisomers (+)-javaberine A 171 and B 172 include a third catechol-type aromatic ring and 
display a strong inhibitory influence on the lipopolysaccharide-induced tumor necrosis parameter [260]. The spiro alkaloid (-)-latifolian A $\mathbf{1 8 3}$ has an extra C-N bond, providing the quaternary nitrogen atom [261]. Latifolian A isolated from Gnetum montanum was demonstrated to exhibit anti-bacterial property against methicillin-resistant Staphylococcus Aureus [262]. Enantiopure 8-benzylprotoberberine derivatives were produced via two consecutive Pictet-Spengler condensations with masked 3,4-dihydroxyphenylacetaldehydes. The initial PSR to $(+)-(R)$-nor protosinome nine was normalized to $90 \%$ ee with $5 \mathrm{~mol} \%$ of (R)-TRIP as chiral Brønsted acid ( $>99 \%$ ee). The second PSR did not need any catalyst, and its regioselectivity was powerfully dependent on the solvent: 99:1 para selectivity was provided in trifluoro-ethanol affording (+)-javaberine A; 81:19 ortho selectivity was achieved in polar aprotic solvents for the formation of $(+)$-javaberine B. Complete, natural diastereoselectivity was detected in the second PSR. Through selective catechol oxidation the spirocyclic alkaloid (-)-latifolian A was synthesized from masked (+)-javaberine A. Concise and extremely selective syntheses of the enantiopure target products have been performed. Starting from $N_{p s}$-masked amine 163 overall yields of $48 \%$ for (+)-javaberine A, 35\% for (+)-javaberine B and 41\% for (-)-latifolian A have been obtained; para selectivity in the second PSR was increased to almost 100:0 in protic solvents, but, more significantly, the ortho selectivity was directed to 80:20 by a polar solvents, which opens a pathway to various bioactive 9-alkoxytetrahy-droprotoberberines.

Hiemstra and co-workers in 2016 demonstrated this synthetic method with the Pictet-Spengler condensation of 163 with masked dopal (dihydroxyphenylacetaldehyde 164) [263]. An investigation to improve the reaction conditions and catalyst loading afforded the undesired observation in which lowering of the quantity of (R)-TRIP from 10 to $5 \mathrm{~mol} \%$ afforded a slight increase of the enantioselectivity to a reproducible $90 \%$. A probable clarification could be the fast construction of enamine 165 with concomitant release of $\mathrm{H}_{2} \mathrm{O}$. Water links to the TRIP/iminium ion pair and has a negative effect on the ee [263]. Lower catalyst loading exhibits slow down the reaction and permits $\mathrm{H}_{2} \mathrm{O}$ to link to the drying agent $\mathrm{Na}_{2} \mathrm{SO}_{4}$ before the asymmetric cyclization occurs. The role of $(S)$-BINOL as a co-catalyst remains uncertain, but is considerable $[263,264]$. Upon selective cleavage of the Nps group from 166, enantiopure $(R)-167$ was extracted in satisfactory yield as an extremely insoluble compound by simple trituration. Elimination of the TBS group from 167 easily occurred to provide $(+)-(R)$-norprotosinomenine 168, the precursor for the second Pictet-Spengler condensation. The free phenolic $\mathrm{OH}$ substituent in $\mathbf{1 6 8}$ was necessary for a smooth cyclization and made heating and strong acids unrequired. The aldehyde TBS-masked dopal 164 was again selected for its poor polarity and relative stability compared to dopal itself. From the first examinination, it became clear that the regioselectivity of this reaction was significantly identified by the solvent. Catalysts including $(R)$-or $(S)$-TRIP and thiourea catalysts slowed down this reaction and afforded incomplete reactions with a slight para preference. The effect of various solvents on the ortho/para regioselectivity of the Pictet-Spengler condensation of 164 and 168 was examined. The increasing H-bond donating character of the solvent matched the amount of para-functionalized product 170, finishing with trifluoroethanol and hexafluoro-2-propanol as equally effective Addition of HOAc to dichloromethane as solvent had a slight influence on the product distribution (ca.1:1) and also reduced the reaction rate [265]. On a preparative scale the para selectivity was increased to $99: 1$ and the yield to $85 \%$.

To improve the construction of ortho product 169 aprotic, polar solvents were needed, and the solubility of the substrates was the merely restriction for more improvement. Lastly, an ortho/para ratio of $81: 19$ with $88 \%$ total yield was performed. In the last stages the OMe and OTBS groups were removed with borontribromide, providing the $\mathrm{HBr}$ salts of javaberine A $\mathbf{1 7 1}$ in $48 \%$ overall yield from 163 and of javaberine B 172 in 35\% overall yield from 163. Careful NMR analysis on these $\mathrm{HBr}$ salts, showed the formation of the desired free bases and the hexa-acetates 173 and 174. The ${ }^{1} \mathrm{H}$ and ${ }^{13} \mathrm{C}-\mathrm{NMR}$ spectra of 171, 173, and $\mathbf{1 7 4}$ [260] and comparison of the sign of the optical rotations demonstrated the absolute configurations of the natural products as $(8 R, 14 S)$ (Scheme 31) [266]. 


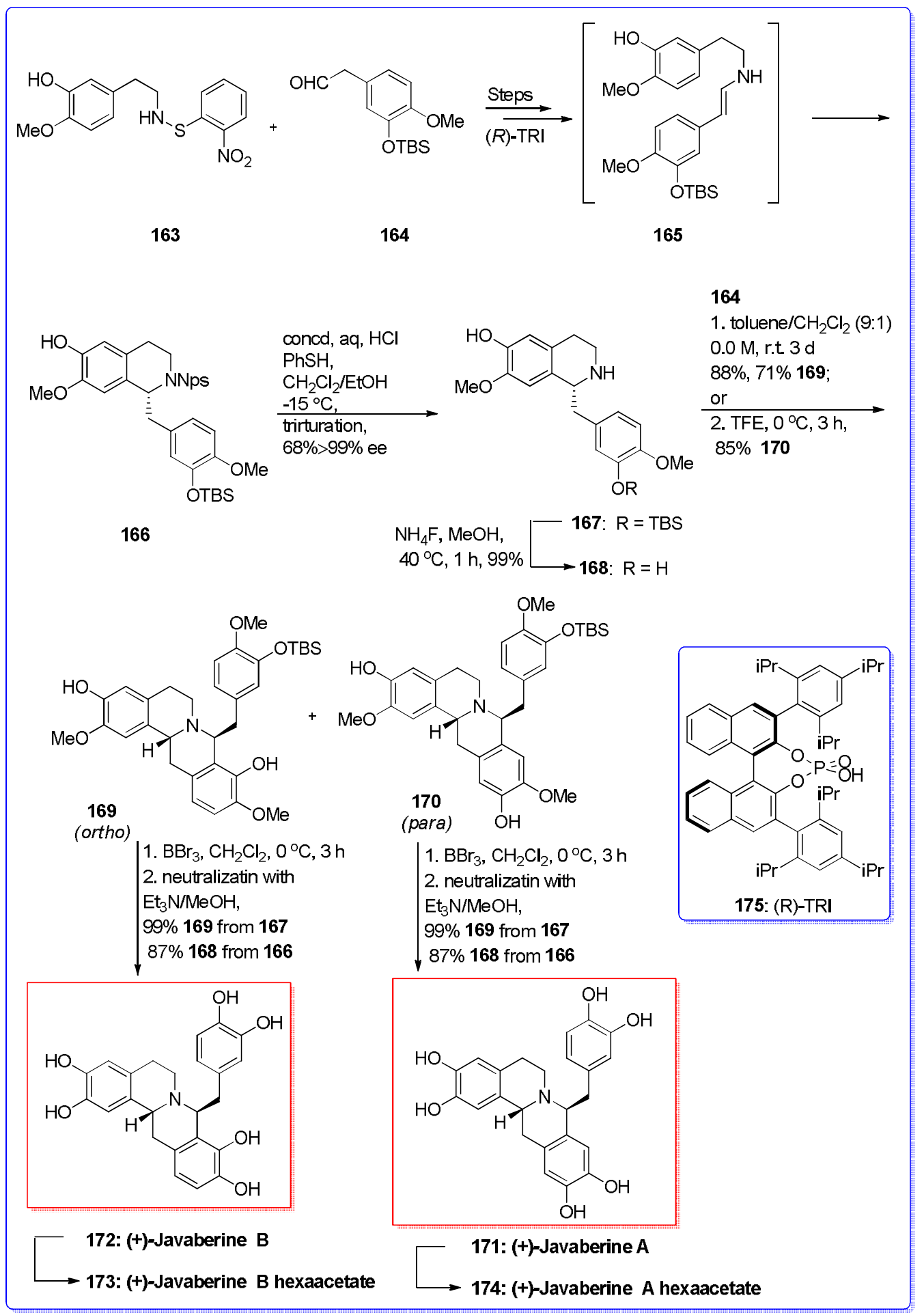

Scheme 31. Total synthesis of javaberine A 171, javaberine B 172, javaberine B hexa-acetate 173 and javaberine A hexa-acetate $\mathbf{1 7 4}$ using PSR as key step.

In polar, aprotic solvents a transition state is exhibited in which the phenolic $\mathrm{OH}$ substituent protonates the originally provided aminal $\mathbf{1 7 6}$ in an intramolecular method to form the iminium salt 177, as in all three natural product targets. Even trace quantities $(<1 \%)$ of the undesired cis isomers were not detected (Scheme 32) [263]. 


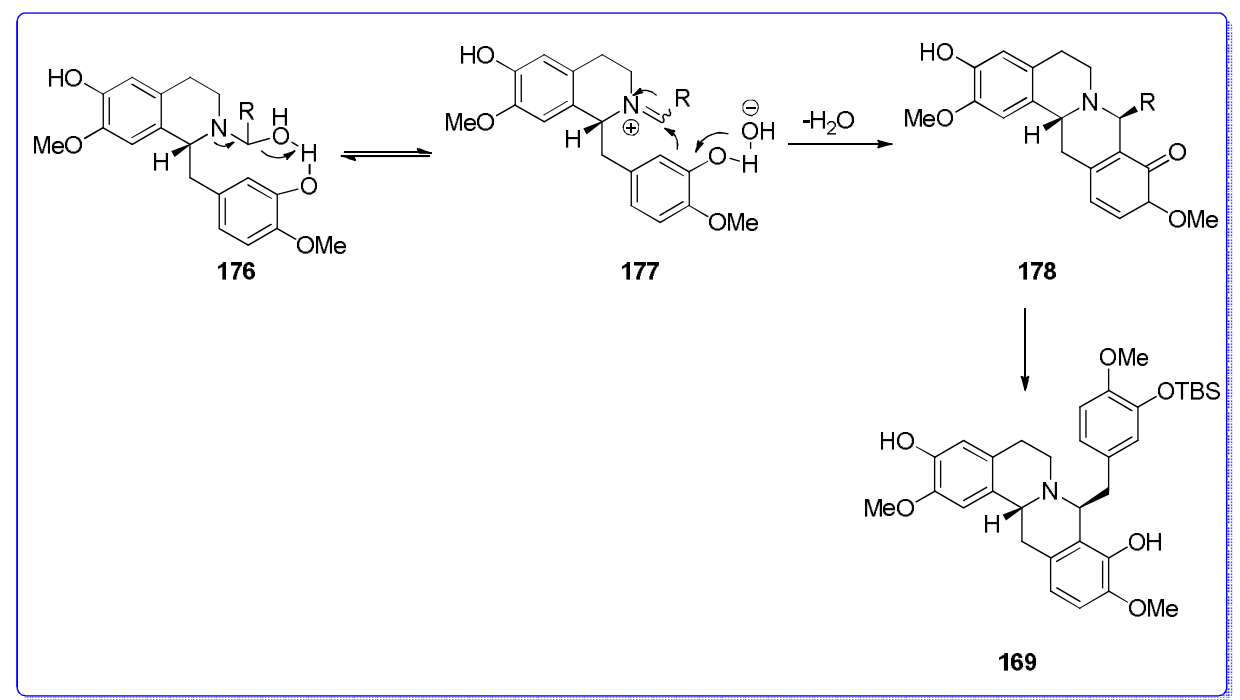

Scheme 32. ortho-Selective Pictet-Spengler condensation.

In addition, the formation of latifolian A 183 was initiated from $(R)$-norprotosinemonine 168 but needed a change of masking groups in the dihydroxyphenyl acetaldehyde PSR. Double-TBS-protected dopal 179 affords free catechol functionality upon desilylation, whereas the other two catechol groups stay masked as mono-methyl ethers. TFE as a regioselective Pictet-Spengler solvent again gave early entirely para-functionalized phenol 180 in excellent yield. Desilylation to $\mathbf{1 8 0}$ and oxidation with bis[(tri-fluoroacetoxy)iodo]benzene (PIFA) afforded the spirocyclic quaternary ammonium salt 182 as its bis-methyl ether, that was deprotected with $\mathrm{HBr}$ in HOAc to enantiopure latifolian A 183 (Scheme 33) [263].

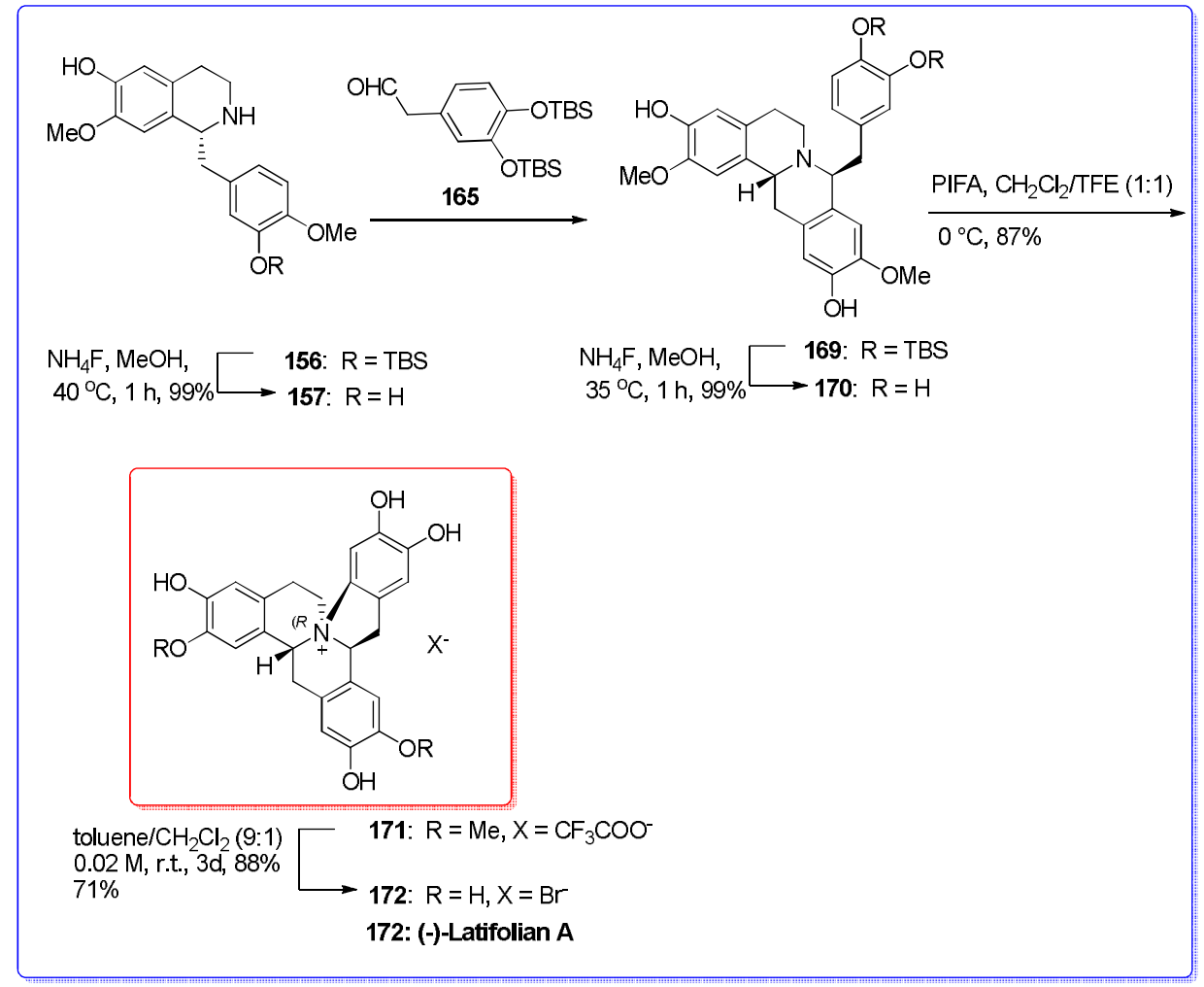

Scheme 33. The synthesis of latifolian A 183. 


\section{Conclusions}

In summary, PSR was discovered by Ame Pictet and Theodor Spengler, an important method for the synthesis of natural biologically active compounds. In this review, we aimed to underscore the significance and importance of PSR as an old reaction under a new perspective, its application in the important and new field of total synthesis of naturally occurring compounds. Nowadays, the PSR plays an important and key role in the total synthesis of natural products with diverse biological activities. Research results relating to the aforementioned points are growing fast in the literature and chemistry libraries. They reveal that the PSR is one of the most significant basic reaction categories in the total synthesis of the most important class of natural products known as alkaloids in nature. The important compounds from the biological point of view such as, ajmaline, vellosimine, talpinine, tryptophan, jamtine, talcarpine, alstonerine, jorumycin, renieramycin $G$, etc. have been synthesized via PSR as a determining step in their multistep total synthesis.

Acknowledgments: The authors are thankful to Alzahra University research Council for partial financial assistance. MMH also appreciates financial support from Iran National Science Foundation (INSF), granted via an individual granted research chair.

Author Contributions: This work has been designed and completed in continuation of Majid M. Heravi in the fiield of applications of name reactions in the total synthesis of natural products. Vahideh Zadsirjan as post-doc fellow has played a key role in the prepration of this review and assigined as co-corresponding author. Masumeh Malmir as a PhD student of Majid M. Heravi has been under supervision and being trained as well as has been helping all through the preparation of the manuscript. Also, this work has been supported by five year granted research chair by INSF as well as Alzahra Universoty Research Council.

Conflicts of Interest: The authors declare no conflict of interest.

\section{References}

1. Seigler, D.S. Plant Secondary Metabolism; Springer: New York, NY, USA, 2001; p. 628.

2. Rao, R.N.; Maiti, B.; Chanda, K. Application of Pictet-Spengler reaction to indole based alkaloids containing tetrahydro- $\beta$-carboline scaffold in combinatorial chemistry. ACS Comb. Sci. 2017, 19, 199-228. [CrossRef] [PubMed]

3. Manske, R.H.F. The Alkaloids, Chemistry and Physiology; Academic Press: New York, NY, USA, 1981; Volume 19, p. 227.

4. Pictet, A.; Spengler, T. Pictet-Spengler reaction. Ber. Dtsch. Chem. Ges. 1911, 44, 2030-2036. [CrossRef]

5. Pictet, A.; Court, G. Uber einige neue pflanzenalkaloide. Ber. Dtsch. Chem. Ges. 1907, 40, 3771-3783. [CrossRef]

6. Pictet, A. Uber die bildungsweise der alkaloide in der pflanze. Arch. Pharma. 1906, 244, 389-396. [CrossRef]

7. Hahn, G.; Ludewig, H. Synthese von Tetrahydro-harman-Derivaten unter physiologischen Bedingungen. Chem. Ber. 1934, 67, 2031-2035. [CrossRef]

8. Tatsui, G.J. Preparation of 1-methyl-1,2,3,4-tetrahydro- $\beta$-carboline. J. Pharm. Soc. Jpn. 1928, 48, 92.

9. Smith, G.N. Strictosidine: A key intermediate in the Biogenesis of indole alkaloids. Chem. Commun. 1968, 912-914. [CrossRef]

10. Battersby, A.R.; Burnett, A.R.; Parsons, P.G. Preparation of secologanin: Its conversion into ipecoside and its role in indole alkaloid biosynthesis. Chem. Commun. 1968, 1280-1281. [CrossRef]

11. Klausen, R.S.; Jacobsen, E.N. Weak Brønsted acid-thiourea co-catalysis: Enantioselective, Catalytic Protio-Pictet-Spengler reactions. Org. Lett. 2009, 11, 887-890. [CrossRef] [PubMed]

12. Bailey, P.D.; Hollinshead, S.P.; McLay, N.R. Exceptional stereochemical control in the Pictet-Spengler reaction. Tetrahedron Lett. 1987, 28, 5177-5180. [CrossRef]

13. Lee, M.; Domínguez-Gil, T.; Hesek, D.; Mahasenan, K.V.; Lastochkin, E.; Hermoso, J.A.; Mobashery, S. Turnover of Bacterial Cell wall by SltB3, a Multidomain Lytic Transglycosylase of Pseudomonas aeruginosa. ACS Chem. Biol. 2016, 11, 1525-1531. [CrossRef] [PubMed]

14. Tsuji, R.; Nakagawa, M.; Nishida, A. An efficient synthetic approach to optically active $\beta$-carboline derivatives via Pictet-Spengler reaction promoted by trimethylchlorosilane. Tetrahedron Asymmetry 2003, 14, 177-180. [CrossRef] 
15. Kawate, T.; Yamanaka, M.; Nakagawa, M. Chiral auxiliary approach to the asymmetric Pictet-Spengler reaction of Tryptamines. Heterocycles 1999, 2, 1033-1039.

16. Herlé, B.; Wanner, M.J.; van Maarseveen, J.H.; Hiemstra, H. Total synthesis of (+)-Yohimbine via an enantioselective organocatalytic Pictet-Spengler reaction. J. Org. Chem. 2011, 76, 8907-8912. [CrossRef] [PubMed]

17. Sewgobind, N.V.; Wanner, M.J.; Ingemann, S.; de Gelder, R.; vanMaarseveen, J.H.; Hiemstra, H. Enantioselective Binol-Phosphoric acid catalyzed Pictet-Spengler reactions of n-Benzyltryptamine. J. Org. Chem. 2008, 73, 6405-6408. [CrossRef] [PubMed]

18. Seayad, J.; Seayad, A.M.; List, B. Catalytic Asymmetric Pictet-Spengler reaction. J. Am. Chem. Soc. 2006, 128, 1086-1087. [CrossRef] [PubMed]

19. Dalpozzo, R. The Chiral pool in the Pictet-Spengler reaction for the synthesis of $\beta$-Carbolines. Molecules 2016, 21, 699. [CrossRef] [PubMed]

20. Nic, M.; Jirat, J.; Kosata, B.; Jenkins, A. IUPAC Compendium of Chemical Terminology, 2nd ed.; Blackwell Scientific Publications: Oxford, UK, 1997.

21. Manske, R.H.F. The Alkaloids: Chemistry and physiology; Academic Press: New York, NY, USA, 1965; Volume VIII, p. 673.

22. Kittakoop, P.; Mahidol, C.; Ruchirawat, S. Alkaloids as Important scaffolds in therapeutic Drugs for the Treatments of Cancer, Tuberculosis, and Smoking Cessation. Curr. Top. Med. Chem. 2014, 14, $239-252$. [CrossRef] [PubMed]

23. Russo, P.; Frustaci, A.; Del Bufalo, A.; Fini, M.; Cesario, A. Multitarget Drugs of Plants Origin Acting on Alzheimer's Disease. Curr. Med. Chem. 2013, 20, 1686-1993. [CrossRef] [PubMed]

24. Sinatra, R.S.; Jahr, J.S.; Watkins-Pitchford, M. The Essence of Analgesia and Analgesics; Sinatra, R.S., Jahr, J.S., Watkins-Pitchford, M., Eds.; Cambridge University Press: Cambridge, UK, 2010; p. 82.

25. Cushnie, T.P.; Cushnie, B.; Lamb, A.J. Alkaloids: An overview of their Antibacterial, Antibiotic-enhancing and Antivirulence Activities. Int. J. Antimicrob. Agents 2014, 44, 377-386. [CrossRef] [PubMed]

26. Qiu, S.; Sun, H.; Zhang, A.H.; Xu, H.Y.; Yan, G.L.; Han, Y.; Wang, X.J. Natural Alkaloids: Basic Aspects, Biological roles, and future Perspectives. Chin. J. Nat. Med. 2014, 12, 401-406. [CrossRef]

27. Robbers, J.E.; Speedie, M.K.; Tyler, V.E. Chapter 9: Alkaloids. In Pharmacognosy and Pharmacobiotechnology; Lippincott. Williams \& Wilkins: Philadelphia, NY, USA, 1996; pp. 143-185.

28. Rhoades, D.F. Evolution of plant chemical defense against Herbivores. In Their Interaction with Secondary Plant Metabolites; Academic Press: New York, NY, USA, 1979; p. 41.

29. Ho, B.T.; McIsaac, W.M.; Walker, K.A.; Estevez, V. Inhibitors of Monoamine Oxidase. Influence of Methyl substitution on the inhibitory activity of 8-Carbolines. J. Pharm. Sci. 1968, 57, 269-273. [CrossRef] [PubMed]

30. Sharma, R.K. Consice Textbook of Forensic Medicine E Toxicology; Elsevier: New Delhi, India, 2008.

31. Roquebert, J.; Demichel, P. Inhibition of the alpha 1 and alpha 2-adrenoceptor-mediated pressor response in Pithed Rats by Raubasine, Tetrahydroalstonine and Akuammigine. Eur. J. Pharm. 1984, 106, 203-205. [CrossRef]

32. Müller, J.M.; Schlittler, E.; Bein, H.J. Reserpin, the sedative principle from Rauwolfia serpentina B. Experientia 1952, 8, 338-343. [CrossRef] [PubMed]

33. Neuss, N.; Gorman, M.; Hargrove, W.; Cone, N.J.; Biemann, K.; Buchi, G.; Manning, R.E. The structures of the Oncolytic alkaloids Vinblastine (VLB) and Vincristine (VCR). J. Am. Chem. Soc. 1964, 86, 1440-1442. [CrossRef]

34. Van der Heijden, R.; Jacobs, D.; Snoeijer, W.; Hallard, D.; Verpoorte, R. The Catharanthus alkaloids: Pharmacognosy and biotechnology. Curr. Med. Chem. 2004, 11, 607-628. [CrossRef] [PubMed]

35. Southin, T.W.; Buckingham, J. Dictionary of Alkaloids; Chapman\&Hall: London, UK, 1979; p. 3.

36. Nicolaou, K.C.; Montagnon, T.; Snyder, S.A. Tandem reactions, Cascade sequences, and Biomimetic strategies in total synthesis. Chem. Commun. 2003, 5, 551-564. [CrossRef]

37. Nicolaou, K.C.; Edmonds, D.J.; Bulger, P.C. Cascade reactions in total synthesis. Angew. Chem. Int. Ed. 2006, 45, 7134-7186. [CrossRef] [PubMed]

38. De Figueiredo, R.M.; Christmann, M. Organocatalytic synthesis of drugs and bioactive natural products. Eur. J. Org. Chem. 2007, 38, 2575-2600. [CrossRef]

39. Tietze, L.F.; Beifuss, U. Sequential transformations in organic chemistry: A synthetic strategy with a future. Angew. Chem. Int. Ed. 1993, 32, 131-163. [CrossRef] 
40. Grondal, C.; Jeanty, M.; Enders, D. Organocatalytic Cascade reactions as a new tool in total synthesis. Nature Chem. 2010, 2, 167-168. [CrossRef] [PubMed]

41. Poisson, T. Macmillan's imidazolidinones: Powerful chiral organocatalysts. Synlett 2008, 1, 147-148. [CrossRef]

42. Souza, D.M.D.; Mueller, T.J.J. Multi-component syntheses of heterocycles by transition-metal catalysis. Chem. Soc. Rev. 2007, 36, 1095-1100. [CrossRef] [PubMed]

43. Yang, L.; Hill, M.; Wang, M.; Panjikar, S.; Stockigt, J. Structural basis and enzymatic mechanism of the biosynthesis of C9- from C10-monoterpenoid indole alkaloids. Angew. Chem. Int. Ed. 2009, 48, 5211-5213. [CrossRef] [PubMed]

44. Cordell, G.A. The Alkaloids: Chemistry and Biology; Academic Press: San Diego, CA, USA, 1998; Volume 51, p. 199.

45. Heravi, M.M.; Khaghaninejad, S.; Nazari, N. Chapter five-Bischler-Napieralski reaction in the syntheses of Isoquinolines. Adv. Heterocycl. Chem. 2015, 112, 183-226.

46. Sadjadi, S.; Heravi, M.M.; Nazari, N. Isocyanide-based multicomponent reactions in the synthesis of heterocycles. RSC Adv. 2016, 6, 53203-53272. [CrossRef]

47. Heravi, M.M.; Hashemi, E.; Nazari, N. Negishi coupling: An easy progress for C-C bond construction in total synthesis. Mol. Divers. 2014, 18, 441-472. [CrossRef] [PubMed]

48. Heravi, M.M.; Hashemi, E.; Azimian, F. Recent developments of the Stille reaction as a revolutionized method in total synthesis. Tetrahedron 2014, 70, 7-21. [CrossRef]

49. Heravi, M.M.; Hashemi, E.; Ghobadi, N. Development of recent total syntheses based on the Heck reaction. Curr. Org. Chem. 2013, 17, 2192-2224. [CrossRef]

50. Heravi, M.M.; Hashemi, E. Recent applications of the Suzuki reaction in total synthesis. Tetrahedron 2012, 68, 9145-9178. [CrossRef]

51. Heravi, M.M.; Zadsirjan, V. Oxazolidinones as chiral auxiliaries in asymmetric Aldol reactions applied to total synthesis. Tetrahedron Asymmetry 2013, 24, 1149-1188. [CrossRef]

52. Heravi, M.M.; Vavsari, V.F. Recent applications of Intramolecular Diels-Alder reaction in total synthesis of natural products. RSC Adv. 2015, 5, 50890-50912. [CrossRef]

53. Heravi, M.M.; Hamidi, H.; Zadsirjan, V. Recent applications of Click reaction in the syntheses of 1,2,3-Triazoles. Curr. Org. Chem. 2014, 11, 647-675. [CrossRef]

54. Heravi, M.M.; Lashaki, T.B.; Fattahi, B.; Zadsirjan, V. Application of asymmetric Sharpless Aminohydroxylation in total synthesis of natural products and some synthetic complex bio-active molecules. RSC Adv. 2018, 8, 6634-6659. [CrossRef]

55. Koshvandi, A.T.K.; Heravi, M.M. Current applications of Suzuki-Miyaura coupling reaction in the total synthesis of natural products: An update: Applications of Suzuki-Miyaura coupling reaction in natural products. Appl. Organomet. Chem. 2018. [CrossRef]

56. Heravi, M.M.; Rohani, S.; Zadsirjan, V.; Zahedi, N. Fischer Indole synthesis applied to the total synthesis of natural products. RSC Adv. 2017, 7, 52852-52887. [CrossRef]

57. Koshvandi, A.T.K.; Heravi, M.M. Applications of Danishefsky's Dienes in asymmetric Oxo-Diels-Alder reactions. Tetrahedron Asymmetry 2017, 28, 1506-1556. [CrossRef]

58. Talaei, B.; Heravi, M.M.; Oskooie, H.A.; Rezvanian, A. An approach to the diastereoselective synthesis of cyclohexane-1,3-dicarboxamide derivatives via a Pseudo five-componentreaction based on diketene. Synlett 2018, 29, 225-229.

59. Heravi, M.M.; Moradi, R.; Malmir, M. Recent advances in the application of the Heck reaction in the synthesis of heterocyclic compounds: An update. Curr. Org. Chem. 2017, 22, 165-198. [CrossRef]

60. Seigler, D.S. Plant Secondary Metabolism. New Phytol. 2000, 147, 483-485.

61. Knunyants, I.L. Chemical Encyclopedia; Wiley: New York, NY, USA, 1988; Volume 1, pp. 1-623.

62. Siddiqui, S.; Siddiqui, R.H. Chemical examination of the roots of Rauwolfia serpentina Benth. J. Indian Chem. Soc. 1931, 8, 667-680.

63. Koskinen, A.; Lounasmaa, M. The Sarpagine-Ajmaline group of indole alkaloids. In Fortschritte der Chemie Organischer Naturstoffe/Progress in the Chemistry of Organic Natural Products; Herz, W., Grisebach, H., Kirby, G.W., Eds.; Springer-Verlag: New York, NY, USA, 1983; Volume 43, p. 275.

64. Brugada, J.; Brugada, P. What to do in patients with no structural heart Disease and sudden arrhythmic Death? Am. J. Cardiol. 1996, 78, 69-75. [CrossRef] 
65. Slowinski, S.; Rajch, D.; Zabowka, M. Myocardial infarction in a man with. Wolff-Parkinson-White syndrome. Przegl. Lek. 1996, 53, 196-198. [PubMed]

66. Mest, H.J.; Winkler, J.; Foerster, W. The antiarrhythmic effect of Prostaglandin E2 on Catecholamine-induced Arrhythmias. Acta Biol. Med. Ger. 1977, 36, 1193-1196. [PubMed]

67. Bi, Y.; Hamaker, L.K.; Cook, J.M. The synthesis of Macroline related alkaloids. In Studies in Natural Products Chemistry, Bioactive Natural Products; Part A; Rahman, A., Basha, F.Z., Eds.; Elsevier Science: Amsterdam, The Netherlands, 1993; Volume 13, p. 383.

68. Endreb, S.; Takayama, H.; Suda, S.; Kitajima, M.; Aimi, N.; Sakai, S.-I.; Sto ckigt, J. Alkaloids from Rauwolfia serpentina cell cultures treated with Ajmaline. Phytochemistry 1993, 32, 725-730. [CrossRef]

69. Li, J.; Wang, T.; Yu, P.; Peterson, A.; Weber, R.; Soerens, D.; Grubisha, D.; Bennett, D.; Cook, J.M. General approach for the synthesis of Ajmaline/Sarpagine Indole alkaloids: Enantiospecific total synthesis of (+)-Ajmaline, Alkaloid G, and Norsuaveoline via the asymmetric Pictet-Spengler reaction. J. Am. Chem. Soc. 1999, 121, 6998-7010. [CrossRef]

70. Hamaker, L.K.; Cook, J.M. The synthesis of Macroline related alkaloids. In Alkaloids: Chemical and Biological Perspectives; Pelletier, S.W., Ed.; Elsevier Science: New York, NY, USA, 1995; Volume 9, p. 23.

71. Wong, W.-H.; Lim, P.-B.; Chuah, C.-H. Oxindole alkaloids from alstonia macrophylla. Phytochemistry 1996, 41, 313-315. [CrossRef]

72. Cook, J.M.; LeQuesne, P.W. Macralstonine from alstonia muelleriana. Phytochemistry 1971, 10, $437-439$. [CrossRef]

73. Chatterjee, A.; Parks, L.M. The Structure of Verbenalin. J. Am. Chem. Soc. 1949, 71, 2249-2250. [CrossRef]

74. Wright, C.W.; Allen, D.; Cai, Y.; Phillipson, J.D.; Said, I.M.; Kirby, G.C.; Warhurst, D.C. In vitro antiamoebic and antiplasmodial activities of alkaloids isolated from Alstonia Angustifolia Roots. Phytother. Res. 1992, 6 , 121-124. [CrossRef]

75. Leclercq, J.; de Pauw-Gillet, M.-C.; Bassleer, R.; Angenot, L. Screening of Cytotoxic activities of Strychnos alkaloids (methods and results). J. Ethnopharmacol. 1986, 15, 305-316. [CrossRef]

76. Tan, G.T.; Pezzuto, J.M.; Kinghorn, A.D.; Hughes, L.S.H. Evaluation of natural products as inhibitors of human immunodeficiency virus type 1 (HIV-1) reverse transcriptase. J. Nat. Prod. 1991, 54, 143-154. [CrossRef] [PubMed]

77. Tan, G.T.; Miller, J.F.; Kinghorn, A.D.; Hughes, S.H.; Pezzuto, J.M. HIV-1 and HIV-2 reverse transcriptases: A comparative study of sensitivity to inhibition by selected natural products. Biochem. Biophys. Res. Commun. 1992, 185, 370-378. [CrossRef]

78. Nordman, C.E.; Kumra, S.K. The structure of Villalstonine. J. Am. Chem. Soc. 1965, 87, 2059-2060. [CrossRef]

79. Waldner, E.E.; Hesse, M.; Taylor, W.I.; Schmid, H. Über die. Konstitution des Macralstonidins.124. Mitteilung über Alkaloide. Helv. Chim. Acta 1967, 50, 1926-1939. [CrossRef] [PubMed]

80. Talapatra, S.K.; Adityachaudhury, N. Macralstonine, an alkaloid of the trunk bark of Alstonia macrophylla. Wall. Sci. Culture 1958, 24, 243-270.

81. Soerens, D.; Sandrin, J.; Ungemach, F.; Mokry, P.; Wu, G.S.; Yamanaka, E.; Hutchins, L.; DiPierro, M.; Cook, J.M. Study of the Pictet-Spengler reaction in aprotic media: Synthesis of the $\beta$-Galactosidase inhibitor, Pyridindolol. J. Org. Chem. 1979, 44, 535-545. [CrossRef]

82. Shimizu, M.; Ishikawa, M.; Komoda, Y.; Nakajima, T.; Yamaguchi, K.; Sakai, S. Asymmetric synthesis and absolute configuration of (-)-Trypargine. Chem. Pharm. Bull. 1984, 32, 1313-1325. [CrossRef]

83. Yu, P.; Wang, T.; Li, J.; Cook, J.M. Enantiospecific total synthesis of the Sarpagine related indole alkaloids Talpinine and Talcarpine as well as the improved total synthesis of Alstonerine and Anhydromacrosalhine-methine via the asymmetric Pictet-Spengler reaction. J. Org. Chem. 2000, 65, 3173-3191. [CrossRef] [PubMed]

84. Rapoport, H.; Onak, T.P.; Hughes, N.A.; Reinecke, M.G. Alkaloids of Geissospermum vellosii. J. Am. Chem. Soc. 1958, 80, 1601-1604. [CrossRef]

85. Rapoport, H.; Moore, E. Alkaloids of Geissospermum vellosii. Isolation and structure determinations of Vellosimine, Vellosiminol, and Geissolosimine. J. Org. Chem. 1962, 27, 2981-2985. [CrossRef]

86. Bertho, A.; von Schuckmann, G.; Schönberger, W. Kurchi-Alkaloide, I. Mitteil.: Über einige neue Basen aus Holarrhena anti-dysenterica. Ber. Dtsch. Chem. Ges. 1933, 66, 786-790. [CrossRef] 
87. Ferreira, F.S.; Brito, S.V.; Ribeiro, S.C.; Saraiva, A.A.; Almeida, W.O.; Alves, R.R. Animal-based folk remedies sold in public markets in Crato and Juazeiro do Norte, Ceará, Brazil. BMC Complement. Altern. Med. 2009, 9, 1-17. [CrossRef] [PubMed]

88. Arthur, H.R.; Johns, S.R.; Lamberton, J.A.; Loo, S.N. Identification of Vellosimine and Peraksine, and demonstration from N.M.R. Data that Peraksine is a mixture of two epimers. Aust. J. Chem. 1968, 21, 1399-1401. [CrossRef]

89. Deng, R.X.; Yu, L.B.; Zhang, H.B.; Geng, R.L.; Ye, K.L.; Zhang, D.F. Studied on antimalarial agents- $\alpha$-(alkylaminomethyl)-halogenated-4-fluorinemetha-nol. Acta Pharm. Sin. 1981, 16, 920-924.

90. Chatterjee, A.; Bandyopadhyay, S. Vellosimine, an alkaloid of Rauwolfia vomitoria. Indian J. Chem. 1979, 18B, 87-88.

91. Sierra, P.; Novotny, L.; Samek, Z.; Budesinsky, M.; Dolejs, L.; Blaha, K. Alkaloids of Rauvolfia salicifolia Griseb species. Collect. Czech. Chem. Commun. 1982, 47, 2912-2921. [CrossRef]

92. Lin, M.; Yang, B.Q.; Yu, D.Q. Studies on the quaternary alkaloids of Rauvolfia verticillata. Acta Pharm. Sin. 1986, 21, 114-118.

93. Ponglux, D.; Wongseripipatana, S.; Subhadhirasakul, S.; Takayama, H.; Yokota, M.; Ogata, K.; Phisalaphong, C.; Aimi, N.; Sakai, S. Studies on the indole alkaloids of Gelsem1um elegans (thailand): Structure elucidation and proposal of biogenetic route. Tetrahedron 1988, 44, 5075-5094. [CrossRef]

94. Wang, T.; Cook, J.M. General approach for the synthesis of Sarpagine/Ajmaline indole alkaloids. Stereospecific total synthesis of the Sarpagine alkaloid (+)-vellosimine. Org. Lett. 2000, 2, 2057-2059. [CrossRef] [PubMed]

95. Yu, P.; Wang, T.; Yu, F.; Cook, J.M. General approach for the synthesis of Macroline/Sarpagine related indole alkaloids via the asymmetric Pictet-Spengler reaction: The enantiospecific synthesis of the $\mathrm{Na}-\mathrm{H}$, azabicyclo[3.3.1]nonone template. Tetrahedron Lett. 1997, 38, 6819-6822. [CrossRef]

96. Kondo, Y.; Kojima, S.; Sakamoto, T. General and facile synthesis of indoles with Oxygen-bearing substituents at the benzene moiety. J. Org. Chem. 1997, 62, 6507-6511. [CrossRef]

97. Ma, C.; Liu, X.; Li, X.; Flippen-Anderson, J.; Yu, S.; Cook, J.M. Efficient asymmetric synthesis of biologically important Tryptophan analogues via a Palladium-mediated Heteroannulation reaction. J. Org. Chem. 2001, 66, 4525-4542. [CrossRef] [PubMed]

98. Zhou, H.; Liao, X.; Cook, J.M. Regiospecific, enantiospecific total synthesis of the 12-alkoxy-substituted indole alkaloids, (+)-12-methoxy-Na-methylvellosimine, (+)-12-Methoxyaffinisine, and (-)-Fuchsiaefoline. Org. Lett. 2004, 6, 249-252. [CrossRef] [PubMed]

99. Cox, E.D.; Hamker, L.K.; Li, J.; Yu, P.; Czerwinski, K.M.; Deng, L.; Bennett, D.W.; Cook, J.M.; Watson, W.H.; Krawiec, M. Enantiospecific formation of trans 1,3-disubstituted tetrahydro- $\beta$-carbolines by the Pictet-Spengler reaction and conversion of cis diastereomers into their trans counterparts by scission of the C-1/N-2 bond. J. Org. Chem. 1997, 62, 44-61. [CrossRef] [PubMed]

100. Zhang, L.H.; Trudell, M.L.; Hollinshead, S.P.; Cook, J.M. [3,3]-Sigmatropic rearrangements in indoloazabicyclo[3.3.1]nonene systems. Reversal of the stereofacial selectivity in the Claisen vs. The ortho Ester Claisen rearrangement. J. Am. Chem. Soc. 1989, 111, 8263-8265. [CrossRef]

101. Elderfield, R.C.; Gilman, R.E. Characterization of the Lipids of some Orchids. Phytochemistry 1972, 11, 339-343. [CrossRef]

102. Keawpradub, N.; Houghton, P.J.; Eno-Amooquaye, E.; Burke, P. Activity of extracts and alkaloids of Thai Alstonia species against human lung cancer cell lines. J. Planta Med. 1997, 63, 97-101. [CrossRef]

103. Keawpradub, N.; Kirby, G.C.; Steele, J.C.P.; Houghton, P. Antiplasmodial activity of extracts and alkaloids of three Alstonia species from Thailand. J. Planta Med. 1999, 65, 690-694. [CrossRef] [PubMed]

104. Burke, D.E.; Cook, J.M.; Le Quesne, P.W. Biomimetic synthesis of the bisindole alkaloids Villalstonine and Alstonisidine. J. Am. Chem. Soc. 1973, 95, 546-552. [CrossRef]

105. Esmond, R.W.; Le Quesne, P.W. Biomimetic synthesis of Macroline. J. Am. Chem. Soc. 1980, 102, 7116-7117. [CrossRef]

106. Burke, D.E.; Cook, G.A.; Cook, J.M.; Haller, K.G.; Lazar, H.A.; Le Quesne, P.W. Further alkaloids of Alstonia muelleriana. Phytochemistry 1973, 12, 1467-1474. [CrossRef]

107. Garnick, R.L.; Le Quesne, P.W. Biomimetic transformations among monomeric Macroline-related indole alkaloids. J. Am. Chem. Soc. 1978, 100, 4213-4219. [CrossRef]

108. Hesse, M.; Bodmer, F.; Gemenden, C.W.; Joshi, B.S.; Taylor, W.I.; Schmid, H. Die struktur des Alstonia-alkaloides Villalstonin. Helv. Chim. Acta. 1966, 49, 1173-1179. [CrossRef] 
109. Zhao, S.; Liao, X.; Cook, J.M. Enantiospecific, stereospecific total synthesis of (+)-Majvinine, (+)-10-methoxyaffinisine, and (+)-Na-methylsarpagine as well as the total synthesis of the Alstonia bisindole macralstonidine. Org. Lett. 2002, 4, 687-690. [CrossRef] [PubMed]

110. Liao, X.; Zhao, S.; Cook, J.M. The enantiospecific total synthesis of the Alstonia bisindole alkaloid, Macralstonidine. Presented at the National Organic Symposium, Bozeman, MT, USA, 10-15 June 2001; p. 239.

111. Heath-Brown, B.; Philpott, P.G. The Fischer indole synthesis. J. Chem. Soc. 1965, 7185-7193. [CrossRef]

112. Abramovitch, R.A.; Shapiro, D.S. 880. Tryptamines, carbolines, and related compounds. Part II. A convenient synthesis of tryptamines and $\beta$-carbolines. J. Chem. Soc. 1956, 4589-4592. [CrossRef]

113. Angenot, L. Nouveaux alcaloïdes oxindoliques du Strychnos usambarensis GILG. Plant Med. Phytother. 1978, 12, 123-129.

114. Bassleer, R.; Depauw-Gillet, M.C.; Massart, B.; Marnette, J.-M.; Wiliquet, P.; Caprasse, M.; Angenot, L. Effets de trois alcalóides extraits du Strychnos usambaren- sis sur des cellules cancéreuses en culture. Planta Med. 1982, 45, 123-126. [CrossRef] [PubMed]

115. Cui, C.-B.; Kakeya, H.; Osada, H. Spirotryprostatin B, a novel Mammalian cell cycle inhibitor produced by Aspergillus fumigatus. J. Antibiot. 1996, 49, 832-835. [CrossRef] [PubMed]

116. Lerchner, A.; Carreira, E.M. First total synthesis of $( \pm)$-Strychnofoline via a highly selective ring-expansion reaction. J. Am. Chem. Soc. 2002, 124, 14826-14827. [CrossRef] [PubMed]

117. Burm, B.E.A.; Meijler, M.M.; Korver, J.; Wanner, J.M.; Koomen, G. Synthesis of the brominated marine alkaloids ( \pm )-Arborescidine A, B and C. Tetrahedron 1998, 54, 6135-6146. [CrossRef]

118. Herdeis, C.; Hubmann, H.P. Synthesis of homochiral R-Baclofen from S-glutamic acid. Tetrahedron Asymmetry 1992, 3, 1213-1221. [CrossRef]

119. Waldmann, H.; Schmidt, G.; Jansen, M.; Geb, J. Asymmetric steering of the Pictet-Spengler reaction by means of Amino-acid esters as chiral auxiliary groups. Tetrahedron 1994, 50, 11865-11884. [CrossRef]

120. Rinehart, K.L., Jr.; Kobayashi, J.; Harbour, G.C.; Hughes, R.G., Jr.; Mizsak, S.A.; Scahill, T.A. Eudistomins C, $\mathrm{E}, \mathrm{K}$, and $\mathrm{l}$, potent antiviral compounds containing A novel Oxathiazepine ring from the Caribbean tunicate Eudistoma olivaceum. J. Am. Chem. Soc. 1984, 106, 1524-1526. [CrossRef]

121. Kobayashi, J.; Harbour, G.C.; Gilmore, J.; Rinehart, K.L., Jr. Eudistomins A, D, G, H, I, J, M, N, O, P, and $\mathrm{Q}$, Bromo, Hydroxy, Pyrrolyl and iminoazepino. Beta.-carbolines from the antiviral Caribbean tunicate Eudistoma olivaceum. J. Am. Chem. Soc. 1984, 106, 1526-1528. [CrossRef]

122. Rinehart, K.L., Jr.; Kobayashi, J.; Harbour, G.C.; Gilmore, J.; Mascal, M.; Holt, T.G.; Shield, L.S.; Lafargue, F. Eudistomins A-Q, Beta.-carbolines from the antiviral Caribbean tunicate Eudistoma olivaceum. J. Am. Chem. Soc. 1987, 109, 3378-3387. [CrossRef]

123. Lake, R.J.; Blunt, J.W.; Munro, M.H. Eudistomins from the New Zealand Ascidian Ritterella sigillinoides. Aust. J. Chem. 1989, 42, 1201-1206. [CrossRef]

124. Kauffman, J.M.; Litak, P.T.; Boyko, W.T. Influence of borate complexation on the electrophoretic behavior of carbohydrates in capillary electrophoresis. J. Heterocycl. Chem. 1995, 32, 1541-1547. [CrossRef]

125. Nakagawa, M.; Liu, J.-J.; Hino, T. Bimetallic solvated metal atom dispersed catalysts. New materials with low-temperature catalytic properties. J. Am. Chem. Soc. 1989, 11, 2721-2722. [CrossRef]

126. Garner, P.; Park, J.M. 1,1,-dimethylethyl (s)- or (r)-4-formyl-2,2-dimethyl-3 oxazolidinecarboxylate: A useful serinal derivative. Org. Synth. 1992, 70, 18-20.

127. Dondoni, A.; Perrone, D. Synthesis of 1,1-dimethylethyl (s)-4-formyl-2,2-dimethyl-3-oxazolidinecarboxylate by oxidation of the alcohol. Org. Synth. 1999, 77, 64-67.

128. Yamashita, T.; Kawai, N.; Tokuyama, H.; Fukuyama, T. Stereocontrolled total synthesis of (-)-Eudistomin C. J. Am. Chem. Soc. 2005, 127, 15038-15039. [CrossRef] [PubMed]

129. Hooper, D. The Anti-Opium leaf. Pharm. J. 1907, 78, 453-454.

130. Field, E. Xcviii.-Mitragynine and Mitraversine, two new alkaloids from species of Mitragyne. J. Chem. Soc. Trans. 1921, 119, 887-891. [CrossRef]

131. Zacharias, D.E.; Rosenstein, R.D.; Jeffrey, G.A. The structure of Mitragynine hydroiodide. Acta Cryst. 1965, 18, 1039-1043. [CrossRef]

132. Ponglux, D.; Wongseripipatana, S.; Takayama, H.; Kikuchi, M.; Kurihara, M.; Kitajima, M.; Aimi, N.; Sakai, S. A new indole alkaloid, $7 \alpha$-hydroxy-7H-mitragynine, from Mitragyna speciosa in Thailand. Planta Med. 1994, 60, 580-581. [CrossRef] [PubMed] 
133. Matsumoto, K.; Takayama, H.; Ishikawa, H.; Aimi, N.; Ponglux, D.; Watanabe, K.; Horie, S. Partial agonistic effect of 9-hydroxycorynantheidine on mu-opioid receptor in the Guinea-pig ileum. Life Sci. 2006, 78, 2265-2271. [CrossRef] [PubMed]

134. Mavar-Manga, H.; Quetin-Leclercq, J.; Labres, G.; Belem-Pinheiro, M.-L.; Da Rocha, A.F.I.; Angenot, L. 9-methoxygeissoschizol, an alkaloid from bark of Strychnos guianensis. Phytochemistry 1996, 43, 1125-1127. [CrossRef]

135. West, R. New acritarch species from Holocene sediments in central West Greenland. Arch. Int. Pharmacodyn. Ther. 1937, 56, 81-88.

136. Penelle, J.; Tits, M.; Christen, P.; Molgo, J.; Brandt, V.; Frederich, M.; Angenot, L. Quaternary indole alkaloids from the stem bark of Strychnos guianensis. Phytochemistry 2000, 53, 1057-1066. [CrossRef]

137. Massiot, G.; Mulamba, T.J. Synthesis of the two enantioners of a tetrahydro- $\beta$-carboline from 1-(-)-Tryptophan. Chem. Soc. Chem. Commun. 1983, 1147-1149. [CrossRef]

138. Yu, S.; Berner, O.M.; Cook, J.M. General Approach for the Synthesis of Indole Alkaloids via the Asymmetric Pictet-Spengler Reaction: First Enantiospecific Total Synthesis of (-)-Corynantheidine as Well as the Enantiospecific Total Synthesis of (-)-Corynantheidol, (-)-Geissoschizol, and (+)-Geissoschizine. J. Am. Chem. Soc. 2000, 122, 7827-7828.

139. Ma, J.; Yin, W.; Zhou, H.; Cook, J.M. Total synthesis of the opioid agonistic indole alkaloid Mitragynine and the first total syntheses of 9-methoxygeissoschizol and 9-methoxy- $\mathrm{Nb}$-methylgeissoschizol. Org. Lett. 2007, 9, 3491-3494. [CrossRef] [PubMed]

140. Brown, R.T. In the Chemistry of Heterocyclic Compounds; Taylor, E.C., Ed.; John Wiley and Sons: New York, NY, USA; Chichester, UK; Brisbane, Australian; Toronto, ON, Canada; Singapore, 1983; Volume 25, Part 4; p. 147.

141. Goldberg, M.R.; Robertson, D. Yohimbine: A pharmacological probe for study of the alpha 2-adrenoreceptor. Pharmacol. Rev. 1983, 35, 143-180. [PubMed]

142. Mergott, D.J.; Zuend, S.J.; Jacobsen, E.N. Catalytic asymmetric total synthesis of (+)-Yohimbine. Org. Lett. 2008, 10, 745-748. [CrossRef] [PubMed]

143. Taylor, M.S.; Jacobsen, E.N. Highly enantioselective catalytic Acyl-Pictet-Spengler reactions. J. Am. Chem. Soc. 2004, 126, 10558-10559. [CrossRef] [PubMed]

144. Smith, A.B.; Safonov, I.G.; Corbett, R.M. Total syntheses of (+)-zampanolide and (+)-dactylolide exploiting A unified strategy. J. Am. Chem. Soc. 2002, 124, 11102-11113. [CrossRef] [PubMed]

145. Lim, K.H.; Komiyama, K.; Kam, T.S. Arboricine and Arboricinine, unusual tetracyclic indole regioisomers from Kopsia. Tetrahedron Lett. 2007, 48, 1143-1145. [CrossRef]

146. Krafft, M.E.; Cran, J.W. A convenient protocol for the $\alpha$-iodination of $\alpha, \beta$-unsaturated carbonyl compounds with I2 in an aqueous medium. Synlett 2005, 8, 1263-1266. [CrossRef]

147. Kumpaty, H.J.; van Linn, M.L.; Kabir, M.S.; Forsterling, F.H.; Deschamps, J.R.; Cook, J.M. Study of the cis to trans isomerization of 1-phenyl-2,3-disubstituted tetrahydro- $\beta$-carbolines at $C(1)$. Evidence for the carbocation-mediated mechanism. J. Org. Chem. 2009, 74, 2771-2779. [CrossRef] [PubMed]

148. Wanner, M.J.; Boots, R.N.A.; Eradus, B.; Gelder, R.; van Maarseveen, J.H.; Hiemstra, H. Total synthesis of Arboricine. Org. Lett. 2009, 11, 2579-2581. [CrossRef] [PubMed]

149. Zhang, Y.W.; Yang, R.; Cheng, Q.; Ofuji, K. Henrycinols A and B, two novel indole alkaloids isolated from melodinus Henryi Craib. Helv. Chim. Acta. 2003, 86, 415-419. [CrossRef]

150. Rahman, A.U.; Basha, A. Indole Alkaloids; Hardwood Academic: Reading, UK, 1999.

151. Iida, H.; Yamazaki, N.; Kibayashi, C. Total synthesis of (+)-Nojirimycin and (+)-1-Deoxynojirimycin. J. Org. Chem. 1987, 52, 3337-3342. [CrossRef]

152. Araki, K.; Suenaga, K.; Sengoku, T.; Uemura, D. Total synthesis of Attenols A and B. Tetrahedron 2002, 58, 1983-1995. [CrossRef]

153. Jawdosiuk, M.; Cook, J.M. Pictet-Spengler reactions in aprotic media. J. Org. Chem. 1984, 49, $2699-2701$. [CrossRef]

154. Sandrin, J.; Hollinshead, S.P.; Cook, J.M. Pictet-Spengler reactions in aprotic media. Stereospecificity in the Pictet-Spengler reaction. J. Org. Chem. 1989, 54, 5636-5640. [CrossRef]

155. Van Linn, M.L.; Cook, J.M. Mechanistic studies on the cis to trans epimerization of trisubstituted 1,2,3,4-tetrahydro- $\beta$-carbolines. J. Org. Chem. 2010, 75, 3587-3599. [CrossRef] [PubMed]

156. Nagashima, N.; Ohno, M. An efficient $o$-monoalkylation of dimethyl l-tartrate viao-stannylene acetal with alkyl halides in the presence of cesium fluoride. Chem. Lett. 1987, 16, 141-144. [CrossRef] 
157. Nagashima, N.; Ohno, M. Selective monoalkylation of acyclic diols by means of dibutyltin oxide and fluoride salts. Chem. Pharm. Bull. 1991, 39, 1972-1982. [CrossRef]

158. Prasad, K.R.; Nidhiry, J.E.; Sridharan, M. Total synthesis of the indole alkaloids Henrycinol A and B. Tetrahedron 2014, 70, 4611-4616. [CrossRef]

159. Saxton, J.E. Recent progress in the chemistry of the monoterpenoid indole alkaloids. Nat. Prod. Rep. 1996, 13, 327-363. [CrossRef]

160. Bonoczk, P.; Panezel, G.; Nagy, Z. Vinpocetine increases Cerebral blood flow and Oxygenation in stroke patients: A near infrared spectroscopy and transcranial doppler study. Eur. J. Ultrasound 2002, 15, 85-91. [CrossRef]

161. Sheng, M.H.; Sun, H.B. Research progress toward total synthesis, structural modification and biological evaluation of Vinpocetine. Prog. Pharm. Sci. 2010, 34, 7-17.

162. Pfaffli, P.; Oppolzer, W.; Wenger, R.; Hauth, H. Stereoselektive synthese von optisch aktivem Vincamin. Helv. Chim. Acta. 1975, 58, 1131-1145. [CrossRef] [PubMed]

163. Node, M.; Nagasawa, H.; Fuji, K. Chiral total synthesis of indole alkaloids of the aspidosperma and hunteria types. J. Org. Chem. 1990, 55, 517-521. [CrossRef]

164. Langlois, Y.; Pouilhes, A.; Genin, D.; Andriamialisoa, R.Z.; Langlois, N. New approaches to the synthesis of eburnane alkaloids. Tetrahedron 1983, 39, 3755-3761. [CrossRef]

165. Ono, N.; Yoshimura, T.; Saito, T.; Tamura, R.; Tanikaga, R.; Kaji, A. Alkylation and acylation of active methylene compounds using 1,8-diazabicyclo[5.4.0]undec-7-ene as a base. Bull. Chem. Soc. Jpn. 1979, 52, 1716-1719. [CrossRef]

166. Chen, X.; Chen, F. An efficient synthesis of Katsube nitrile: A key building block for Eburnamine-Vincamine alkaloids. Synthesis 2014, 46, 1506-1510. [CrossRef]

167. Bencao, Z. An editorial committee of the administration bureau of traditional Chinese medicine. In Chinese Materia Medica (Zhonghua Benchao); Shanghai Science \& Technology Press: Shanghai, China, 1999; Volume 3, p. 56.

168. Noda, Y.; Mori, A. Antioxidant activities of Uyaku (Lindera Strychnifolia) leaf extract: A natural extract used in traditional medicine. J. Clin. Biochem. Nutr. 2007, 41, 139-145. [CrossRef] [PubMed]

169. Gu, L.H.; Wu, T.; Zhang, Z.J.; Chou, G.X.; Wang, Z.T. Evaluation of antioxidant activity of radix Linderae and other two Chinese drugs using tlc-bioautography. Acta Pharm. Sin. 2006, 41, 956-962.

170. Wang, N.Y.; Minatoguchi, S.; Arai, M.; Uno, Y.; Hashimoto, K.; Chen, X.H.; Fukuda, K.; Akao, S.; Takemura, G.; Fujiwara, H. Lindera strychnifolia is protective against post-ischemic myocardial dysfunction through scavenging hydroxyl radicals and opening the Mitochondrial KATP channels in isolated rat hearts. Am. J. Chin. Med. 2004, 32, 587-598. [CrossRef] [PubMed]

171. Trujillo, J.I.; Meyers, M.J.; Anderson, D.R.; Hegde, S.; Mahoney, M.W.; Vernier, W.F.; Buchler, I.P.; Wu, K.K.; Yang, S.; Hartmann, S.J.; et al. Novel tetrahydro- $\beta$-carboline-1-carboxylic acids as inhibitors of Mitogen activated protein Kinase-activated protein Kinase 2 (mk-2). Bioorg. Med. Chem. Lett. 2007, 17, 4657-4663. [CrossRef] [PubMed]

172. Winkler, J.D.; Londregan, A.T.; Ragains, J.R.; Hamann, M.T. Synthesis and biological evaluation of manzamine analogues. Org. Lett. 2006, 8, 3407-3409. [CrossRef] [PubMed]

173. Hartung, J.; Drees, S.; Geiss, B.; Schmidt, P. Vanadium(V)-catalyzed oxidation of (3R)-Linalool- the selective formation of furanoid Linalool oxides and their conversion into Isocyclocapitelline derivatives. Synlett 2003, 2, 223-226. [CrossRef]

174. Yang, M.L.; Kuo, P.C.; Damu, A.G.; Chang, R.J.; Chiou, W.F.; Wu, T.S. A versatile route to the synthesis of 1-substituted $\beta$-carbolines by a single step Pictet-Spengler cyclization. Tetrahedron 2006, 62, 10900-10906. [CrossRef]

175. Kuo, P.C.; Li, Y.-C.; Hwang, T.-L.; Ma, G.-H.; Yang, M.-L.; Lee, E.-J.; Wu, T.-S. Synthesis and structural characterization of an anti-inflammatory principle purified from Lindera aggregata. Tetrahedron Lett. 2014, 55, 108-110. [CrossRef]

176. Wang, K.-B.; Di, Y.-T.; Bao, Y.; Yuan, C.-M.; Chen, G.; Li, D.-H.; Bai, J.; He, H.-P.; Hao, X.-J.; Pei, Y.-H.; et al. Peganumine A, a $\beta$-carboline dimer with a new octacyclic scaffold from Peganum harmala. Org. Lett. 2014, 16, 4028-4031. [CrossRef] [PubMed]

177. Farina, V.; Kapadia, S.; Krishnan, B.; Wang, C.; Liebeskind, L.S. On the nature of the "Copper effect" in the Stille cross-coupling. J. Org. Chem. 1994, 59, 5905-5911. [CrossRef]

178. Banfi, L.; Riva, R. The Passerini reaction. Org. React. 2005, 65, 1-140. 
179. Wittenberg, R.; Srogl, J.; Egi, M.; Liebeskind, L.S. Ketone synthesis under neutral conditions. $\mathrm{Cu}(\mathrm{I})$ diphenylphosphinate-mediated, Palladium-catalyzed coupling of thiol esters and organostannanes. Org. Lett. 2003, 5, 3033-3035. [CrossRef] [PubMed]

180. Schönherr, H.; Leighton, J.L. Direct and highly enantioselective iso-Pictet-Spengler reactions with $\alpha$-ketoamides: Access to underexplored indole core structures. Org. Lett. 2012, 14, 2610-2613. [CrossRef] [PubMed]

181. Mittal, N.; Sun, D.X.; Seidel, D. Conjugate-base-stabilized brønsted acids: Catalytic enantioselective Pictet-Spengler reactions with unmodified Tryptamine. Org. Lett. 2014, 16, 1012-1015. [CrossRef] [PubMed]

182. Piemontesi, C.; Wang, Q.; Zhu, J. Enantioselective synthesis of (+)-Peganumine A. J. Am. Chem. Soc. 2016, 138, 11148-11151. [CrossRef] [PubMed]

183. Wong, S.; Chong, K.; Lim, K.; Lim, S.; Low, Y.; Kam, T. Arborisidine and Arbornamine, two monoterpenoid indole alkaloids with new polycyclic Carbon-Nitrogen skeletons derived from a common pericine precursor. Org. Lett. 2016, 18, 1618-1621. [CrossRef] [PubMed]

184. Kitajima, M.; Koyama, T.; Wu, Y.; Kogure, N.; Zhang, R.; Takayama, H. Kopsiyunnanines J1 and J2, new Strychnos-type homo-monoterpenoid indole alkaloids from Kopsia arborea. Nat. Prod. Commun. 2015, 10, 49-51. [PubMed]

185. Kitajima, M.; Murakami, Y.; Takahashi, N.; Wu, Y.; Kogure, N.; Zhang, R.; Takayama, H. Asymmetric total synthesis of novel pentacyclic indole alkaloid, Kopsiyunnanine e, isolated from Kopsia arborea. Org. Lett. 2014, 16, 5000-5003. [CrossRef] [PubMed]

186. Tokuda, R.; Okamoto, Y.; Koyama, T.; Kogure, N.; Kitajima, M.; Takayama, H. Asymmetric total synthesis of Kopsiyunnanine K, A monoterpenoid indole alkaloid with a rearranged skeleton. Org. Lett. 2016, 18, 3490-3493. [CrossRef] [PubMed]

187. Lin, H.; Danishefsky, S.J. Gelsemine: A thought-provoking target for total synthesis. Angew. Chem. Int. Ed. 2003, 42, 36-51. [CrossRef]

188. Marti, C.; Carreira, E.M. Construction of spiro[pyrrolidine-3,3'-oxindoles]- recent applications to the synthesis of oxindole alkaloids. Eur. J. Org. Chem. 2003, 2209-2219. [CrossRef]

189. Borges, J.; Manresa, M.T.; Martin Ramon, J.L.; Pascual, C.; Rumbero, A. Two new oxindole alkaloids isolated from Hamelia patens Jacq. Tetrahedron Lett. 1979, 20, 3197-3200. [CrossRef]

190. Tsuda, M.; Kasai, Y.; Komatsu, K.; Sone, T.; Tanaka, M.; Mikamiand, Y.; Kobayashi, J. Citrinadin A, a novel pentacyclic alkaloid from Marine-derived Fungus Penicillium Citrinum. Org. Lett. 2004, 6, 3087-3089. [CrossRef] [PubMed]

191. Sonnenschein, F.L. Ueber einige Bestandtheile von Gelsemium sempervirens. Ber. Dtsch. Chem. Ges. 1876, 9 , 1182-1186. [CrossRef]

192. Bond, R.F.; Boeyens, J.C.A.; Holzapfel, C.W.; Steyn, P.S. Cyclopiamines A and B, novel oxindole metabolites of Penicillium cyclopium Westling. J. Chem. Soc. Perkin Trans. 1979, 1, 1751-1761. [CrossRef]

193. Yu, Q.; Guo, P.; Jian, J.; Chen, Y.; Xu, J. Nine-step total synthesis of (-)-Strychnofoline. Chem. Commun. 2018, 54, 1125-1128. [CrossRef] [PubMed]

194. Schmeller, T.; Wink, M. Utilization of alkaloids in modern medicine. In Alkaloids: Biochemistry, Ecology, and Medicinal Applications; Roberts, M.F., Wink, M., Eds.; Plenum: New York, NY, USA, 1998; pp. 435-459.

195. Kam, T.-S.; Choo, Y.-M.; Komiyama, K. Unusual spirocyclic Macroline alkaloids, nitrogenous derivatives, and a cytotoxic bisindole from Alstonia. Tetrahedron 2004, 60, 3957-3966. [CrossRef]

196. Naranjo, J.; Pinar, M.; Hesse, M.; Schmid, H. Über die Indolalkaloide von Pleíocarpa talbotii Wernham. Helv. Chim. Acta. 1972, 55, 752-771. [CrossRef] [PubMed]

197. Pan, L.; Terrazas, C.; Acuña, U.N.; Ninh, T.N.; Chai, H.; de Blanco, E.J.C.; Soejarto, D.D.; Satoskar, A.R.; Kinghorn, A.D. Bioactive indole alkaloids isolated from Alstonia angustifolia. Phytochem. Lett. 2014, 10, 54-59. [CrossRef] [PubMed]

198. Kiang, A.; Loh, S.; Demanczyk, M.; Gemenden, C.; Papariello, G.; Taylor, W. The structures of peraksine (RP-5) and RP-7 constituents of the leaves and stems of Rauwolfia perakensis. Tetrahedron 1966, 22, 3293-3300. [CrossRef]

199. Rahman, M.T.; Deschamps, J.R.; Imler, G.H.; Cook, J.M. Total synthesis of Sarpagine-related bioactive indole alkaloids. Chem. A Eur. J. 2017. [CrossRef] [PubMed]

200. Ahmad, V.U.; Iqbal, S. Jamtinine, an alkaloid from. Cocculus Hirsutus. Phytochemistry 1993, 3, $735-736$. [CrossRef] 
201. Chopra, R.N.; Chopra, I.C.; Handa, K.L.; Kapoor, L.D. Indigenous Drugs of India; U. N. Dhar and Sons Pvt. Ltd.: Calcutta, India, 1958; p. 501.

202. Ahmad, V.U.; Rahman, A.; Rasheed, T.; Rehman, H. Jamtine-N-oxide a new isoquinoline alkaloid from Cocculus hirsutus. Heterocycles 1987, 26, 1251-1255.

203. Padwa, A.; Danca, M.D. Total synthesis of $( \pm$ )-jamtine using a thionium $/ N$-acyliminium ion Cascade. Org. Lett. 2002, 4, 715-717. [CrossRef] [PubMed]

204. Denmark, S.E. Nazarov and related. Cationic Cyclizations. In Comprehensive Organic Synthesis; Trost, B.M., Fleming, I., Eds.; Pergamon Press: Oxford, UK, 1991; Volume 5, p. 751.

205. Rinehart, K.L.; Holt, T.G.; Fregeau, N.L.; Stroh, J.G.; Keifer, P.A.; Sun, F.; Li, L.H.; Martin, D.G. Ecteinascidins $729,743,745,759 a, 759 b$, and 770: Potent antitumor agents from the Caribbean tunicate Ecteinascidia turbinata. J. Org. Chem. 1990, 55, 4512-4515. [CrossRef]

206. Sakai, R.; Rinehart, K.L.; Guan, Y.; Wang, A. Additional antitumor Ecteinascidins from a Caribbean tunicate: Crystal structures and activities in vivo. Proc. Natl. Acad. Sci. USA 1992, 89, 11456-11460. [CrossRef] [PubMed]

207. Moore, B.M.; Miranda, N.F. Biosynthetic studies of Ecteinascidins in the Marine Tunicate Ecteinascidia turbinata. J. Nat. Prod. 1995, 58, 1618-1621.

208. Takahashi, F.; Kubo, A. Structure of Vineomycin B2. J. Antibiot. 1977, 30, 1015-1020. [CrossRef]

209. Takahashi, K.; Tomita, F. DC-52, a novel antitumor antibiotic. 2. Isolation, physico-chemical characteristics and structure determination. J. Antibiot. 1983, 36, 468-469. [CrossRef] [PubMed]

210. Sakai, R.; Jares-Erijiman, E.A.; Manzanares, I.; Silva Elipe, M.V.; Rinehart, K.L. Ecteinascidins: Putative biosynthetic precursors and absolute stereochemistry. J. Am. Chem. Soc. 1996, 118, 9017-9020. [CrossRef]

211. Zewail-Foote, M.; Hurley, L.H. Ecteinascidin 743: A minor groove alkylator that bends DNA toward the major groove. J. Med. Chem. 1999, 42, 2493-2497. [CrossRef] [PubMed]

212. Corey, E.J.; Gin, D.Y.; Kania, R.S. Enantioselective total synthesis of Ecteinascidin 743. J. Am. Chem. Soc. 1996, 118, 9202-9203. [CrossRef]

213. Zhou, B.; Guo, J.; Danishefsky, S.J. Studies directed to the total synthesis of Et 743 and analogues Thereof: An expeditious route to the ABFGH subunit. Org. Lett. 2002, 4, 43-46. [CrossRef] [PubMed]

214. Endo, A.; Yanagisawa, A.; Abe, M.; Tohma, S.; Kan, T.; Fukuyama, T. Total synthesis of Ecteinascidin 743. J. Am. Chem. Soc. 2002, 124, 6552-6554. [CrossRef] [PubMed]

215. Burk, M.J.; Feaster, J.E.; Nugent, W.A.; Harlow, R.L. Preparation and use of C2-symmetric bis(phospholanes): Production of. Alpha.-amino acid derivatives via highly enantioselective hydrogenation reactions. J. Am. Chem. Soc. 1993, 115, 10125-10138. [CrossRef]

216. Buckley, T.F.; Rapoport, H. Mild and simple biomimetic conversion of amines to carbonyl compounds. J. Am. Chem. Soc. 1982, 104, 4446-4450. [CrossRef]

217. Cuevas, C.; Perez, M.; Martin, M.J.; Chicharro, J.L.; Fernandez-Rivas, C.; Flores, M.; Francesch, A.; Gallego, P.; Zarzuelo, M.; Calle, F.; et al. Synthesis of Ecteinascidin Et-743 and phthalascidin Pt-650 from Cyanosafracin B. Org. Lett. 2000, 2, 2545-2548. [CrossRef] [PubMed]

218. Suwanborirux, K.; Charupant, K.; Amnuoypol, S.; Pummangura, S.; Kubo, A.; Saito, N. Ecteinascidins 770 and 786 from the Thai tunicate Ecteinascidia Thurstoni. J. Nat. Prod. 2002, 65, 935-937. [CrossRef] [PubMed]

219. Whaley, H.A.; Patterson, E.L.; Dann, M.; Shay, A.J.; Porter, J.N. Isolation and characterization of Lemonomycin, a new antibiotic. Antimicrob. Agents Chemother. 1964, 8, 83-86.

220. He, H.; Shen, B.; Carter, G.T. Structural Elucidation of Lemonomycin, a potent antibiotic from Streptomyces candidus. Tetrahedron Lett. 2000, 41, 2067-2071. [CrossRef]

221. Scott, J.D.; Williams, R.M. Chemistry and biology of the tetrahydroisoquinoline antitumor antibiotics. Chem. Rev. 2002, 102, 1669-1730. [CrossRef] [PubMed]

222. Garner, P.; Ho, W.B.; Shin, H. The asymmetric synthesis of (-)-quinocarcin via a 1,3-dipolar cycloadditive strategy. J. Am. Chem. Soc. 1993, 115, 10742-10753. [CrossRef]

223. Maurer, P.J.; Knudsen, C.G.; Palkowitz, A.D.; Rapoport, H. Alpha.-amino acids as chiral educts for asymmetric products. Chirospecific syntheses of methyl l-sibirosaminide and its C-3 epimer from 1-allothreonine. J. Org. Chem. 1985, 50, 325-332. [CrossRef]

224. Evans, D.A.; Hu, E.; Tedrow, J.S. An aldol-based approach to the asymmetric synthesis of l-callipeltose, the deoxyamino sugar of 1-callipeltoside A. Org. Lett. 2001, 3, 3133-3136. [CrossRef] [PubMed] 
225. Ashley, E.R.; Cruz, E.J.; Stoltz, B.M. The total synthesis of (-)-lemonomycin. J. Am. Chem. Soc. 2003, 125, 15000-15001. [CrossRef] [PubMed]

226. Pettit, G.R.; Knight, J.C.; Collins, J.C.; Herald, D.L.; Pettit, R.K.; Boyd, M.R.; Young, V.G. Antineoplastic agents 430. Isolation and structure of Cribrostatins 3, 4, and 5 from the republic of Maldives Cribrochalina species. J. Nat. Prod. 2000, 63, 793-798. [CrossRef] [PubMed]

227. Saito, N.; Sakai, H.; Suwanborirux, K.; Pummangura, S.; Kubo, A. ${ }^{13}$ C-NMR spectral assignment of 5-hydroxy-1,5-imino-3-benzazocin-4,7,10-trione derivatives: The revised structure of Renieramycin $\mathrm{H}$. Heterocycles 2001, 55, 21-28. [CrossRef]

228. Parameswaran, P.S.; Naik, C.G.; Kamat, S.Y.; Pramanik, B.N. Renieramycins H\&L two novel alkaloids from the sponge Halidona Cribricutis dendy. Indian J. Chem. Sect. B 1998, 120, 10272-10273.

229. Chen, J.; Chen, X.; Zhu, J. Decomposition of the polymerized phases fullerenes nanotubes carbon nanostructures. Angew. Chem. Int. Ed. 2006, 118, 8196-8200. [CrossRef]

230. Garner, P.; Park, J.M. The synthesis and configurational stability of differentially protected. Beta.-hydroxy-.Alpha.-amino aldehydes. J. Org. Chem. 1987, 52, 2361-2364. [CrossRef]

231. Chen, X.; Zhu, J. Total synthesis of the marine natural product (-)-cribrostatin 4 (Renieramycin $\mathrm{H}$ ). Angew. Chem. Int. Ed. 2007, 46, 3962-3965. [CrossRef] [PubMed]

232. Tomita, F.; Takahashi, K.; Shimizu, K. DC-52, a novel antitumor antibiotic. 1. Taxonomy, fermentation and biological activity. J. Antibiot. 1983, 36, 463-467. [CrossRef] [PubMed]

233. Takahashi, K.; Tomita, F. Dc-52, a novel antitumor antibiotic. J. Antibiot. 1983, 36, 468-470. [CrossRef] [PubMed]

234. Fujimoto, K.; Oka, T.; Morimoto, M. Aiititiinior activity of a novel antitumor antibiotic, Quinocarmycin Citrate (KW2152). Cancer Res. 1987, 47, 1516-1522. [PubMed]

235. Saito, H.; Hirata, T.; Kasai, M.; Fujimoto, K.; Ashizawa, T.; Morimoto, M.; Sato, A. Synthesis and biological evaluation of quinocarcin derivatives: Thioalkyl-substituted Quinones and Hydroquinones. J. Med. Chem. 1991, 34, 1959-1966. [CrossRef] [PubMed]

236. Plowman, J.; Dykers, D.J.; Narayanan, V.L.; Abbott, B.J.; Saito, H.; Hirata, T.; Grever, M.R. Efficacy of the quinocarmycins KW2152 and DX-52-1 against human melanomalines growing in culture and in mice. Cancer Res. 1995, 55, 862-867. [PubMed]

237. Bunnell, C.A.; Supko, J.G.; Eder, J.P.; Clark, J.W.; Lynch, T.J.; Kufe, D.W.; Shulman, L.N. Phase I clinical trial of 7-cyanoquinocarcinol (DX-52-1) in adult patients with refractory solid Malignancies. Cancer Chemother. Pharmacol. 2001, 48, 347-355. [CrossRef] [PubMed]

238. Williams, R.M.; Flanagan, M.E.; Tippie, T.N. $\mathrm{O}_{2}$-dependent cleavage of DNA by tetrazomine. Biochemistry 1994, 33, 4086-4092. [CrossRef] [PubMed]

239. Wu, Y.-C.; Liron, M.; Zhu, J. Asymmetric total synthesis of (-)-quinocarcin. J. Am. Chem. Soc. 2008, 130, 7148-7152. [CrossRef] [PubMed]

240. Aune, G.J.; Furuta, T.; Pommier, Y. Ecteinascidin 743: A novel anticancer drug with a unique mechanism of action. Anticancer Drug. 2002, 13, 545-555. [CrossRef]

241. Charupant, K.; Suwanborirux, K.; Amnuoypol, S.; Saito, E.; Kubo, A.; Saito, N. Jorunnamycins A-C, new stabilized Renieramycin-type bistetrahydroisoquinolines isolated from the Thai Nudibranch Jorunna Funebris. Chem. Pharm. Bull. 2007, 55, 81-86. [CrossRef] [PubMed]

242. Fontana, A.; Cavaliere, P.; Wahidulla, S.; Naik, C.G.; Cimino, G. A new antitumor isoquinoline alkaloid from the marine Nudibranch Jorunna Funebris. Tetrahedron 2000, 56, 7305-7308. [CrossRef]

243. Frincke, J.M.; Faulkner, D.J. Antimicrobial metabolites of the sponge Reniera sp. J. Am. Chem. Soc. 1982, 104, 265-269. [CrossRef]

244. Lown, J.W.; Joshua, A.V.; Lee, J.S.; Hurley, L.H. Molecular mechanisms of binding and single-strand scission of DNA by the antitumor antibiotics saframycins A and C. Biochemistry 1982, 21, 419-428. [CrossRef] [PubMed]

245. Oku, N.; Matsunaga, S.; van Soest, R.W.M.; Fusetani, N. Renieramycin J, a highly cytotoxic tetrahydroisoquinoline alkaloid, from a marine sponge Neopetrosia sp. J. Nat. Prod. 2003, 66, 1136-1139. [CrossRef] [PubMed] 
246. Saito, N.; Tanaka, C.; Koizumi, Y.; Suwanborirux, K.; Amnuoypol, S.; Pummangura, S.; Kubo, A. Chemistry of renieramycins. Part 6: Transformation of Renieramycin M into Jorumycin and Renieramycin J including oxidative degradation products, Mimosamycin, Renierone, and Renierol acetate. Tetrahedron 2004, 60, 3873-3881. [CrossRef]

247. Davidson, B.S. Renieramycin G, a new alkaloid from the sponge Xestospongia caycedoi. Tetrahedron Lett. 1992, 33, 3721-3724. [CrossRef]

248. Chen, R.; Zhu, D.; Hu, Z.; Zheng, Z.; Chen, X. A new approach to the synthesis of 1-3-hydroxy-4-methoxy-5-methyl-phenylalanine derivatives from L-tyrosine. Tetrahedron Asymmetry 2010, 21, 39-42. [CrossRef]

249. Wright, B.J.D.; Chan, C.; Danishefsky, S.J. Synthesis and cytotoxic evaluation of some Cribrostatin-ecteinascidin analogues. J. Nat. Prod. 2008, 71, 409-414. [CrossRef] [PubMed]

250. Liu, W.; Dong, W.; Liao, X.; Yan, Z.; Guan, B.; Wang, N.; Liu, Z. Synthesis and cytotoxicity of (-)-renieramycin g analogs. Bioorg. Med. Chem. Lett. 2011, 21, 1419-1421. [CrossRef] [PubMed]

251. Lane, J.W.; Chen, Y.; Williams, R.M. Asymmetric total syntheses of (-)-jorumycin, (-)-renieramycin G, 3-epi-jorumycin, and 3-epi-renieramycin G. J. Am. Chem. Soc. 2005, 127, 12684-12690. [CrossRef] [PubMed]

252. Vincent, G.; Williams, R.M. Asymmetric total synthesis of (-)-cribrostatin 4 (Renieramycin H). Angew. Chem. Int. Ed. 2007, 46, 1517-1520. [CrossRef] [PubMed]

253. Magnus, P.; Matthews, K.S. Synthesis of the tetrahydroisoquinoline alkaloid ( \pm )-Renieramycin G and A $( \pm$ )-lemonomycinone analogue from a common intermediate. J. Am. Chem. Soc. 2005, 127, 12476-12477. [CrossRef] [PubMed]

254. Chen, R.; Liu, H.; Chen, X. Asymmetric total synthesis of (-)-jorunnamycins A and C and (-)-jorumycin from L-tyrosine. J. Nat. Prod. 2013, 76, 1789-1795. [CrossRef] [PubMed]

255. Liu, H.; Chen, R.; Chen, X. A rapid and efficient access to renieramycin-type alkaloids featuring A temperature-dependent stereoselective cyclization. Org. Biomol. Chem. 2014, 12, 1633-1640. [CrossRef] [PubMed]

256. Hagel, J.M.; Facchini, P.J. Benzylisoquinoline alkaloid metabolism: A century of discovery and a Brave New World. Plant Cell Physiol. 2013, 54, 647-672. [CrossRef] [PubMed]

257. Sun, H.; Zhu, L.; Yang, H.; Qian, W.; Guo, L.; Zhou, S.; Gao, B.; Li, Z.; Zhou, Y.; Jiang, H.; et al. Asymmetric total synthesis and identification of tetrahydroprotoberberine derivatives as new antipsychotic agents possessing a dopamine $\mathrm{D}(1), \mathrm{D}(2)$ and serotonin 5-HT(1A) multi-action profile. Bioorg. Med. Chem. Lett. 2013, 21, 856-868. [CrossRef] [PubMed]

258. Gadhiya, S.; Shashikanth, P.; Harding, W.W. A divergent route to 9,10-oxygenated tetrahydroprotoberberine and 8-oxoprotoberberine alkaloids: Synthesis of $( \pm)$-isocorypalmine and oxypalmatine. Tetrahedron 2015, 71, 1227-1231. [CrossRef] [PubMed]

259. Rasterlli, L.; Capasso, A.; Pizza, L.; De Tommasi, N. New protopine and benzyltetrahydroprotoberberine alkaloids from aristolochia constricta and their activity on isolated Guinea-Pig ileum. J. Nat. Prod. 1997, 60, 1065-1069. [CrossRef] [PubMed]

260. Matsuda, H.; Ninomiya, K.; Shimoda, H.; Nishida, N.; Yoshikawa, M. Javaberine A, new TNF- $\alpha$ and nitric oxide production inhibitor, from the roots of talinum paniculatum. Heterocycles 2001, 55, 2043-2050.

261. Rochfort, S.J.; Towerzey, L.; Carroll, A.; King, G.; Michael, A.; Pierens, G.; Rali, T.; Redburn, J.; Whitmore, J.; Quinn, R.J. Latifolians A and B, novel JNK3 Kinase inhibitors from the Papua new Guinean plant Gnetum latifolium. J. Nat. Prod. 2005, 68, 1080-1082. [CrossRef] [PubMed]

262. Martin, F.; Grkovic, T.; Sykes, M.L.; Shelper, T.; Avery, V.M.; Camp, D.; Quinn, R.J.; Davis, R.A. Alkaloids from the Chinese Vine Gnetum montanum. J. Nat. Prod. 2011, 74, 2425-2430. [CrossRef] [PubMed]

263. Ruiz-Olalla, A.; Würdemann, M.A.; Wanner, M.J.; Ingemann, S.; van Maarseveen, J.H.; Hiemstra, H. Organocatalytic enantioselective Pictet-Spengler approach to biologically relevant 1-benzyl-1,2,3,4-tetrahydroisoquinoline alkaloids. J. Org. Chem. 2015, 80, 5125-5132. [CrossRef] [PubMed]

264. Mons, E.; Wanner, M.J.; Ingemann, S.; van Maarseveen, J.H.; Hiemstra, H. Organocatalytic enantioselective Pictet-Spengler reactions for the syntheses of 1-substituted 1,2,3,4-tetrahydroisoquinolines. J. Org. Chem. 2014, 74, 7380-7739. [CrossRef] [PubMed] 
265. Cashaw, J.L.; Davis, V.E.; Mcmurtrey, K.D.; Meyerson, L.R. Kinetics and product distribution in Pictet-Spengler cyclization of tetrahydropapaveroline to tetrahydroprotoberberine alkaloids. J. Org. Chem. 1984, 49, 947-948.

266. Kayhan, J.; Wanner, M.J.; Ingemann, S.; van Maarseveen, J.H.; Hiemstra, H. Consecutive Pictet-Spengler condensations toward bioactive 8-benzylprotoberberines: Highly selective total syntheses of (+)-javaberine A, (+)-javaberine B, and (-)-latifolian A. Eur. J. Org. Chem. 2016, 2016, 3705-3708. [CrossRef]

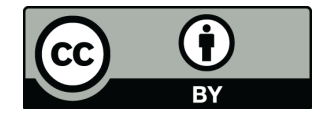

(C) 2018 by the authors. Licensee MDPI, Basel, Switzerland. This article is an open access article distributed under the terms and conditions of the Creative Commons Attribution (CC BY) license (http:/ / creativecommons.org/licenses/by/4.0/). 